\title{
DRIS PARA CAFEEIROS PODADOS
}

\author{
JOSEF ANDREAS NICK
}

Engenheiro Agrônomo

Orientador: Prof. Dr. ANTONIO ROQUE DECHEN

\begin{abstract}
Dissertação apresentada à Escola Superior de Agricultura "Luiz de Queiroz", Universidade de São Paulo, para obtenção do título de Mestre em Agronomia, Área de Concentração: Solos e Nutrição de Plantas.
\end{abstract}

P I RA C I C A B A

Estado de São Paulo - Brasil

Fevereiro - 1998 
Dados Internacionais de Catalogação na Publicação (CIP) DIVISÃO DE BIBLIOTECA E DOCUMENTAÇÃO - Campus "Luiz de Queiroz"/USP

Nick, Josef Andreas

DRIS para cafeeiros podados / Josef Andreas Nick. - - Piracicaba, 1998.

86 p. : il.

Dissertação (mestrado) - - Escola Superior de Agricultura Luiz de Queiroz, 1998.

Bibliografia.

1. Café 2. DRIS 3. Diagnose foliar 4. Fisiologia vegetal 5. Nutrição vegetal 6. Poda 7. Prática cultural 1. Titulo 


\section{DRIS PARA CAFEEIROS PODADOS}

\section{JOSEF ANDREAS NICK}

Aprovada em: 30.03 .1998

Comissão julgadora:

Prof. Dr. Antonio Roque Dechen

ESALQ/USP

Dr. Ondino Cleante Bataglia

IAC

Prof. Dr. Luiz Ignacio Prochnow

ESALQ/USP

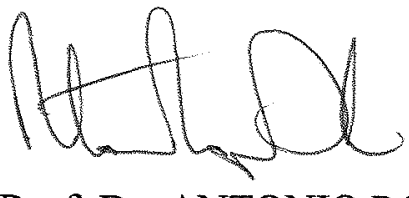

Prof. Dr. ANTONIO ROQUE DECHEN

Orientador 


\section{Aos mens pais \\ Johann e Ida com eterna gratidão}

dedico 


\section{AGRADECIMENTOS}

Ao Professor e Pesquisador Dr. Antonio Roque Dechen, pelo apoio, confiança e amizade dispensados no decorrer deste trabalho;

À Escola Superior de Agricultura "Luiz de Queiroz", Universidade de São Paulo, pela bela e completa estrutura de estudo, alimentação, saúde, esportes e lazer oferecida aos seus alunos:

Aos Professores do Setor de Nutrição Mineral de Plantas, Departamento de Química, Dr. Quirino Augusto de Camargo Carmello e Dr. Francisco Antônio Monteiro, pela grande amizade e apoio à execução deste trabalho;

Aos funcionarios do laboratório de Nutrição Mineral de Plantas, Departamento de Química Giovana Maria de Oliveira, Lurdes Aparecida Dário de Gonzalez, Nivanda Maria de Moura, Lúcia Helena Spessotto Pavan Forti, Sueli Maria Amaral Campos Bovi, Mirtes Ventura Sesso, Edinéia Cristina Scervino Mondoni e Alexandre de Oliveira, pelo auxilio na realização das análises químicas e pela grande amizade;

À CAPES, pela bolsa de estudo concedida durante o curso;

Aos cafeicultores paranaenses e paulistas, senhores Orlando Orestes Patrial, Luiz Marcos Suplicy Hafers, Annibal Mendes Gonçalves Neto, Newton Isaac da Silva Carneiro, Florian Nick, Sinus Harmannus Loman, Max Peter Schweizer, Johann Nick, Júlio Ferracioli, Eduardo Giovannetti, José Carlos Ribeiro, Pedro Alcântara Ribeiro Neto, Albert Gubler, Flávio de Moraes Campos e Hans Christian Nick, pela grande amizade e abertura ao disponibilizar suas lavouras para a realização desta pesquisa;

Ao Pesquisador científico M.S. Wagner Rodrigues dos Santos, pela troca de experièncias sobre o método DRIS;

Ao Pesquisador cientifico M.S. Júlio César Chaves, do Instituto Agronômico do Paraná, pela colaboração na definição da metodologia de lavagem das amostras foliares;

Ao Professor Dr. Eduardo Meneghel Rando, da Fundação Faculdade de Agronomia "Luiz Meneghel", pela estrutura laboratorial que disponibilizou para a lavagem e secagem das amostras foliares;

Ao amigo Mauricio Rizzato Coelho, pela grande amizade e coleguismo;

A querida Denise, pelo apoio e carinho;

Ao Sr. Johann Nick, pela inestimável contribuição técnica e apoio dedicados para a realização deste trabalho. 


\section{SUMÁRIO}

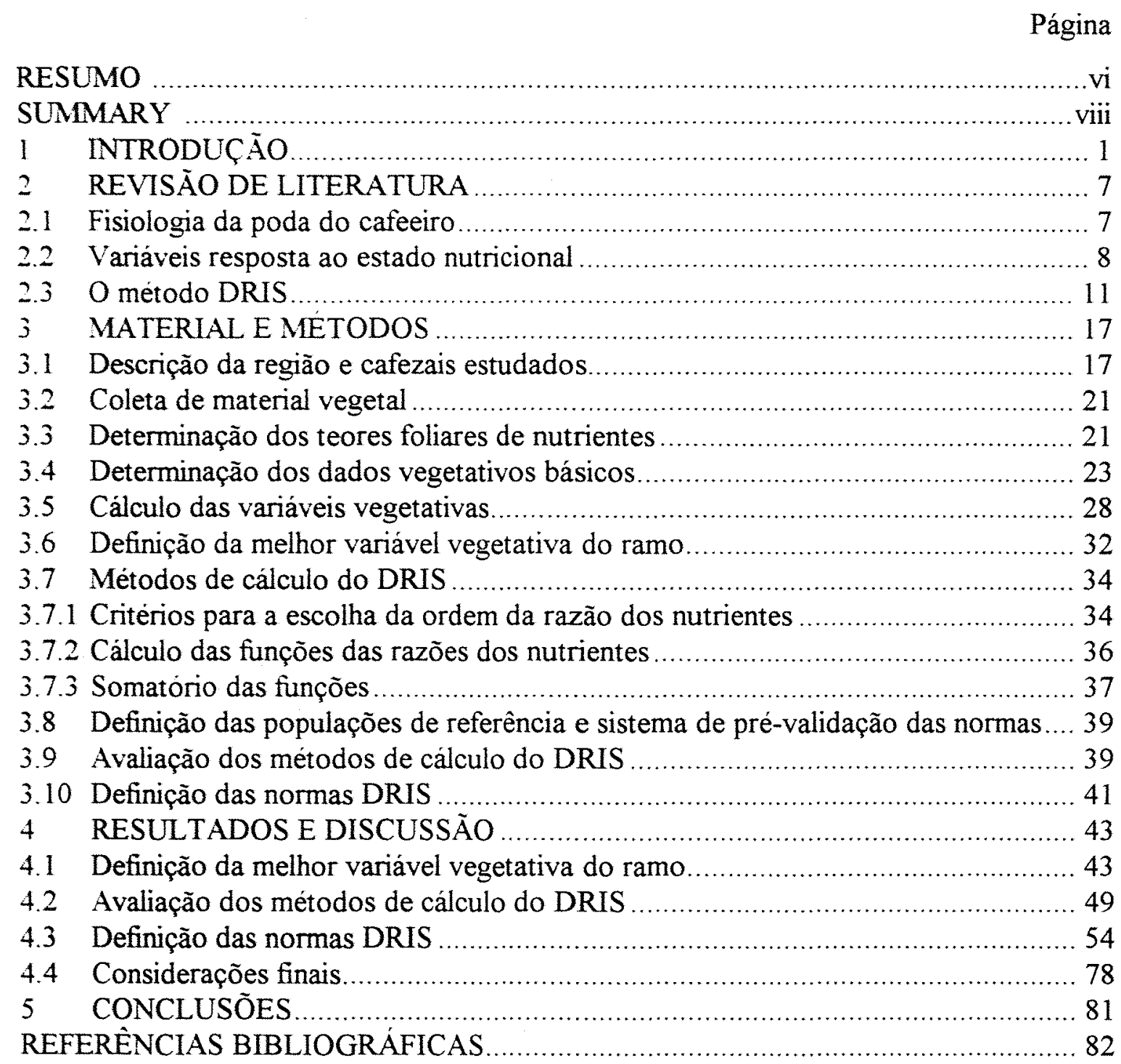




\title{
DRIS PARA CAFEEIROS PODADOS
}

\author{
Autor: JOSEF ANDREAS NICK \\ Orientador: Prof. Dr. ANTONIO ROQUE DECHEN
}

\section{RESUMO}

As tecnicas de poda são essenciais para atingir e manter alta produtividade nas lavouras de café. Dentre as diversas técnicas, a poda redutora do comprimento dos ramos, conhecida como poda tipo esqueletamento, rejuvenesce os cafeeiros, restabelecendo alta produtividade em curto espaço de tempo e a baixo custo. A nutrição durante o primeiro ano após a poda exerce grande influência sobre a produtividade do ano seguinte. Contudo, não existem padrões nutricionais específicos para melhor diagnosticar o estado nutricional nesta fase inicial. Por isso, neste estudo objetivou-se estabelecer padrōes nutricionais (normas) para o Sistema Integrado de Diagnose e Recomendação (DRIS), especificas para diferentes cultivares e épocas do ano após a poda Para determinar as normas DRIS a partir de talhões de café, localizados nos estados do Paraná e São Paulo, duas limitações metodológicas foram observadas. Primeiro, os talhões comerciais apresentam grande variabilidade quanto ao espaçamento e a condição da copa, o que mascara o efeito da nutrição sobre a produtividade. Segundo, a técnica DRIS, que consiste em diversas etapas de cálculo, apresenta várias opções de métodos para cada uma delas, sendo que a melhor combinação destes métodos ainda deveria ser estabelecida. Para resolver a primeira limitação metodológica, fez-se necessário realizar um estudo para desenvolver uma variável resposta alternativa, uma variável vegetativa, para ser usada em substituição à produtividade de grãos. Ramos e folhas de 117 talhões de café, na sua maioria dos cultivares Catuaí Amarelo e Mundo 
Novo, foram amostrados em quatro épocas durante o ano vegetativo (Dezembro/96, Fevereiro, Abril e Julho/97). Determinaram-se os teores foliares para $\mathrm{N}, \mathrm{P}, \mathrm{K}, \mathrm{Ca}, \mathrm{Mg}, \mathrm{S}$, $\mathrm{B}, \mathrm{Cu}, \mathrm{Fe}, \mathrm{Mn}$ e $\mathrm{Zn}$. Determinaram-se também a evolução do número, comprimento e massa dos internódios dos ramos, e a partir destas variáveis, diversas outras foram calculadas. Através de uma análise das relações de causa e efeito, identificou-se o "comprimento especifico do ramo" ( $\mathrm{mm} \mathrm{g}^{-1}$ matéria seca) como a variável resposta alternativa que melhor representou o potencial produtivo do ramo. Para resolver a segunda limitação, avaliaram-se métodos de três etapas de cálculo do DRIS. Primeiro, avaliaram-se dois metodos para a escolha da ordem da razão dos nutrientes, o Valor F e o Valor r. Segundo, testaram-se três métodos para o cálculo das funções das razões dos nutrientes, os de Beaufils, Jones e Elwali \& Gascho. Finalmente, testaram-se ainda dois métodos para o somatório das funções das razões dos nutrientes, DRIS e DRIS modificado (M-DRIS). Os resultados indicaram que: (i) as normas DRIS definidas pelo Valor $r$, critério por nós desenvolvido, foram mais precisas que aquelas definidas pelo Valor $F$, desde que aplicadas a funções calculadas pelo método de Jones; (ii) o método de Jones resultou em indices DRIS e M-DRIS mais precisos que os gerados pelos outros dois métodos; e (iii) DRIS e M-DRIS geraram índices semelhantes. Uma vez definida a melhor variável vegetativa (comprimento especifico do ramo) e a melhor combinação dos métodos de cálculo do DRIS (Valor $r$, Jones e, por opção, M-DRIS), definiram-se normas DRIS especificas para os dois principais cultivares e três épocas. Estas contribuições ao método e às normas DRIS se traduzem na melhoria dos instrumentos disponiveis aos produtores para diagnosticar problemas nutricionais em cafezais submetidos à poda. 


\title{
DRIS FOR PRUNED COFFEE TREES
}

\author{
Author: JOSEF ANDREAS NICK \\ Adviser: Prof. Dr. ANTONIO ROQUE DECHEN
}

\section{SUMMARY}

Pruning techniques are essential to achieve and maintain high yields in coffee plantations. Among the several different pruning systems, the branch pruning system is actualy the best way for rejuvenating coffee plants while restablishing high yields in the short term with low costs. Mineral nutrition in the early stages after pruning has a marked effect on yield one year later. There is, however, a gap in the norms for diagnosing nutritional disorders in these early stages. Therefore, this study was concerned with establishing Diagnosis and Recommendation Integrated System (DRIS) norms, for different cultivars at different stages after pruning. To determine the DRIS norms based on a number of coffee plantations in the states of Paraná and São Paulo, two limiting characteristics were noted. First, coffee plantations are quite variable with regards to planting density and canopy closure, which masks the nutritional effects on yield. Second, the DRIS method, which consists of several steps, presents many options for calculating variables in each step, which the best combination still has to be determined. In order to solve the first limiting characteristic, a study was performed to develop an alternative response variable, a vegetative variable, to be used in place of coffee yield. Branches and leaves from 117 coffee plantations, mainly from the cultivars Catuai Amarelo and Mundo Novo, were sampled at four periods (December/96; Februay, April and July/97). Leaf samples were analysed for determinig $\mathrm{N}, \mathrm{P}, \mathrm{K}, \mathrm{Ca}, \mathrm{Mg}, \mathrm{S}, \mathrm{B}, \mathrm{Cu}, \mathrm{Fe}, \mathrm{Mn}$ and $\mathrm{Zn}$ concentraions. Number, weight and length of the internodes for the branches were 
determined and other variables derived from these basic ones, were calculated. Based on a study of cause and effect, the "new branch specific length" (in $\mathrm{mm} \mathrm{g}^{-1}$ dry matter) was identified as the alternative response variable that best estimates the branch yield potential. In order to solve the second limiting characteristic, methods of three basic DRIS steps were evaluated. First, two methods for deciding the ratio order of a pair of nutrients, either the $F$ Value and the $r$ Value, were compared. Second, three different methods for calculating ratio functions, either that of Beaufils, or Jones or Elwali \& Gascho, were examined. Finally, two methods for summing the ratio functions, DRIS and modified DRIS (M-DRIS), were evaluated. The results indicated: (i) DRIS norms determined by the $r$ Value, which we created, were more precise than those determined by the F Value. since applied to ratio functions calculated by the Jones' method; (ii) the Jones' method resulted in a more precise DRIS or M-DRIS indeces than those calculated by the other two methods; and (iii) DRIS and M-DRIS resulted in similar indices. Once defined the best vegetative variable (new branch specific length) and the best combination of calculating methods ( $r$ Value, Jones, and optionally M-DRIS), specific DRIS norms for two cultivars and three periods were established. These improvements in the DRIS method and norms will help farmers better identify and solve early nutritional disorders in their pruned coffee plantations. 


\section{INTRODUÇ̃̃o}

A cultura do café exerce importância fundamental sobre a economia e a sociedade das regiões Norte do Paraná e Sudoeste de São Paulo, desde a época da colonização até os dias atuais.

Nesta região, o cafeeiro encontra condições de clima e solo favoráveis ao seu desenvolvimento. Contudo, o risco iminente de geadas, além da possibilidade da ocorrència de periodos prolongados de preços baixos para o produto, torna a busca por aumentos na produtividade, com redução do custo de produção unitário, uma questão estrategica para a permanència de cada cafeicultor na atividade. Neste sentido, os recentes avanços nas tecnologias dos insumos, cultivares, sistemas de plantio e práticas culturais, tèm tido papel fundamental.

No campo das práticas culturais, o avanço mais recente e de maior impacto sobre a cafeicultura é, sem dúvida, o aperfeiçoamento das técnicas de poda. As podas deixaram de ser meramente um instrumento para recuperar plantas após grandes estresses, como o de uma geada quando normalmente se realiza a simples redução da altura do tronco. Atualmente, aplica-se a poda também como rotina no manejo da produção, com o objetivo de rejuvenescer as plantas e elevar o seu potencial produtivo. Para este fim destaca-se a modalidade da poda redutora do comprimento dos ramos, mais conhecida como poda tipo esqueletamento.

A poda tipo esqueletamento encontra aplicação em cafeeiros cujos ramos já tenham produzido por várias safras, uma condição bastante freqüente. Após cada colheita aumenta a proporção de segmentos do ramo que já frutificaram uma vez e que não 
voltarão a frutificar. Embora improdutivos, estes segmentos continuam crescendo em diàmetro, acumulando biomassa, competindo com os demais órgãos da planta pelos açúcares soluveis produzidos pela fotossíntese. Dentre os órgãos prejudicados pela competição estão os segmentos de ramo jovens, que vão diminuindo seu vigor e, consequentemente, o seu potencial produtivo. Nesta situação, aplica-se bem a poda tipo esqueletamento, que consiste em eliminarem-se de $1 / 3$ a $2 / 3$ do comprimento dos ramos plagiotropicos (ramos laterais), e até $1 / 3$ do comprimento dos ramos ortotrópicos (tronco), resultando na diminuição da quantidade de segmentos de ramos improdutivos. Dos ramos suporte remanescentes da poda brotam numerosos ramos novos, os quais desenvolvem-se com grande vigor durante o chamado "ano vegetativo". Este vigor reflete no florescimento e na frutificação do ano seguinte, o "ano reprodutivo". Se executada corretamente, a poda tipo esqueletamento pode dobrar o potencial produtivo original da lavoura.

O comportamento de uma lavoura podada durante o ano vegetativo, se comparado ao de uma lavoura não podada, é diferenciado especialmente nos aspectos fitossanitário e nutricional. A incidência de pragas e doenças normalmente diminui, e nutricionalmente a lavoura passa a apresentar características particulares. Sintomas de desordem nutricional relacionados a micronutrientes são freqüentemente observados nas folhas mais jovens dos cafeeiros podados, sintomas estes que em cafeeiros não podados ocorrem com menor freqüència. Além disso, as adubações nitrogenadas e potássicas nem sempre surtem o efeito esperado, ora promovendo vegetação em demasia, ora não promovendo resposta da planta.

Estas particularidades nutricionais revelam-se como conseqüências da brusca interferència da poda tanto sobre a fertilidade do solo como sobre a fisiologia da planta. Com a poda, uma expressiva quantidade de nutrientes contida na biomassa retorna ao solo, e a exposição da superficie do solo ao sol é momentaneamente intensificada. Ambas caracteristicas conduzem à maior disponibilização dos nutrientes no solo. A planta, por sua vez, após a drástica diminuição da área foliar, mobiliza reservas de carboidratos não 
estruturais dos caules para promover a nova brotação. O sistema radicular, que pode até mesmo ter sua extensão reduzida, proporcionalmente à intensidade da poda, tem seu metabolismo afetado pela súbita restrição no fornecimento de açúcares solúveis pela parte aérea, o que irá interferir momentaneamente na absorção ativa dos nutrientes.

O manejo nutricional durante o ano vegetativo dos cafeeiros podados carece de conhecimento. O uso do método das Faixas de Suficiência de teores foliares, ajustado para cafeeiros não podados, tem resultado em diagnósticos pouco precisos nesta situação. A causa da inadequação certamente não está no método, mas sim nos padrões utilizados. que foram determinados para cafeeiros em produção. Portanto, um primeiro passo em busca de instrumentos para melhorar o manejo nutricional dos cafeeiros podados seria a definição de padrões nutricionais específicos para o ano vegetativo. Em função das intensas transformações fisiológicas da planta e da fertilidade de solo que procedem no decorrer do periodo, comuns às lavouras podadas, é possivel que haveria a necessidade de serem definidos padrões específicos para diferentes épocas do ano vegetativo.

Os padrōes nutricionais de qualquer método diagnóstico, para que possam ser idealmente utilizados em uma região, devem ter sido originados dela mesmo, ou validados de outras bases de dados. A vantagem de serem originados da própria região é que são mantidas semelhantes as condições de clima, solo e comportamento fenológico entre as plantas padrão e amostra, favorecendo a acurácia do diagnóstico.

Para determinar padrões nutricionais, a base de dados é normalmente constituída dos teores foliares e da produtividade de grãos. Contudo, a produtividade de grãos com base em área pode ser considerada variável resposta inadequada nas condições de uma região. Isto porque os talhões de toda uma região são muito heterogêneos entre si, em vários aspectos. Destes aspectos fazem parte o espaçamento, a uniformidade de plantio, a altura e estrutura da copa e a densidade de ramos, os quais influem muito sobre a produtividade de grãos. Estas características, quanto mais heterogêneas, mais prejudicam 
a acurácia da correspondència entre o estado nutricional e a resposta da planta, impedindo a determinação de padrões nutricionais mais precisos.

Para que padrões nutricionais possam ser determinados em lavouras comerciais de uma região com maior precisão, evidenciou-se a necessidade de desenvolver um critério alternativo para avaliar a resposta da planta ao estado nutricional. Estabeleceu-se a hipotese de que a variável resposta da planta ao estado nutricional poderia ser uma variável relacionada ao desenvolvimento vegetativo do ramo, cuja base para isso é o conhecimento de que o vigor vegetativo do ramo reflete diretamente sobre a sua produtividade.

O método de diagnose do estado nutricional mais utilizado na cafeicultura é o das Faixas de Suficiència dos teores foliares. Este é uma evolução do método do Nivel Crítico. para o qual as faixas de teores foliares são definidas de acordo com a produção relativa. A popularização deste método encontrou forte argumento na praticidade de manuseio das tabelas das faixas de teores. Dentre os demais métodos de diagnose nutricional, o DRIS (Sistema Integrado de Diagnose e Recomendação) tem sido o mais estudado. Este método avalia o equilibrio nutricional da planta através de índices, dentro de uma escala contínua. Para calculá-los, os valores das razões entre os teores dos nutrientes da amostra são comparados aos dos padrões, denominados normas DRIS, que consistem nos valores médios das razões dos nutrientes e seus respectivos desvios padrões, extraidos de uma população de alta produtividade.

* Embora na sua concepção original o DRIS envolva recomendação, os estudos atuais tèm aplicado esta técnica voltada para o diagnóstico. O DRIS vem sendo empregado como rotina no manejo nutricional de diversas culturas, como espécies cereais e florestais. Por ser um método que depende da computação, sua popularização é incipiente, necessitando que, para muitas espécies, cultivares e sistemas de cultivo, as normas ainda sejam estabelecidas, como é o caso atualmente do cafeeiro. As caracteristicas positivas apontadas para o método DRIS são: a escala é contínua e 
facilmente interpretada; os nutrientes podem ser classificados desde o mais deficiente ao mais excessivo: podem ser identificados casos onde a produtividade está limitada por um desbalanço de nutrientes mesmo que nenhum deles esteja abaixo de seu nível crítico; e o IBN (Indice de Balanço Nutricional) dá uma medida do efeito conjunto dos niveis de nutrientes sobre a produtividade.

O metodo DRIS envolve diversas etapas de cálculo para chegar à determinação das normas e indices DRIS. Após o seu lançamento por Beaufils (1973), diferentes autores sugeriram modificações em determinadas etapas de cálculo, resultando na existência atual de ate mais de um metodo de cálculo para cada etapa. As avaliações dos métodos têm sido realizadas isoladamente, sem a combinação com variações nos métodos das demais etapas de calculo. Assim, estabeleceu-se a hipótese de que as diferentes combinações entre os metodos das etapas de cálculo do DRIS possam modificar os resultados finais da avaliação do estado nutricional.

Na etapa de cálculo onde são determinadas as normas DRIS, o único critério que tem sido utilizado para decidir pelo uso da razão direta ou inversa de cada par de nutrientes é o da razão das variàncias, aqui denominado de critério do Valor $F$, de Letzsch (1985). Considerou-se válido propor e testar um novo critério, em comparação ao do Valor $F$, na hipótese de que pudessem ser melhorados os resultados finais do DRIS. Este novo critério realiza a escolha pela razão direta ou inversa de cada par de nutrientes, baseado no grau de correlação entre a variável produtiva da planta e a razão de cada par de nutrientes.

Diante das hipóteses levantadas, o presente estudo teve três objetivos. Os dois objetivos iniciais, voltados ao desenvolvimento de métodos, foram: primeiro, definir a variável vegetativa que melhor representa o potencial produtivo do ramo; e segundo, definir a melhor combinação entre os métodos de cálculo do DRIS. O terceiro e último objetivo do estudo, dependente das conclusões dos dois primeiros, foi determinar normas 
DRIS para cafeeiros podados, especificas para diferentes cultivares e épocas de amostragem foliar ao longo do ano vegetativo. 


\section{REVTSÃO DE LITERATURA}

\subsection{Fisiologia da poda do cafeeiro}

Do ponto de vista fisiológico, todo tipo de poda é um instrumento para manipular a partição dos açúcares soluveis disponíveis dentro do sistema de fontes e drenos (Gathaara 1996). Fontes e drenos são bem conceituados por Taiz \& Zaiger (1991). Fontes são quaisquer órgãos de exportação, tipicamente uma folha madura, que sejam capazes de produzir fotossintetatos em excesso às próprias necessidades. Outro tipo de fontes são órgãos de reserva durante sua fase de exportação, como os ramos suporte remanescentes após a poda. Drenos são quaisquer órgãos não fotossintéticos ou órgãos que não produzem fotossintetatos suficientes para sustentar o seu próprio crescimento ou necessidades de reserva.

Os principais drenos do cafeeiro são, em ordem decrescente de intensidade: flores e frutos $>$ crescimento secundário dos caules $>$ desenvolvimento de novos brotos $>$ desenvolvimento de raízes > metabolismo de manutenção celular (Rena \& Maestri, 1987). Com a redução no comprimento do ramo, a poda tipo esqueletamento visa diminuir o fluxo de açúcares solúveis direcionados ao engrossamento de segmentos de ramo improdutivos, para favorecer sua partição no sentido do desenvolvimento de novos ramos, unidades básicas para a produção dos frutos.

Logo após a poda, a planta procura restabelecer o equilíbrio entre as fontes e drenos. Neste ajuste, o sistema radicular é afetado com a morte de raízes, cuja 
intensidade, segundo Miguel et al. (1984), é proporcional à interferência realizada sobre a parte aérea. Miguel et al. (1984) registraram a morte de até $83 \%$ das radicelas três meses após a poda tipo esqueletamento. A intensidade da morte das radicelas está relacionada à velocidade da brotação dos novos ramos após a poda. Esta, por sua vez, está condicionada ao clima e às reservas de carboidratos não estruturais contidas nos ramos suporte. Por ocasião da poda, os ramos suporte assumem temporariamente a condição de fontes, até que os novos tecidos foliares tornem-se auto-suficientes e produzam excedente fotossintético, momento quando os ramos suporte voltam a ser drenos. Independente da extensão da mortalidade das radicelas, este fenômeno seguramente afeta o suprimento de nutrientes à planta, pelo menos até o restabelecimento do equilíbrio entre o sistema radicular e a parte aérea.

\subsection{Variáveis resposta ao estado nutricional}

Bancos de dados de teores foliares e produtividades, provenientes de lavouras comerciais e ensaios experimentais, têm sido utilizados para estabelecer padrões nutricionais, como fora realizado por Letzsch e Sumner (1984) para a cultura do milho. Embora seja conhecido que caracteristicas tais como a densidade de plantio influam sobre a produtividade de qualquer cultura, estas têm sido irrelevadas nestes estudos. Isto pode acarretar em prejuizo à acurácia dos padrões assim definidos, pois as variações na produtividade poderão estar sob considerável influência de causas não nutricionais. $\mathrm{Na}$ cultura do café, a heterogeneidade entre os talhões está ligada particularmente ao espaçamento, uniformidade de plantio, altura e estrutura da copa e densidade de ramos. São tantas as combinações entre estas variáveis, que o uso da produtividade de grãos como variável resposta ao estado nutricional, de uma população de talhões de café, merece cautela.

Como alternativa à produtividade de grãos do cafeeiro, as características vegetativas têm sido utilizadas como variáveis resposta ao estado nutricional. Freqüentemente são medidos o comprimento dos ramos plagiotrópicos, comprimento de 
ramos ortotrópicos e diâmetro da copa. Estas medições apropriam-se mais aos estudos envolvendo plantas jovens (até cinco anos de idade, aproximadamente), e nem sempre representam um bom vínculo entre o estado nutricional e a produtividade de grãos, como pode ser constatado no trabalho de Bolivar et al. (1993).

Em cafeeiros adultos, as variáveis potencialmente úteis para contornar o efeito indesejajvel da heterogeneidade dos talhões podem ser identificadas através de uma analise dos componentes da produtividade do cafeeiro. De acordo com o esquema da Figura 1, adaptado de Beaufils (1973), a produtividade nominal de uma lavoura é a produtividade real com os erros de determinação nela embutidos. A produtividade real é, por sua vez parcialmente determinada pela densidade de plantio, tamanho da copa, estrutura da copa e densidade dos ramos, variáveis que caracterizam a heterogeneidade estrutural de uma população de talhões. Estas variáveis estão sob baixo efeito do estado nutricional a curto prazo, mas estão principalmente sob efeito do manejo de condução da lavoura a longo prazo. A produtividade real é ainda parcialmente determinada por outro grupo de variáveis, composto pelo número de nós por ramo, número de frutos por nó e tamanho dos frutos. Estas influem diretamente sobre a produtividade real, e ao mesmo tempo estão sob influência direta do estado nutricional. Destas três variáveis, as duas primeiras são definidas no ano vegetativo, e a última, no ano reprodutivo.

De acordo ainda com a Figura 1, o estado nutricional é a resposta da planta às condições ambientais e do manejo. $\mathrm{O}$ estado nutricional afeta diretamente a capacidade fotossintética da planta, portanto, a disponibilidade dos açúcares solúveis no sistema de fontes e drenos. Em virtude de que no ano vegetativo, para o cafeeiro podado, os frutos praticamente inexistem, os açúcares solúveis são partilhados entre os demais drenos, o que vem a favorecer o desenvolvimento vigoroso dos ramos novos. Este vigor traduz-se no potencial produtivo do ramo para o ano reprodutivo, e pode ser definido quanto ao número, comprimento e massa dos novos internódios. Se a planta estiver mal nutrida no ano vegetativo, baixa o seu potencial produtivo para o ano seguinte, o ano reprodutivo. No ano reprodutivo, mesmo que o cafeeiro esteja sob boa nutrição, o 


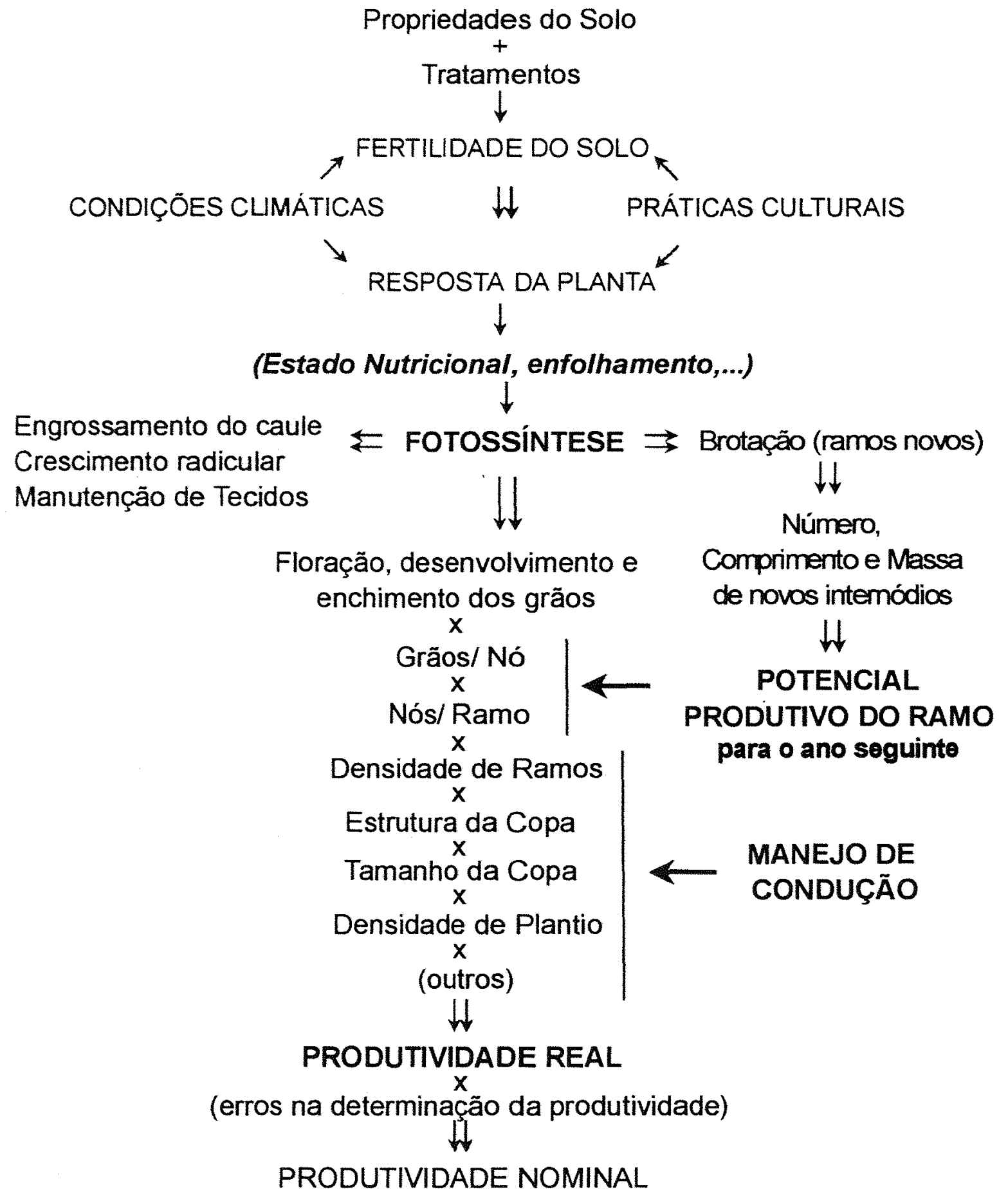

Figura 1. Representação esquemática dos fatores envolvidos na determinação da produtividade de uma lavoura de café. Adaptado de Beaufils (1973). 
potencial produtivo máximo predeterminado no ano anterior não poderá ser elevado, apenas mantido. Assim, variáveis vegetativas inerentes ao ramo, avaliadas no ano vegetativo, são potencialmente úteis na classificação de talhões estruturalmente heterogèneos.

\subsection{O método DRIS}

O método DRIS, Sistema Integrado de Diagnose e Recomendação, foi proposto por Beaufils (1973), desenvolvendo estudo com plantas de milho e seringueira na África do Sul. Foi adaptado e teve seu desenvolvimento continuado por Sumner (1977a, 1977b, 1979, 1981) nos EUA. A interface do DRIS que expressa os resultados da avaliação do estado nutricional, são índices que representam numericamente, em uma escala contínua, a influència de cada nutriente no balanço nutricional da planta. Os índices são valores negativos ou positivos. Valores negativos significam deficiência do elemento em relação aos demais. Valores positivos indicam excesso, e quanto mais próximos do zero estiverem esses indices, mais próxima estará a planta do equilíbrio nutricional.

Segundo Baldock \& Schulte (1996), o método DRIS tem quatro vantagens: (i) a escala é contínua e facilmente interpretada; (ii) o DRIS classifica os nutrientes desde o mais deficiente ao mais excessivo; (iii) o DRIS pode identificar alguns casos onde a produtividade está limitada por um desbalanço de nutrientes mesmo que nenhum deles esteja abaixo de seu nível crítico; e (iv), o IBN (Índice de Balanço Nutricional) dá uma medida do efeito conjunto dos níveis de nutrientes sobre a produtividade. Os mesmos autores também apontam quatro desvantagens do DRIS: (i) é um sistema que exige computação não muito simples; (ii) os índices não são independentes, ou seja, o nível de um nutriente pode ter um marcante efeito sobre os outros índices; (iii) ele resulta em diagnoses positivas falsas com muita freqüência; e (iv), embora tenha sido pregado que este sistema é menos sensível à maturidade da planta, na prática ele é freqüentemente tão sensivel à idade da planta quanto o método concorrente das Faixas de Suficiência. 
Das desvantagens do método DRIS apontadas por Baldock \& Schulte (1996), as duas primeiras (i e ii) merecem considerações adicionais. Com a popularização dos computadores e "softwares", a complexidade da computação passa a ser pouco relevante. Já a não independència dos indices é justamente a vantagem oferecida pelo método DRIS. e e uma das características que o distinguem do método das Faixas de Suficiência. Neste ponto. talvez o que Baldock \& Schulte (1996) pretendiam dizer seja o mesmo aspecto levantado por Soltanpour et al. (1995). Estes ressaltam que o teor muito alto de um determinado nutriente pode causar um falso diagnóstico de deficiência para os demais nutrientes.

Os padrōes nutricionais do DRIS são denominados normas. As normas DRIS são extraidas de uma população de alta produtividade, chamada população de referência. Assim segundo Beaufils (1973), o método DRIS exige que uma determinada população em estudo. da qual deseja-se extrair os padrões nutricionais, seja separada em duas categorias: (i) plantas não anormais, ou população de referência (a expressão "plantas não anormais" é original do autor), que não foram afetadas por condições adversas e que possuem uma produtividade superior a um nivel arbitrariamente estabelecido; e (ii), plantas anormais, ou população não referência, que foram afetadas por condições adversas, produzindo menos que o nivel definido.

A seleção da população de referência é de grande importância para o sucesso do DRIS. Leite (1992), utilizou 24 observações para dar origem às normas DRIS especificas para Coffea canephora cv. Conilon, cultivado no Norte do estado do Espírito Santo. O mesmo autor ponderou serem poucas as suas observações, se comparadas às 2.800 utilizadas por Sumner (1977a) para estabelecer normas gerais para a cultura do milho, na África do Sul. Neste ponto constata-se, no entanto, que embora o número de observações feitas por Sumner (1977a) seja muito superior, sua abrangência é também mais generica que a de Leite (1992), referindo-se a todos os cultivares de milho e a todo território da África do Sul. Segundo Walworth et al. (1988), o tamanho da base de dados 
pode não estar diretamente relacionado à qualidade dos padrões. Walworth et al. (1988) demonstrou que normas DRIS desenvolvidas a partir de 10 observações de milho cultivado a campo, com produtividade acima de $18 \mathrm{Mg} \mathrm{ha}^{-1}$, foram melhores que normas provenientes de grandes bases de dados. Em contraposição, Letzsch \& Sumner (1984) estabeleceram que as melhores normas tiveram origem de grandes bases de dados com observações de alta produtividade. Possivelmente, normas DRIS muito abrangentes e genéricas representam prejuizo à acurácia do diagnóstico proporcionado. Certamente a qualidade. mais que a quantidade de observações, deve ser a característica mais importante de uma base de dados que contém a população de referência.

Uma vez definida a população de referência, dela são determinadas as normas, que consistem na razão entre todos os pares de nutrientes e seus respectivos desvios padrões, ou coeficientes de variação. A razão entre um par de nutrientes pode ser tanto direta como inversa ( $\mathrm{A} / \mathrm{B}$ ou $\mathrm{B} / \mathrm{A}$, onde $\mathrm{A}$ e $\mathrm{B}$ são um par de nutrientes). Para decidir pela melhor ordem de razão, existe atualmente um único critério, o da razão das variâncias, proposto por Letzsch (1985), aqui denominado de critério do "Valor F". Segundo Santos (1997), este critério permite a escolha da razão que melhor realça o parâmetro de interesse. Bataglia \& Santos (1990) não utilizaram o critério do valor F, mas sim testaram as razōes ora na ordem direta, ora na ordem inversa. Concluíram que a ordem das razões interfere nos resultados dos indices dos nutrientes, especialmente se as funções forem calculadas pelo método de Jones (1981).

Estando as normas estabelecidas, os teores de nutrientes de uma amostra podem ser submetidos ao cálculo dos índices DRIS. Estes índices compreendem os índices individuais para cada nutriente e o Índice de Balanço Nutricional, IBN, que dá uma idéia do equilibrio nutricional global da planta. Os índices individuais para cada nutriente são calculados em duas etapas: na primeira são calculadas as funções das razões de cada par de nutrientes, e na segunda, os somatórios das funções envolvendo cada nutriente. 
Para calcular as funções das razões dos nutrientes, existem três métodos: (i) a concepção original de Beaufils (1973); (ii) o método de Jones (1981); e (iii), o método de Elwali \& Gascho (1984), sendo este uma modificação do método de Beaufils (1973). Bataglia \& Santos (1990), trabalhando com seringueira, testaram estes três métodos e conchuiram que os de Beaufils (1973) e Elwali \& Gascho (1984) apresentaram resultados semelhantes entre si, e que o método de Jones (1981) mostrou-se muito dependente da ordem da razão de cada par de nutrientes. Santos (1997) também testou o desempenho destes très metodos sobre dados de citros, concluindo: (i) o método de Beaufils (1973) realçou melhor as deficièncias; (ii) o método de Jones (1981) apresentou vantagem sobre os demais por ser mais facilmente calculado e apresentar maior formalidade estatística; e (iii), o método de Elwali \& Gascho (1984) apresentou menor número de interpretações erròneas. Muito embora os métodos de cálculo das funções das razões dos nutrientes tivessem sido testados nos trabalhos de Bataglia \& Santos (1990) e de Santos (1997), ainda não está definido qual deles é o mais recomendado.

Para realizar o somatório das funções das razões dos nutrientes, a segunda e última etapa para o cálculo dos índices DRIS, segundo Beverly (1991) existem dois métodos: o DRIS (Beaufils, 1973) e o M-DRIS (Walworth et al., 1986; Hallmark et al., 1987). O metodo DRIS, original, se utiliza apenas das funções das razões entre nutrientes. Já o método M-DRIS, que é uma variação do DRIS, trata a concentração do nutriente na folha como um par de fatores, onde a massa do nutriente é dividida pela massa da matéria seca do tecido vegetal. No somatório das funções para o M-DRIS, são envolvidas as funções das concentrações dos nutrientes isolados. O M-DRIS gera um índice adicional, o indice de massa da matéria seca ( $\mathrm{I}_{\mathrm{MS}}$ ), útil na verificação da maturidade do tecido amostrado em relação à do padrão.

Através da soma dos valores absolutos dos índices dos nutrientes, obtém-se o Índice de Balanço Nutricional (IBN). Este índice dá uma idéia do estado nutricional global da planta, sem no entanto indicar as causas, e pode ser feito tanto para o DRIS 
como para o M-DRIS. O IBN tem sido relacionado à produtividade das culturas, como foi feito por Sumner (1977b). Este autor relatou que existe correspondência entre os valores da produtividade do milho e os do IBN.

São poucas e recentes as utilizações do DRIS na cultura do café. Segundo Malavolta (1993), a primeira utilização prática do DRIS no cafeeiro foi feita na Colômbia por Arboleda et al. (1988). No Brasil, Leite (1992) comparou diferentes métodos de diagnose foliar em Coffea camephora no estado do Espírito Santo, dentre eles o DRIS, além do Nivel Crítico, Alimentação Global e Equilíbrios Fisiológicos, e Índices Balanceados de Kenworthy. Das 65 lavouras amostradas por três anos, a população de referència foi de 24 , que preencheram o quesito de ter atingido produtividade acima de 30 sacas de café beneficiado por hectare, em pelo menos uma das três safras. Neste estudo, os métodos de índices balanceados de Kenworthy e DRIS apresentaram resultados bastante semelhantes entre si. Com o Índice de Balanço Nutricional global da lavoura (IBN - DRIS), foi possível evidenciar limitações de ordem não nutricional. Leite (1992) concluiu: (i) o DRIS foi o melhor método para diagnosticar as limitações nutricionais das lavouras; (ii) a utilização do método dos Equilíbrios Fisiológicos foi melhor a nivel regional que para cada lavoura em particular; e (iii), a maior limitação nutricional naquela região foi com relação aos micronutrientes $\mathrm{Mn}$ e $\mathrm{Cu}$, ora em excesso $(\mathrm{Mn})$, ora em deficiència (Mn e $\mathrm{Cu}$ ). Leite (1992) observou que as normas obtidas para o cafeeiro conilon foram notadamente discrepantes dos valores obtidos por Arboleda et al. (1988), para Coffea arabica na Colômbia, atribuindo ao fato de serem espécies diferentes.

Tanto Arboleda et al. (1988) quanto Leite (1992), concluíram que o DRIS possui vantagens comparativas em relação a outros métodos de diagnose, como o das Faixas de Suficiència. Contudo, há necessidade de mais pesquisa para que o uso do DRIS possa ser melhor avaliado e popularizado. Baldock \& Schulte (1996) entendem que os dois métodos, DRIS e Faixas de Suficiência, possuem vantagens individuais que reciprocamente complementariam suas fraquezas. Estes autores propõem um novo 
método, o chamado PASS (Plant Analisys with Standardized Scores), que segundo eles, pretende efetuar estas complementações. Também Elwali \& Gascho (1988), com base em sua experiència com a cultura do milho, ponderam que para um diagnóstico mais seguro do estado nutricional, devem-se levar em consideração os resultados dos dois métodos, o DRIS e as Faixas de Suficiència. 


\section{MATERIAL E MÉTODOS}

\subsection{Descrição da região e cafezais estudados}

O estudo foi realizado na região Norte do Paraná e região vizinha do Sudoeste do Estado de São Paulo. Os municípios abrangidos no Paraná foram Tomazina, Carlópolis, Ribeirão Claro, Santo Antônio da Platina, Ribeirão do Pinhal e Jundiaí do Sul. No estado de São Paulo os municípios foram Taguaí e Fartura. Todos estes municípios pertencem à bacia hidrografica do Rio Paranapanema. A altitude varia de 450 a 580 m.s.n.m. O clima é classificado como Cfa, segundo critérios de Koepen (Mota, 1981).

Esta região é caracterizada pela transição geológica entre rochas sedimentares e rochas eruptivas básicas (Minerais do Paraná S.A., 1989). As rochas sedimentares variam de arenitos pouco consolidados a folhelhos siltosos e argilosos, proporcionando solos com baixa fertilidade natural. Sobre as rochas sedimentares são encontrados Latossolo Vermelho-Escuro (LE), Podzólico Vermelho-Escuro (PE), Podzólico Vermelho-Amarelo (PV) e Cambissolo (C). As rochas eruptivas básicas compreendem derrames de basalto que recobrem as rochas sedimentares, e diques de diabásio que afloram de fendas das rochas sedimentares. Sobre as rochas eruptivas básicas são encontrados solos com maior fertilidade natural, como Terra Roxa Estruturada (TR) e Latossolo Roxo (LR). O relevo desta região varia de suave ondulado a ondulado, mas em todos os cafezais estudados a mecanização é viável.

Foram avaliados 117 talhões de café (Coffea arabica L.) que receberam poda do tipo esqueletamento na primavera de 1996, os quais estão listados na Tabela 1. 
Tabela 1. Características dos talhões de café estudados.

\begin{tabular}{|c|c|c|c|c|c|}
\hline Talhão & $\begin{array}{c}\text { Proprie- } \\
\text { dade }\end{array}$ & Cultivar & $\begin{array}{c}\text { Material de } \\
\text { origem do solo }\end{array}$ & $\begin{array}{l}\text { Classe do } \\
\text { solo }^{* *}\end{array}$ & $\begin{array}{c}\text { Data da } \\
\text { poda }\end{array}$ \\
\hline 1 & 1 & Mundo Novo & RS & LE & 10.11 .96 \\
\hline 2 & 1 & Catuai Amarelo & RS & LE & 28.10 .96 \\
\hline 3 & 1 & Mundo Novo & RS & LE & 04.11 .96 \\
\hline 4 & 1 & Catuaí Amarelo & REB & LR & 11.12 .96 \\
\hline 5 & 1 & Mundo Novo & RS & LE & 06.11 .96 \\
\hline 6 & 1 & Mundo Novo & REB & LR & 17.11 .96 \\
\hline 7 & 1 & Catuaí Amarelo & RS & LE & 03.11 .96 \\
\hline 8 & 2 & Mundo Novo & RS & LE & 28.09 .96 \\
\hline 9 & 2 & Mundo Novo & RS & LE & 25.09 .96 \\
\hline 10 & 2 & Catuai Amarelo & RS & LE & 02.10 .96 \\
\hline 11 & 2 & Mundo Novo & $\mathrm{RS}$ & LE & 22.09 .96 \\
\hline 12 & 3 & Mundo Novo & RS & LE & 17.09 .96 \\
\hline 13 & 3 & Catuaí Amarelo & RS & LE & 13.10 .96 \\
\hline 14 & 4 & Mundo Novo & REB & LR & 10.09 .96 \\
\hline 15 & 5 & Catuaí Amarelo & RS & LE & 16.10 .96 \\
\hline 16 & 6 & Mundo Novo & REB & TR & 21.09 .96 \\
\hline 17 & 6 & Mundo Novo & REB & TR & 07.09 .96 \\
\hline 18 & 6 & Mundo Novo & REB & TR & 21.09 .96 \\
\hline 19 & 6 & Mundo Novo & REB & TR & 07.09 .96 \\
\hline 20 & 7 & Mundo Novo & REB & TR & 06.10 .96 \\
\hline 21 & 7 & Mundo Novo & $\mathrm{RS}$ & LE & 08.11 .96 \\
\hline 22 & 8 & Mundo Novo & RS & LE & 02.10 .96 \\
\hline 23 & 8 & Mundo Novo & RS & LE & 13.09 .96 \\
\hline 24 & 8 & Mundo Novo & RS & $\mathrm{LE}$ & 24.09 .96 \\
\hline 25 & 8 & Mundo Novo & RS & LE & 22.09 .96 \\
\hline 26 & 8 & Mundo Novo & RS & LE & 30.09 .96 \\
\hline 27 & 8 & Mundo Novo & RS & LE & 11.10 .96 \\
\hline 28 & 8 & Mundo Novo & RS & LE & 21.09 .96 \\
\hline 29 & 8 & Mundo Novo & RS & LE & 12.09 .96 \\
\hline 30 & 8 & Mundo Novo & RS & LE & 04.10 .96 \\
\hline 31 & 9 & Catuaí Amarelo & REB & TR & 29.12 .96 \\
\hline 32 & 9 & Catuaí Amarelo & REB & TR & 18.12 .96 \\
\hline 33 & 9 & Catuaí Amarelo & REB & TR & 13.12 .96 \\
\hline 35 & 10 & Mundo Novo & RS & PE & 04.10 .96 \\
\hline 36 & 10 & Mundo Novo & RS & $\overline{P E}$ & 16.10 .96 \\
\hline 37 & 10 & Catuaí Amarelo & RS & $\mathrm{PE}$ & 30.09 .96 \\
\hline 38 & 10 & Mundo Novo & RS & $\mathrm{PE}$ & 18.09 .96 \\
\hline 39 & 10 & Catuaí Amarelo & $\mathrm{RS}$ & $\mathrm{PE}$ & 29.09 .96 \\
\hline 40 & 11 & Mundo Novo & REB & LR & 09.08 .96 \\
\hline 41 & 11 & Mundo Novo & REB & LR & 02.09 .96 \\
\hline 42 & 11 & Mundo Novo & REB & TR & 31.08 .96 \\
\hline
\end{tabular}


Características dos talhões de café estudados.

\begin{tabular}{|c|c|c|c|c|c|}
\hline Talhào & $\begin{array}{c}\text { Proprie- } \\
\text { dade }\end{array}$ & Cultivar & $\begin{array}{c}\text { Material de } \\
\text { origem do solo }\end{array}$ & $\begin{array}{l}\text { Classe do } \\
\text { solo }^{* *}\end{array}$ & $\begin{array}{c}\text { Data da } \\
\text { poda }\end{array}$ \\
\hline 43 & 11 & Mundo Novo & REB & LR & 18.09 .96 \\
\hline 44 & 11 & Mundo Novo & REB & TR & 01.09 .96 \\
\hline 45 & 12 & Catuaí Amarelo & RS & LV & 28.10 .96 \\
\hline 46 & 12 & Catuai Amarelo & RS & LV & 05.09 .96 \\
\hline 47 & 12 & Catuaí Amarelo & RS & LV & 12.09 .96 \\
\hline 48 & 12 & Catuai Amarelo & RS & LV & 19.09 .96 \\
\hline 49 & 12 & Catuaí Amarelo & RS & LV & 26.09 .96 \\
\hline 50 & 12 & Catuai Amarelo & RS & LV & 03.10 .96 \\
\hline 51 & 12 & Mundo Novo & RS & LV & 10.10 .96 \\
\hline 52 & 13 & Catuai Amarelo & RS & LE & 30.09 .96 \\
\hline 53 & 13 & Catuai Amarelo & RS & LE & 19.08 .96 \\
\hline 54 & 14 & Mundo Novo & REB & LR & 15.09 .96 \\
\hline 55 & 14 & Mundo Novo & REB & LR & 11.09 .96 \\
\hline 56 & 14 & Mundo Novo & REB & LR & 12.09 .96 \\
\hline 57 & 14 & Mundo Novo & REB & LR & 05.09 .96 \\
\hline 58 & 14 & Mundo Novo & REB & TR & 09.09 .96 \\
\hline 59 & 15 & Mundo Novo & RS & $\mathrm{C}$ & 24.11 .96 \\
\hline 60 & 16 & Bourbon & REB & TR & 24.10 .96 \\
\hline 61 & 16 & Bourbon & REB & TR & 31.10 .96 \\
\hline 62 & 16 & Bourbon & REB & TR & 07.11 .96 \\
\hline 63 & 16 & Bourbon & REB & TR & 14.11 .96 \\
\hline 64 & 16 & Bourbon & REB & TR & 20.11 .96 \\
\hline 65 & 16 & Bourbon & REB & TR & 02.12 .96 \\
\hline 66 & 17 & Mundo Novo & RS & $\mathrm{LE}$ & 04.09 .96 \\
\hline 67 & 17 & Mundo Novo & RS & LE & 05.10 .96 \\
\hline 68 & 17 & Mundo Novo & RS & $\mathrm{C}$ & 22.09 .96 \\
\hline 69 & 17 & Mundo Novo & RS & $\mathrm{C}$ & 10.09 .96 \\
\hline 70 & 17 & Catuaí Amarelo & RS & $\mathrm{C}$ & 13.09 .96 \\
\hline 71 & 17 & Catuai Amarelo & RS & $\mathrm{C}$ & 02.09 .96 \\
\hline 72 & 17 & Mundo Novo & RS & $\mathrm{C}$ & 04.09 .96 \\
\hline 73 & 18 & Catuaí Amarelo & REB & LR & 17.08 .96 \\
\hline 74 & 18 & Mundo Novo & REB & LR & 23.08 .96 \\
\hline 75 & 18 & Catuaí Amarelo & REB & LR & 18.09 .96 \\
\hline 76 & 18 & Mundo Novo & REB & TR & 24.08 .96 \\
\hline 77 & 18 & Catuaí Amarelo & REB & TR & 30.08 .96 \\
\hline 78 & 18 & Mundo Novo & REB & TR & 10.09 .96 \\
\hline 79 & 19 & Mundo Novo & RS & LE & 08.09 .96 \\
\hline 80 & 19 & Mundo Novo & RS & LE & 11.09 .96 \\
\hline 81 & 20 & Mundo Novo & REB & TR & 21.10 .96 \\
\hline 82 & 20 & Acaiá & REB & TR & 17.09 .96 \\
\hline 83 & 20 & Icatú Amarelo & REB & LR & 08.10 .96 \\
\hline
\end{tabular}


Características dos talhões de café estudados.

\begin{tabular}{|c|c|c|c|c|c|}
\hline Talhão & $\begin{array}{c}\text { Proprie- } \\
\text { dade }\end{array}$ & Cultivar & $\begin{array}{c}\text { Material de } \\
\text { origem do solo" }\end{array}$ & $\begin{array}{c}\text { Classe do } \\
\text { solo }^{* *}\end{array}$ & $\begin{array}{c}\text { Data da } \\
\text { poda }\end{array}$ \\
\hline 84 & 20 & Mundo Novo & REB & TR & 21.10 .96 \\
\hline 85 & 20 & Catuai Amarelo & REB & LR & 27.09 .96 \\
\hline 86 & 20 & Mundo Novo & REB & LR & 27.09 .96 \\
\hline 87 & 20 & Catuaí Amarelo & REB & LR & 27.09 .96 \\
\hline 88 & 20 & Mundo Novo & REB & LR & 27.09 .96 \\
\hline 89 & 20 & Mundo Novo & REB & TR & 10.09 .96 \\
\hline 90 & 20 & Mundo Novo & REB & LR & 17.09 .96 \\
\hline 91 & 20 & Catuai Amarelo & REB & LR & 14.10 .96 \\
\hline 02 & 20 & Mundo Novo & REB & TR & 02.10 .96 \\
\hline 93 & 20 & Mundo Novo & REB & TR & 02.10 .96 \\
\hline 04 & 20 & Mundo Novo & REB & TR & 02.10 .96 \\
\hline 95 & 20 & Mundo Novo & REB & TR & 10.09 .96 \\
\hline 96 & 21 & Mundo Novo & $\mathrm{RS}$ & LE & 13.09 .96 \\
\hline 97 & 21 & Mundo Novo & RS & LE & 27.09 .96 \\
\hline 98 & 21 & Mundo Novo & RS & $\mathrm{C}$ & 29.09 .96 \\
\hline 99 & 21 & Mundo Novo & RS & $\mathrm{C}$ & 01.10 .96 \\
\hline 100 & 22 & Catuai Amarelo & RS & LE & 18.10 .96 \\
\hline 101 & 22 & Catuai Amarelo & RS & LE & 30.09 .96 \\
\hline 102 & 22 & Mundo Novo & RS & LE & 03.10 .96 \\
\hline 103 & 22 & Mundo Novo & RS & LE & 04.10 .96 \\
\hline 104 & 22 & Mundo Novo & RS & LE & 04.10 .96 \\
\hline 105 & 22 & Catuaí Amarelo & RS & LE & 12.10 .96 \\
\hline 106 & 23 & Mundo Novo & RS & $\mathrm{C}$ & 22.09 .96 \\
\hline 107 & 23 & Icatú Amarelo & REB & $\mathrm{C}$ & 29.09 .96 \\
\hline 108 & 23 & Sarchimor & REB & $\mathrm{C}$ & 01.09 .96 \\
\hline 109 & 24 & Catuai Amarelo & REB & LR & 10.10 .96 \\
\hline 110 & 24 & Catuaí Amarelo & REB & LR & 01.10 .96 \\
\hline 111 & 24 & Catuaí Amarelo & REB & LR & 15.10 .96 \\
\hline 112 & 24 & Catuaí Amarelo & REB & LR & 22.09 .96 \\
\hline 113 & 24 & Mundo Novo & REB & LR & 17.08 .96 \\
\hline 114 & 24 & Mundo Novo & REB & LR & 22.09 .96 \\
\hline 115 & 24 & Mundo Novo & REB & LR & 13.10 .96 \\
\hline 116 & 25 & Mundo Novo & RS & LE & 30.07 .96 \\
\hline 117 & 25 & Mundo Novo & RS & LE & 28.08 .96 \\
\hline 118 & 25 & Mundo Novo & RS & LE & 16.08 .96 \\
\hline
\end{tabular}

* RS = rocha sedimentar. REB = rocha eruptiva básica

** TR = Terra Roxa Estruturada: LR = Latossolo Roxo; LE = Latossolo Vermelho-Escuro; LV = Latossolo Vermelho-Amarelo; $\mathrm{C}=$ Cambissolo; $\mathrm{PE}=$ Podzólico Vermelho-Escuro. 
Análises químicas do solo das lavouras estudadas não foram realizadas. Segundo Nick et al.(1994), a linha de plantio e o manejo cultural adotado por cada cafeicultor resultam em profundas alterações nas características químicas do solo dos cafezais. Com o avançar do tempo de cultivo, definem-se nestas lavouras, faixas paralelas de solo de alta e baixa fertilidade. Tal característica tem comprometido a representatividade da amostragem e a interpretação das análises químicas do solo, quando estas são feitas de acordo com as recomendações oficiais. Os mesmos autores determinaram que, para uma avaliação mais segura da fertilidade do solo de um cafezal adulto, são necessárias amostragens mais detalhadas, o que foge dos recursos e propósitos do atual trabalho.

\subsection{Coleta de material vegetal}

Foram realizadas coletas de ramos em 4 épocas após a poda: Dezembro/96, Fevereiro/97, Abril/97 e Julho/97. A amostragem consistiu em percorrer uma trajetória pelo talhão dentro dos princípios da representatividade, amostrando-se por casualidade aproximadamente 25 plantas. De cada planta destacaram-se 2 ramos, ambos adjacentes, brotados à meia altura da copa, contemplando-se todas as direções cardeais ao longo da coleta. Cada amostra composta era formada por 40 a 60 ramos. Os ramos coletados eram imediatamente acondicionados em sacos de polietileno e mantidos em ambiente escuro e fresco, para preservar a hidratação dos tecidos.

\subsection{Determinação dos teores foliares de nutrientes}

Foram determinados os teores foliares de nutrientes dos 117 talhões, para as 4 épocas de amostragem (Dezembro/96, Fevereiro, Abril e Julho/97). Os procedimentos estão descritos a seguir.

De cada ramo coletado destacou-se o $2^{\circ}$ e o $3^{\circ}$ par de folhas totalmente expandidas, contados do ápice para a base, perfazendo um total de 160 a 240 folhas por amostra composta. O sistema de amostragem adotado difere do sistema proposto por Malavolta 
(1993), amplamente adotado em todo pais, que recomenda a coleta do $3^{\circ}$ ou $4^{\circ}$ par de folhas para a analise quimica. Isto justifica-se por dois aspectos. Primeiro, com a experiència adquirida ao longo dos anos com lavouras podadas, vem-se suspeitando que os maiores problemas nutricionais destas plantas envolvem micronutrientes $(\mathrm{Cu}, \mathrm{Fe}, \mathrm{Mn}$, Zn e B), os quais são todos considerados pouco móveis e até imóveis quanto à sua redistribuiçào na planta. Em virtude desta baixa mobilidade é de se esperar que deficièncias e excessos possam ser melhor e mais rapidamente detectados em folhas mais jovens. Segundo, as folhas do $2^{\circ}$ par, embora totalmente expandidas, nem sempre estão plenamente maduras. Portanto, com a inclusão do $2^{\circ}$ e $3^{\circ}$ pares de folhas na amostra composta. esperou-se obter amostras de tecido mais jovem, garantindo ainda a estabilidade nos resultados analíticos, no que diz respeito à massa da matéria seca.

A amostra composta, com as folhas ainda verdes, passou então pelo processo de lavagem. Nesta etapa seguiu-se o método definido por Pavan et al. (1984), no qual as folhas são imersas inicialmente por 30 segundos em solução $\mathrm{HCl} 3 \% \mathrm{~m} / \mathrm{v}$, e enxaguadas por 3 vezes em água desionizada. Segundo os autores do método, a lavagem assim realizada maximiza a remoção dos resíduos químicos e físicos da superficie foliar, sem comprometer os teores internos das folhas. Os resíduos podem ser de sais e compostos de fertilizantes e defensivos foliares, especialmente os que contém $\mathrm{Cu}, \mathrm{B}$ e $\mathrm{Zn}$ em sua composição, além das contaminações com solo.

Logo após a lavagem, as folhas foram centrifugadas a baixa rotação para eliminar o excesso de água da superficie, e acondicionadas em sacos de papel para secagem em estufa a $70^{\circ} \mathrm{C}$, por 48 horas, sob ventilação forçada. Após a secagem, as amostras foliares foram moidas e acondicionadas em pequenos sacos de polietileno, prontas para serem submetidas à análise química.

As amostras foliares foram analisadas quimicamente para os nutrientes $\mathrm{N}, \mathrm{P}, \mathrm{K}, \mathrm{Ca}$, $\mathrm{Mg}, \mathrm{Fe}, \mathrm{Zn}, \mathrm{Cu}, \mathrm{Mn}$ e B, pela metodologia descrita por Sarruge \& Haag (1974), e S, pela metodologia de Blanchar et al. (1963). Os teores de $\mathrm{N}, \mathrm{P}, \mathrm{K}, \mathrm{Ca}, \mathrm{Mg}$ e S foram expressos 
em $\mathrm{g} \mathrm{kg}^{-1}$, e os teores de $\mathrm{B}, \mathrm{Cu}, \mathrm{Fe}, \mathrm{Mn}$ e $\mathrm{Zn}$, em $\mathrm{mg} \mathrm{kg}^{-1}$. Nenhum tipo de correção, ajuste ou transformação estatística foi aplicado aos valores dos teores dos nutrientes.

\subsection{Determinação dos dados vegetativos básicos}

Foram determinadas variáveis vegetativas dos 117 talhões apenas para as 3 últimas épocas de amostragem (Fevereiro, Abril e Julho/97). O mês de Dezembro/96 não foi avaliado em virtude de muitos talhões terem sido recentemente podados, cujos ramos estavam ainda muito jovens. Os procedimentos estão descritos a seguir.

Uma vez com as folhas destacadas para análise química, os ramos foram submetidos ao total destacamento do restante das folhas, as quais foram desprezadas. Estes ramos, agora sem folhas, foram acondicionados em sacos de papel e secos ao ar. Foram determinados très tipos de dados básicos para a avaliação da resposta vegetativa das plantas. São eles: (i) o número de internódios por ramo, NI; (ii) o comprimento médio de cada ordem de internódio, $\mathrm{Cl}$ (ordem de internódio $=$ internódio $\mathrm{n}^{\circ} 1,2,3$, etc. contados a partir do ápice do ramo); e (iii), a massa média da matéria seca, também de cada ordem de internódio, MI. Os procedimentos destas determinações estão descritos a seguir.

Realizou-se inicialmente um preparo dos ramos, que consistiu na eliminação, com uma tesoura de poda, do primeiro internódio do ápice e os dois primeiros internódios da base de cada ramo. Justificou-se esta prática pois em testes preliminares estes internódios apresentaram altos coeficientes de variação, tanto para comprimento como para massa. Isto ocorre pois o primeiro internódio do ápice está normalmente em expansão e com baixo teor de matéria seca. O primeiro internódio da base é normalmente muito curto e possui residuos de sua inserção no ramo de onde brotou. O segundo internódio da base tem comprimento muito variável, pois o seu alongamento sofre alta influência das reservas de carboidratos não estruturais dos ramos suporte logo após a poda. 
O número de nós por ramo foi contado manualmente da seguinte forma. Todos os ramos de cada amostra eram dispostos paralelamente um ao outro sobre uma mesa. Uma linha traçada ao longo da mesa servia de ponto de intercepção com os nós. Ajustavam-se inicialmente todos os ramos interceptando a linha no primeiro nó do ápice. Os ramos eram deslocados sobre a linha, todos juntos, um nó por vez. Eram retirados da mesa e contados o numero de ramos que atingia o último nó a cada deslocamento feito. $\mathrm{O}$ número de ramos acumulados em cada classe de número de nós era registrado, de modo a obter-se a distribuição de frequêencia de ramos por classe de número de nós, conforme ilustra a Tabela 2.

Tabela 2. Mustração da distribuição de freqüência de classes de número de nós por ramo.

\begin{tabular}{cccccccccccccccc}
\hline & \multicolumn{11}{c}{ Classes de número de nós por ramo } \\
\cline { 2 - 13 } Coleta & 4 & 5 & 6 & 7 & 8 & 9 & 10 & 11 & 12 & 13 & 14 & 15 & 16 & 17 & 18 \\
\hline Fevereiro/97 & 1 & 5 & 22 & 30 & 15 & 3 & 1 & & & & & & & \\
Abril/97 & & & 2 & 3 & 11 & 16 & 13 & 8 & 5 & 0 & 0 & 1 & & \\
Julho/97 & & & & 1 & 2 & 8 & 9 & 12 & 11 & 6 & 1 & 2 & 1 & 1 \\
\hline
\end{tabular}

A interpretação da distribuição de frequeencias permitiu verificar a representatividade da amostragem em cada talhão. O número médio de internódios por ramo (NI, internódios $r^{-1}{ }^{-1}$ ), que equivale ao número médio de nós por ramo, foi calculado pela média ponderada, conforme demonstra a equação a seguir:

$\mathrm{NI}=\left[\left(\mathrm{FR}_{1} * 1\right)+\left(\mathrm{FR}_{2} * 2\right)+\ldots+\left(\mathrm{FR}_{\mathrm{n}} * \mathrm{n}\right)\right] /\left[\mathrm{FR}_{1}+\mathrm{FR}_{2}+\ldots+\mathrm{FR}_{\mathrm{n}}\right]$

Onde:

$\mathrm{FR}_{\mathrm{n}}=$ freqüência de ramos em cada classe de ramos com $\mathbf{n}$ internódios $\mathrm{n}$ = número de internódios de cada classe de ramo 
Uma vez determinado o número médio de internódios, agrupou-se os ramos pertencentes às très classes adjacentes de maior frequência (porção hachurada da Tabela 2), desprezando-se os ramos das classes superior e inferior da distribuição normal. Este procedimento teve como finalidade agrupar ramos que surgiram em época semelhante, que representam o pico da brotação após a poda, diminuindo assim a variabilidade da amostragem.

Após o agrupamento dos ramos das três classes principais, partiu-se para a determinação do comprimento e massa da matéria seca médios de cada ordem de internodio. Para isso, procedeu-se o fracionamento de cada ramo em internódios, cortando-se sobre os nós com uma tesoura de poda. O fracionamento era iniciado a partir dos internodios do ápice, os quais eram agrupados em recipientes numerados. Uma vez fracionados os internódios de todos os ramos da amostra, cada grupo de internódios de uma mesma ordem foi acondicionado em sacos de papel devidamente identificados. Os internodios assim preparados foram secos em estufa a $70^{\circ} \mathrm{C}$, por 48 horas, sob ventilação forçada para posteriormente determinarem-se o seu comprimento e massa.

O comprimento dos internódios foi determinado através de um processo de aquisição, tratamento e análise de imagens (Figura 2). Para a aquisição das imagens, confeccionou-se um tabuleiro de cor bege clara, com 6 quadrículas de $15 \times 15 \mathrm{~cm}$ cada uma, dispostas em 2 linhas e 3 colunas, o qual ficava fixo sobre uma ampla mesa. Dentro de cada quadrícula eram dispostos os internódios de cada ordem da amostra. Foram tomadas imagens deste tabuleiro, em projeção aproximadamente ortogonal, por uma câmara de video fixada verticalmente a um tripé. A câmara de vídeo emitia o sinal via cabo para um computador IBM/PC, onde a imagem era digitalizada em tons de cinza atraves do sistema de hardware e software Snappy Shot v1.0 (Play Incorporated, 1995). A imagem era arquivada no formato TIF, e purificada através dos recursos disponiveis do software Adobe Photoshop v3.0.5 (Adobe Systems Incorporated, 1995), de modo a reduzir os vários tons de cinza para apenas 2 cores (preto e branco), processo 
Digitalização da imagem (SNAPPY SHOT v1.0)

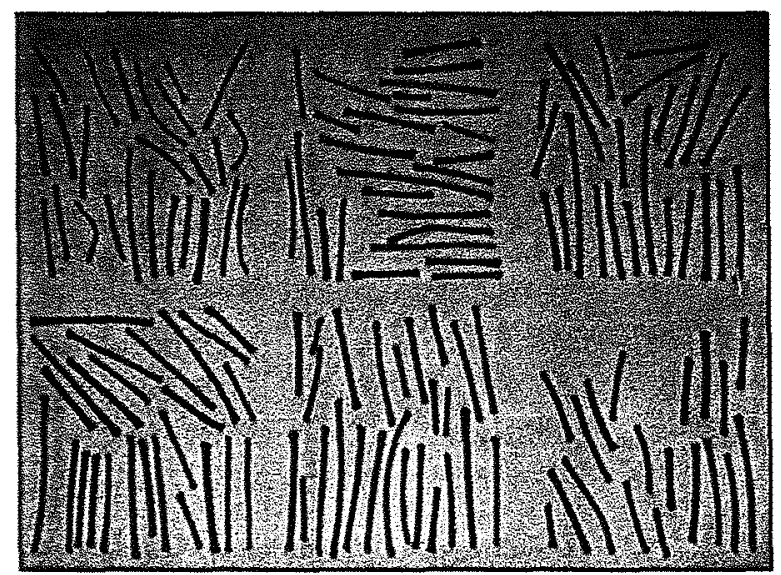

Binarização das cores (ADOBE PHOTOSHOP v3.0.5)

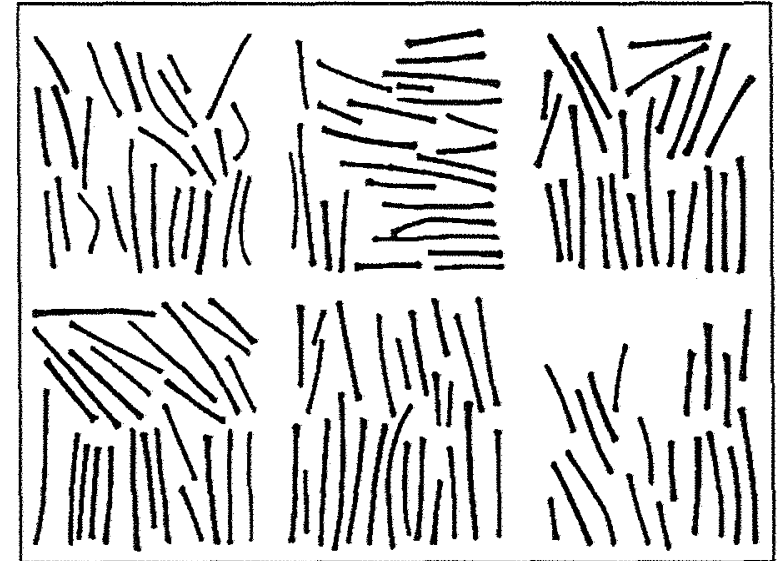

Afinamento e determinação do comprimento (SIARCS v3.1)

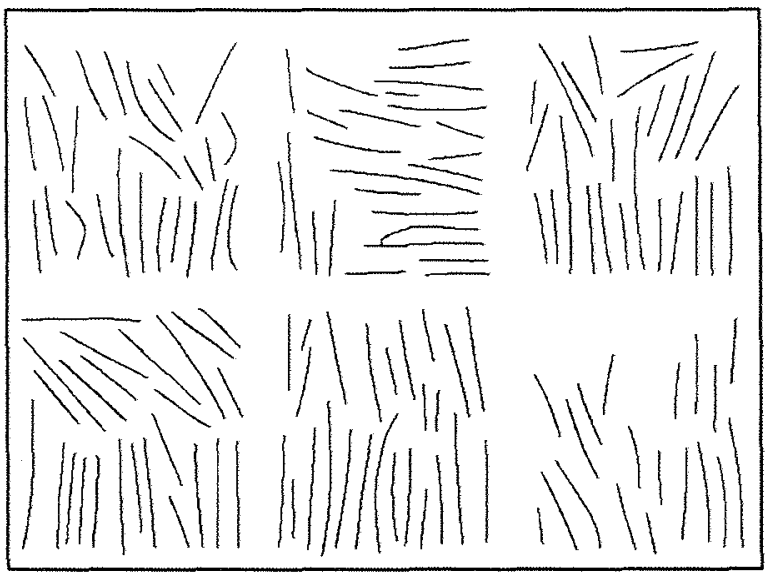

Figura 2. Tratamento de imagem para obtenção do comprimento dos internódios. Exemplificação com internódios de ordem 1 a 6 do talhão 92, amostrado em Abril/97. Escala: $45 \mathrm{~cm}$ na horizontal. 
denominado binarização. A imagem resultante era então convertida para o formato BMP e aplicada ao software SIARCS v3.1 (Empresa Brasileira de Pesquisa Agropecuária, 1996), utilizando-se dele os recursos de "afinamento" e "determinação do comprimento". Os resultados de comprimento eram dados em centímetros, para cada uma das seis quadriculas da imagem. Os dados de comprimento de cada imagem eram transferidos eletronicamente para uma planilha do software Microsoft Excel para Windows 95 v7.0 (Microsoft Corporation, 1995). O comprimento médio de cada ordem de internódios (CI, $\mathrm{cm}$ internodio ${ }^{-1}$ ), foi calculado da seguinte forma:

$\mathrm{CI}=\mathrm{ClA} / \mathrm{FLA}$

Onde:

$\mathrm{ClA}=$ comprimento dos internódios da amostra $(\mathrm{cm})$

FIA = freqüència dos internódios da amostra (internódios)

A massa dos internódios foi determinada com o uso de balança eletrônica da marca "OHAUS", modelo "Precision Plus". A balança foi conectada via cabo à porta serial de um computador IBM/PC, pelo protocolo RS232. Os dados emitidos pela balança eram automaticamente tabulados em planilha do software Excel através do software WEDGE v1.2 (T.A.L. Technologies Incorporated, 1997). A massa média de cada ordem de internódios (MI, mg internódio ${ }^{-1}$ ), foi calculada da seguinte forma:

$\mathrm{MI}=\mathrm{MIA} / \mathrm{FIA}$

Onde:

MIA = massa dos internódios da amostra $(\mathrm{mg})$

FIA = frequêencia dos internódios da amostra (internódios) 


\subsection{Cálculo das variáveis vegetativas}

A partir dos dados básicos de NI, CI e MI, calcularam-se as variáveis vegetativas detalhadas a seguir.

Taxa média diária de lançamento de internódios do ramo ( $\mathrm{TI}$, internódios ramo $^{-1}$ dia $\left.^{-1} 10^{-3}\right)$, calculada da seguinte forma:

$\mathrm{TI}=\left[\left(\mathrm{NI}_{\mathrm{B}}-\mathrm{NI}_{\mathrm{A}}\right) /\left(\operatorname{dias}_{\mathrm{B}-\mathrm{A}}\right)\right] / 1000$

Onde:

$\mathrm{NI}=$ número médio de internódios por ramo (internódios $\mathrm{ramo}^{-1}$ )

$A=$ amostragem do inicio do periodo

$B=$ amostragem do final do periodo

$\operatorname{dias}_{\mathrm{B}-\mathrm{A}}=$ numero de dias entre as amostragens A e B (dias)

Taxa média diária de aumento da massa da matéria seca do ramo (TM, mg ramo $^{-1} \mathrm{dia}^{-1}$ ), calculada da seguinte forma:

$\mathrm{TM}=\left[\left(\mathrm{MR}_{\mathrm{B}}-\mathrm{MR}_{\mathrm{A}}\right) /\left(\operatorname{dias}_{\mathrm{B}-\mathrm{A}}\right)\right]$

Onde:

$\mathrm{MR}=$ massa média da matéria seca do ramo $\left(\mathrm{mg} \mathrm{ramo}^{-1}\right)$

$M R=\left(M_{1}+M_{2}+M_{n} \ldots+M_{y}+M_{z}\right) *$ (internódio / ramo)

$\mathrm{MI}_{\mathrm{n}}=$ massa média da matéria seca da ordem $n$ de internódios (mg internódio ${ }^{-1}$ )

$\mathrm{MI}_{\mathrm{z}}=\left(\mathrm{MI}_{\mathrm{y}-1}\right)^{*} \mathrm{z} \quad(\mathrm{mg})$

$\mathrm{y}=$ número inteiro de $\mathrm{NI}$ 
$z=$ resto de $\mathrm{NI}$

$\mathrm{NI}=$ numero medio de internódios por ramo (internódios $\mathrm{ramo}^{-1}$ )

$A=$ amostragem do início do período

$\mathrm{B}=$ amostragem do final do periodo

$\operatorname{dias}_{\mathrm{B}-\mathrm{A}}=$ número de dias entre as amostragens A e B (dias)

Taxa média diária de aumento do comprimento do ramo $\left(\mathrm{TC}, \mathrm{mm}\right.$ ramo ${ }^{-1}$ $\mathrm{dia}^{-1}$, calculada da seguinte forma:

$\mathrm{TC}=\left[\left(\mathrm{CR}_{\mathrm{B}}-\mathrm{CR}\right) /\left(\operatorname{dias}_{\mathrm{B}-\mathrm{A}}\right)\right]$

Onde:

$\mathrm{CR}=$ comprimento médio do ramo $\left(\mathrm{mm} \mathrm{ramo}^{-1}\right)$

$\mathrm{CR}=\mathrm{CI}_{1}+\mathrm{CI}_{2}+\mathrm{CI}_{\mathrm{n}} \ldots+\mathrm{CI}_{\mathrm{y}}+\mathrm{CI}_{\mathrm{z}}$

$\mathrm{Cl}_{\mathrm{n}}=$ comprimento médio da ordem $n$ de internódios (mm)

$\mathrm{CI}_{z}=\left(\mathrm{CI}_{y-1}\right) * \mathrm{z} \quad(\mathrm{mm})$

$\mathrm{y}=$ numero inteiro de $\mathrm{NI}$

$z=$ resto de NI

$\mathrm{NI}=$ número médio de internódios por ramo (internódios ramo ${ }^{-1}$ )

$A=$ amostragem do inicio do periodo

$B=$ amostragem do final do periodo

$\operatorname{dias}_{\mathrm{B}-\mathrm{A}}=$ número de dias entre as amostragens $\mathrm{A}$ e $\mathrm{B}$ (dias) 
Comprimento médio dos internódios gerados no período (CIP, $\mathrm{mm}$ internódio-

1), calculado da seguinte forma:

$C I P=\left[\left(C R_{B}-C R_{A}\right) /\left(N_{B}-N_{A}\right)\right]$

Onde:

$\mathrm{CR}=$ comprimento médio do ramo $\left(\mathrm{mm} \mathrm{ramo}^{-1}\right)$

$\mathrm{NI}=$ numero médio de internódios por ramo (internódios ramo ${ }^{-1}$ )

$A=$ amostragem do inicio do periodo

$\mathrm{B}=$ amostragem do final do periodo

Taxa média diária de aumento da massa específica do ramo (TME, $\mu \mathrm{g} \mathrm{cm}^{-1} \mathrm{dia}^{-}$

$\left.{ }^{1}\right)$, calculado da seguinte forma:

$\mathrm{TME}=\left[\left(\mathrm{MI}_{3,4,5,6 \mathrm{~B}}-\mathrm{MI}_{3,4,5,6 \mathrm{~A}}\right) /\left(\mathrm{CI}_{3,4,5,6 \mathrm{~B}}-\mathrm{CI}_{3,4,5,6 \mathrm{~A}}\right)\right] / \operatorname{dias}_{\mathrm{B}-\mathrm{A}}$

Onde:

$\mathrm{MI}_{3.4 .5 .6}=\left(\mathrm{MI}_{\mathrm{b}:}+\mathrm{MI}_{\mathrm{b4}}+\mathrm{MI}_{\mathrm{bs}}+\mathrm{MI}_{\mathrm{b} 6}\right)$

$\mathrm{MI}_{\mathrm{b}}=$ Massa média da matéria seca dos internódios basais de ordem 3 ( $\mu \mathrm{g}$ internódio ${ }^{-1}$ )

$\mathrm{CI}_{\text {5.4.5.6 }}=\left(\mathrm{Cl}_{\mathrm{bi}}+\mathrm{Cl}_{\mathrm{b} 4}+\mathrm{CI}_{\mathrm{b5}}+\mathrm{CI}_{\mathrm{b6}}\right)$

$\mathrm{CI}_{\mathrm{bi}}=$ Comprimento médio dos internódios basais de ordem $3\left(\mathrm{~cm}\right.$ internódio ${ }^{-1}$ )

$A=$ amostragem do inicio do período

$B=$ amostragem do final do periodo

$\operatorname{dias}_{\mathrm{B}-\mathrm{A}}=$ número de dias entre as amostragens $\mathrm{A}$ e $\mathrm{B}$ (dias) 
Razão entre taxa média diária de aumento do comprimento e taxa média diária de aumento da massa do ramo ( $\mathrm{TC} / \mathrm{TM}, \mathrm{mm} \mathrm{g}^{-1}$ ), calculado da seguinte forma: $\mathrm{TC} / \mathrm{TM}=(\mathrm{TC} / \mathrm{TM}) *(1000 \mathrm{mg} / \mathrm{g})$

Onde:

$\mathrm{TC}=$ Taxa média de aumento do comprimento do ramo $\left(\mathrm{mm} \mathrm{ramo}^{-1} \mathrm{dia}^{-1}\right)$ $\mathrm{TM}=$ Taxa média de aumento da massa da matéria seca do ramo (mg ramo ${ }^{-1} \mathrm{dia}^{-1}$ )

Razão entre a taxa média diária de aumento do comprimento e a taxa média diária de aumento da massa específica do ramo ( $\mathrm{TC} / \mathrm{TME}, \mathrm{cm}^{2} \mathrm{ramo}^{-1} \mu \mathrm{g}^{-1}$ ), calculado da seguinte forma:

$\mathrm{TC} / \mathrm{TME}=(\mathrm{TC} / \mathrm{TME}) *(0,1 \mathrm{~cm} / \mathrm{mm})$

Onde:

$\mathrm{TC}=$ Taxa média de aumento do comprimento do ramo $\left(\mathrm{mm} \mathrm{ramo}^{-1} \mathrm{dia}^{-1}\right)$

$\mathrm{TME}=$ Taxa média de aumento da massa especifica do ramo $\left(\mu \mathrm{g} \mathrm{cm}^{-1} \mathrm{dia}^{-1}\right)$

Comprimento específico do ramo $\left(\mathrm{C} / \mathrm{M}, \mathrm{mm} \mathrm{g}^{-1}\right)$, calculado da seguinte forma: $\mathrm{C} / \mathrm{M}=(\mathrm{CR} / \mathrm{MR}) *(1000 \mathrm{mg} / \mathrm{g})$

Onde:

$\mathrm{CR}=$ comprimento médio do ramo $\left(\mathrm{mm} \mathrm{ramo}^{-1}\right)$ $\mathrm{MR}=$ massa média do ramo $\left(\mathrm{mg} \mathrm{ramo}^{-1}\right)$

Também para os valores das variáveis vegetativas, nenhum tipo de correção, ajuste ou transformação estatística foi aplicado. 
Quanto à forma de determinação, há dois tipos de parâmetros vegetativos. Do primeiro tipo fazem parte TI, TM, TC, CIP, TME, TC/TME e TC/TM, cujos valores correspondem a um periodo de tempo, logo, sua determinação depende dos dados de duas épocas de amostragem. Do segundo tipo faz parte apenas a relação $\mathrm{C} / \mathrm{M}$, que corresponde a uma avaliação pontual no tempo, determinada com dados apenas de uma época.

Para as variáveis vegetativas que correspondem a um periodo de tempo, foram calculados 3 conjuntos de dados, em função da combinação entre as 3 épocas de coleta: (i) período entre Fevereiro/97 e Abril/97; (ii) período entre Abril/97 e Julho/97; e (iii), periodo entre Fevereiro/97 e Julho/97. Para o parâmetro vegetativo $\mathrm{C} / \mathrm{M}$, o único do tipo pontual no tempo, foram calculados também 3 conjuntos de dados: um para Fevereiro/97, outro para Abril/97 e outro para Julho/97.

\subsection{Definição da melhor variável vegetativa do ramo}

Para chegar à definição da variável vegetativa que melhor representa o potencial produtivo do ramo, foi necessário, inicialmente, realizar uma avaliação das interrelações entre as variáveis vegetativas, através da interpretação dos seus coeficientes de correlação (r), postas dentro de um sistema de relações de causa e efeito.

Para definir o quadro de correlações entre as variáveis vegetativas, foram feitos testes preliminares. Foram elaborados doze quadros de correlação, que correspondem a quatro grupos de cultivares avaliados em três períodos e épocas. Os grupos de cultivares foram: (i) Catuaí Amarelo; (ii) Mundo Novo; (iii) Catuaí Amarelo e Mundo Novo; e (iv), todos os cultivares. Os periodos para as variáveis TI, TM, TC, CIP, TME, TC/TE e TC/TM, foram: de Fevereiro/97 a Abril/97; de Abril/97 a Julho/97; e de Fevereiro/97 e Julho/97. As épocas para a variável C/M foram: Fevereiro/97, Abril/97 e Julho/97. Nestes quadros avaliou-se a ocorrência de comportamento diferenciado das correlações dos 12 bancos de dados. Como não foram constatadas diferenças marcantes, utilizou-se, para 
este trabalho apenas o quadro de correlações que envolveu dados de todos os cultivares do periodo entre Fevereiro/97 e Julho/97.

Para estabelecer um sistema de causa e efeito entre as variáveis através dos valores dos coeficientes de correlação, partiu-se do princípio de que a TI e o CIP são as causas morfo-fisiológicas básicas, e que todas as demais variáveis são suas consequências, diretas ou indiretas.

Justifica-se o uso das variáveis TI e CIP como causas básicas pelo seu interesse agronômico. É de interesse que os valores de TI, taxa média diária de lançamento de internódios por ramo (internódios ramo $\mathrm{dia}^{-1} 10^{-3}$ ), sejam os maiores possiveis para que o ramo acumule, ao final de um ciclo vegetativo, um grande número de nós, que vão florir e frutificar no ano seguinte.

Também é de interesse agronômico que os valores de CIP, comprimento médio dos internódios formados no período avaliado ( $\mathrm{mm}_{\text {internódio }}{ }^{-1}$ ), sejam intermediários, ou seja, os valores extremos são indesejáveis. Tal interesse justifica-se uma vez que internódios muito curtos levam ao sombreamento entre folhas vizinhas, limitam a capacidade de reserva de carboidratos não estruturais na medula caulinar e até mesmo limitam o espaço para o desenvolvimento dos frutos. Internódios muito longos, por sua vez, tornam-se grandes drenos de carboidratos para realizar o crescimento em diâmetro do seu próprio caule, sem reflexo positivo sobre a produtividade do ramo.

A partir dos valores dos coeficientes de correlação entre as variáveis vegetativas, e de posse do conhecimento de que a TI e o CIP são as causas morfo-fisiológicas básicas das demais, estabeleceu-se o esquema das relações de causa e efeito entre todas as variáveis.

Estabelecidas as relações de causa e efeito entre as variáveis, e de posse do conhecimento que os valores desejáveis de TI são máximos, e que os valores desejáveis de CIP são intermediários, definiram-se as faixas de valores desejáveis para as demais variáveis. Se a variável em questão estivesse sob efeito quase exclusivo de TI, sua faixa 
de valores desejável seria máxima. Se estivesse sob efeito quase exclusivo de CIP, sua faixa de valores desejável seria intermediária. E se estivesse sob efeito equilibrado de ambos (TI e CIP), sua faixa de valores desejável seria também intermediária.

Finalmente, com o esquema de causa e efeito montado, e com as faixas de valores desejáveis estabelecidas, identificou-se dentre as variáveis vegetativas, aquela capaz de quantificar, em um só valor, o quanto as variáveis de interesse agronômico, TI e CIP, estão próximas do desejável.

\subsection{Métodos de cálculo do DRIS}

\subsubsection{Critérios para a escolha da ordem da razão dos nutrientes}

Foram testados dois critérios para a escolha da ordem da razão entre um par de nutrientes $\mathrm{A}$ e $\mathrm{B}$ (ordem direta ou inversa, $\mathrm{A} / \mathrm{B}$ ou $\mathrm{B} / \mathrm{A}$ ). $\mathrm{O}$ primeiro critério, denominado de "Valor F" (Letzsch, 1985), seleciona a ordem da razão entre um par de nutrientes pela razão das variâncias (valor $F$ ), da seguinte forma:

se:

$\left[s^{2}{ }_{(A B) \text { pop. referència }} / s^{2}{ }_{(A B)}\right.$ pop. nào referència $]>\left[s_{(B / A) \text { pop. referência }}^{2} / s_{(B / A) \text { pop. não referència }]}^{2}\right.$ então: razão da norma $=\mathrm{A} / \mathrm{B}$

se:

$\left[\mathrm{s}_{(\mathrm{AB}) \text { pop. referència }}^{2} / \mathrm{s}_{(\mathrm{A} / \mathrm{B}) \text { pop. não referència }}^{2}\right]<\left[\mathrm{s}_{(\mathrm{B} / \mathrm{A}) \text { pop. referência }}^{2} / \mathrm{s}_{(\mathrm{B} / \mathrm{A}) \text { pop. não referència }]}^{2}\right.$ então: razão da norma $=\mathrm{B} / \mathrm{A}$

Onde:

$s^{2}(\mathrm{AB})$ pop. referència - Variância dos valores de $A / B$ na população de referência 


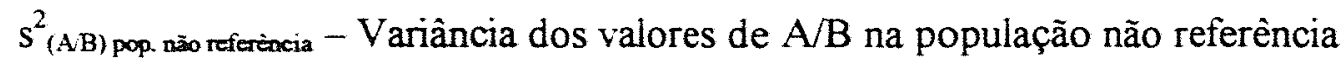

$\mathrm{s}_{(\mathrm{B} / \mathrm{A}) \text { pop referincia }}^{2}$ - Variância dos valores de B/A na população de referência

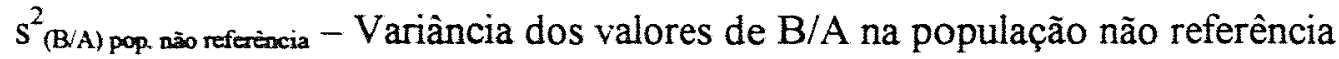

A/B e B/A - Razão entre os teores de um par nutrientes A e B;

ou teor de um nutriente A com base na matéria seca B (para o M-DRIS).

$\mathrm{O}$ segundo critério, denominado de "Valor $\mathrm{r}$ ", proposto no presente estudo, compreende o cálculo dos coeficientes de correlação (r) entre os valores da variável resposta da planta e a razão entre os pares de nutrientes, tanto na ordem direta como inversa. É escolhida a ordem da razão que resultar no mais alto valor absoluto do coeficiente de correlação ( $\mathrm{r}$ ), conforme é apresentado a seguir:

se: $\left|\mathrm{r}_{\mathrm{AB}}\right|>\left|\mathrm{r}_{\mathrm{B} / \mathrm{A}}\right|$

então: razão da norma $=\mathrm{A} / \mathrm{B}$

se: $\left|r_{A B}\right|<\left|r_{B / A}\right|$

então: razão da norma $=\mathrm{B} / \mathrm{A}$

Onde:

$\left|r_{A B}\right|$ - Valor absoluto do coeficiente de correlação entre a variável produtiva da planta e a razão $A / B$ de toda a população (talhões de referência e não referência);

$\left|\mathrm{r}_{\mathrm{B} / \mathrm{A}}\right|$ - Valor absoluto do coeficiente de correlação entre a variável produtiva da planta $\mathrm{e}$ a razão B/A de toda a população (talhões de referência e não referência); 
A/B e B/A - Razão entre os teores de um par nutrientes A e B; ou teor de um nutriente A com base na matéria seca B (para o M-DRIS).

\subsubsection{Cálculo das funções das razões dos nutrientes}

Para o cálculo das funções das razões dos nutrientes foram testados três diferentes métodos, Beaufils (1973), Elwali \& Gascho (1984) e Jones (1981), os quais estão descritos a seguir.

\section{Beaufils (1973):}

se: $\mathrm{Y} / \mathrm{Xa}<\mathrm{Y} / \mathrm{Xn}$

então: $f(Y / X)=[1-(Y / X n / Y / X a)] \cdot(100 . k / C V)$

se: $Y / X a \geq Y / X n$

então: $f(Y / X)=[(Y / X a / Y / X n)-1] \cdot(100 . k / C V)$

\section{Beaufils Modificado, Elwali \& Gascho (1984):}

se: $Y / X a<Y / X n-s$

então: $f(Y / X)=[1-(Y / X n / Y / X a)] \cdot(100 \cdot k / C V)$

se: $\mathrm{Y} / \mathrm{Xn}-\mathrm{s} \leq \mathrm{Y} / \mathrm{Xa} \leq \mathrm{Y} / \mathrm{Xn}+\mathrm{s}$

então: $f(Y / X)=0$

se: $\mathrm{Y} / \mathrm{Xa}>\mathrm{Y} / \mathrm{Xn}+\mathrm{s}$

então: $f(Y / X)=[(Y / X a / Y / X n)-1] .(100 . k / C V)$ 


\section{Jones (1981):}

$$
f(Y / X)=(Y / X a-Y / X n) \cdot k / s
$$

Onde:

$$
\begin{aligned}
\mathrm{f}(\mathrm{Y} / \mathrm{X}) & \text { - função calculada da razão dos nutrientes } \mathrm{Y} \text { e X } \\
\mathrm{Y} / \mathrm{Xa} & \text { - razão dos nutrientes (ou concentração de um nutriente, M-DRIS) da amostra } \\
\mathrm{Y} / \mathrm{Xn} & \text { - razão dos nutrientes (ou concentração de um nutriente, M-DRIS) da norma } \\
\mathrm{S} & \text { - desvio padrão da razão } \mathrm{Y} / \mathrm{Xn} \\
\mathrm{CV} & \text { - coeficiente de variação }(\%) \text { da razão } \mathrm{Y} / \mathrm{Xn} \\
\mathrm{k} & \text { - constante de sensibilidade (neste trabalho, } \mathrm{k}=10 \text { ). }
\end{aligned}
$$

\subsubsection{Somatório das funções}

Foram testados dois métodos para o somatório das funções das razões: DRIS e MDRIS. O método de cálculo dos indices DRIS, original (Beaufils, 1973), envolve apenas as funções das razões entre pares de nutrientes, tal como $f(X / Y)$, onde $X$ e $Y$ são um par de nutrientes, não envolvendo a matéria seca da amostra. Os índices gerados pelo DRIS foram: $I_{N}, I_{P}, I_{k}, I_{C a}, I_{M g}, I_{S}, I_{B}, I_{C u}, I_{F e}, I_{M n}$ e $I_{Z n}$.

Já o método de cálculo dos indices M-DRIS, que é uma variação do DRIS, incorpora, além das funções $\mathrm{f}(\mathrm{X} / \mathrm{Y})$, adicionalmente as funções das razões entre nutrientes e a matéria seca da amostra, tal como $\mathrm{f}(\mathrm{X} / \mathrm{ms})$ ou $\mathrm{f}(\mathrm{ms} / \mathrm{X})$, onde $\mathrm{X}$ é o nutriente e ms a matéria seca da amostra (Walworth et al., 1986; Hallmark et al., 1987).

O método M-DRIS gera, além dos índices para os nutrientes, o "índice de massa da matéria seca" ( $\left.I_{M S}\right)$. Os indices gerados pelo M-DRIS foram: $I_{N}, I_{P}, I_{K}, I_{C a}, I_{M g}, I_{S}, I_{B}, I_{C u}$, $\mathrm{I}_{\mathrm{Fe}}, \mathrm{I}_{\mathrm{Mn}}, \mathrm{I}_{\mathrm{Zn}}$ e I $\mathrm{I}_{\mathrm{MS}}$. 
O índice DRIS para um dado nutriente, ou indice M-DRIS para um dado nutriente ou matéria seca, foi calculado da seguinte forma:

$$
I_{X}=\left[\Sigma^{m}{ }_{i=1} f\left(Y / X_{i}\right)-\Sigma_{j=1}^{n} f\left(X_{j} / Y\right)\right] /(m+n)
$$

Onde:

$\mathrm{I}_{\mathrm{X}}=$ Indice DRIS ou M-DRIS para $\mathrm{X}$

$\mathrm{X}=$ nutriente ou matéria seca a calcular o indice DRIS ou M-DRIS

$\mathrm{Y}=$ nutriente ou matéria seca

$\mathrm{m}=$ número de funções cujo fator $\mathrm{X}$ encontra-se no denominador da razão da norma

$\mathrm{n}=$ número de funções cujo fator $\mathrm{X}$ encontra-se no numerador da razão da norma

Tanto para o DRIS como para o M-DRIS, foi calculado o índice de balanço nutricional (IBN). Este índice representa a média dos valores absolutos de todos os índices dos nutrientes, DRIS ou M-DRIS, sendo calculado da forma representada abaixo.

IBN para o DRIS:

$\mathrm{IBN}=\left(\left|\mathrm{I}_{\mathrm{N}}\right|+\left|\mathrm{I}_{\mathrm{P}}\right|+\left|\mathrm{I}_{\mathrm{K}}\right|+\left|\mathrm{I}_{\mathrm{Ca}}\right|+\left|\mathrm{I}_{\mathrm{Mg}}\right|+\left|\mathrm{I}_{\mathrm{S}}\right|+\left|\mathrm{I}_{\mathrm{B}}\right|+\left|\mathrm{I}_{\mathrm{Cu}}\right|+\left|\mathrm{I}_{\mathrm{Fe}}\right|+\left|\mathrm{I}_{\mathrm{Mn}}\right|+\left|\mathrm{I}_{\mathrm{Zn}}\right|\right) / 11$

IBN para o M-DRIS:

$\mathrm{IBN}=\left(\left|\mathrm{I}_{\mathrm{N}}\right|+\left|\mathrm{I}_{\mathrm{P}}\right|+\left|\mathrm{I}_{\mathrm{K}}\right|+\left|\mathrm{I}_{\mathrm{Ca}}\right|+\left|\mathrm{I}_{\mathrm{Mg}}\right|+\left|\mathrm{I}_{\mathrm{S}}\right|+\left|\mathrm{I}_{\mathrm{B}}\right|+\left|\mathrm{I}_{\mathrm{Cu}}\right|+\left|\mathrm{I}_{\mathrm{Fe}}\right|+\left|\mathrm{I}_{\mathrm{Mn}}\right|+\left|\mathrm{I}_{\mathrm{Zn}}\right|+\left|\mathrm{I}_{\mathrm{MS}}\right|\right) / 12$ 


\subsection{Definição das populações de referência e sistema de pré-validação das normas}

Para definir a população de referência de um conjunto de dados de talhões e teores foliares, foram seguidos os procedimentos descritos abaixo.

Classificou-se inicialmente a população de talhões pelo valor da variável produtiva. Com base em observações pessoais, delimitou-se arbitrariamente um grupo de talhões considerados potencialmente mais produtivos, portanto, possivelmente melhor nutridos.

Procederam-se, então, os cálculos para a determinação das normas. A elas foram submetidos os teores foliares de toda a população de talhões, para determinarem-se os índices DRIS e M-DRIS. Destes, o IBN foi relacionado com a variável produtiva em um gráfico, obtendo-se o coeficiente de determinação $\left(\mathrm{R}^{2}\right)$ da equação de regressão melhor ajustada. As observações envolvidas na geração da equação de regressão foram apenas as da população anormal (população não referência), na faixa de valores da variável resposta acima da faixa desejável (população de referência). O processo de determinação do grau de correspondência entre os valores do IBN e a variável produtiva, foi chamado de sistema de pré-validação das normas DRIS.

Iniciava-se, então, um processo de variação dos limites da população de referência, repetindo-se os passos de determinação das normas e indices DRIS. Registrava-se o valor de $\mathrm{R}^{2}$ das equações resultantes a cada alteração feita nos limites da população de referência . A população de referência finalmente adotada seria aquela para a qual tivesse sido registrado o maior valor $\mathrm{R}^{2}$ da equação ajustada.

\subsection{Avaliação dos métodos de cálculo do DRIS}

Para cada conjunto de dados de talhões e teores foliares dos nutrientes, foram testados 12 combinações de métodos de determinação das normas e índices DRIS, os quais foram descritos anteriormente e estão resumidos a seguir. 


\section{Escolha da ordem da razão dos nutrientes:}

Valor F (Letzsch, 1984)

Valor $\mathrm{r}$ (Proposto neste trabalho)

Cálculo das funções das razões dos nutrientes:

Beaufils (1973)

Jones (1981)

Elwali \& Gascho (1984)

Somatório das funções das razões dos nutrientes:

DRIS (Beaufils, 1973)

M-DRIS (Walworth et al., 1986; Hallmark et al., 1987)

Da mesma forma como foi feito para a definição das populações de referência, os valores de $\mathrm{IBN}$ foram relacionados com os valores da variável produtiva em gráfico, no sistema de pré-validação das normas, obtendo-se o coeficiente de determinação $\left(R^{2}\right)$ da equação de regressão melhor ajustada.

Os valores de $\mathrm{R}^{2}$ de cada combinação de métodos foram tabulados e analisados estatisticamente segundo esquema fatorial $2 \times 3 \times 2$, com 9 blocos. Os blocos corresponderam aos bancos de dados resultantes das combinações entre época de amostragem foliar e época de avaliação da variável resposta ao estado nutricional. Esta análise foi realizada tanto para o cultivar Catuai Amarelo, como para o cultivar Mundo Novo. Realizou-se a análise de variância e o teste de Tukey, para verificação do efeito individual e das interações entre os métodos de cálculo sobre os valores $\mathrm{R}^{2}$ resultantes do sistema de pré-validação. 


\subsection{Definição das normas DRIS}

Para cada época de amostragem de folhas (Dezembro/96, Fevereiro, Abril e Julho/97) foram estabelecidas uma ou mais populações de referência, de acordo com o número de épocas ou períodos de avaliação vegetativa, conforme está detalhado na Tabela 3.

Para cada uma das combinações de época de amostragem foliar vs. época de classificação da população de referência, apresentadas na Tabela 3, foram calculadas as normas e os índices nutricionais pela melhor combinação de métodos de cálculo do

DRIS. Foram determinados os valores de $\mathrm{R}^{2}$ das equações de regressão entre IBN e a variável vegetativa, no sistema de pré-validação das normas DRIS.

Para cada época de amostragem foliar, adotou-se a época de classificação da população de referência que apresentou equação de regressão com o maior valor $\mathrm{R}^{2}$. As normas DRIS assim definidas para cada época de amostragem, e para cada cultivar, foram consideradas agronomicamente aceitas e aplicáveis desde que o valor de $\mathrm{R}^{2}$ da equação ajustada fosse maior que o mínimo estabelecido arbitrariamente de 0,35 .

O banco de dados e todos os cálculos deste trabalho foram realizados em planilhas eletrônicas do software Microsoft Excel para Windows 95 v7.0 (Microsoft Corporation, 1995). Algumas figuras foram elaboradas no software Harvard F/X v1.10 (Software Publishing Corporation, 1994), e a edição final do trabalho foi realizada no software Microsoft Word para Windows 95 v7.0 (Microsoft Corporation, 1995b). 
Tabela 3. Combinações entre épocas de amostragem foliar e épocas de classificação da população de referência.

\begin{tabular}{ccc}
\hline & \multicolumn{2}{c}{ ÉPOCA DE CLASSIFICAÇ̃̃O DA POPULAÇÃO DE REFERẼNCIA } \\
\cline { 2 - 3 } $\begin{array}{c}\text { EMOCA DE } \\
\text { AMOSTRAGEM } \\
\text { FOLIAR }\end{array}$ & $\begin{array}{c}\text { Variável vegetativa de } \\
\text { determinação em um periodo } \\
\text { de tempo }\end{array}$ & $\begin{array}{c}\text { Variável vegetativa de } \\
\text { determinação pontual no tempo }\end{array}$ \\
\hline Dezembro/96 & $\begin{array}{c}\text { Fevereiro/97 a Abril/97 } \\
\text { Fevereiro/97 a Julho/97 }\end{array}$ & Fevereiro/97 \\
& Abril/97 a Julho/97 & Abril/97 \\
& Fevereiro/97 a Abril/97 & Julho/97 \\
\hline Fevereiro/97o/97 & Fevereiro/97 a Julho/97 & Abril/97 \\
& Abril/97 a Julho/97 & Julho/97 \\
\hline Abril/97 & Abril/97 a Julho/97 & Abril/97 \\
& & Julho/97 \\
\hline Julho/97 & Abril/97 a Julho/97 & Julho/97 \\
\hline
\end{tabular}




\section{RESULTADOS E DISCUSSÃO}

\subsection{Definição da melhor variável vegetativa do ramo}

Através dos coeficientes de correlação entre as variáveis vegetativas estudadas, e partindo do pressuposto que TI e CIP são as causas morfo-fisiológicas primárias de todas as demais variáveis, elaborou-se o esquema de relações de causa e efeito entre as variáveis correspondentes às medidas de comprimento e massa do ramo (Figura 3), que são discutidas a seguir.

Medidas de comprimento - De acordo com a Figura 3, a TC é o resultado final da ação conjunta e independente de 2 fatores anteriores, TI $(\mathrm{r}=0,70)$ e $\mathrm{CIP}(\mathrm{r}=0,74)$, ou seja, quanto mais internódios forem produzidos (TI), e quanto mais longos forem eles (CIP), mais longo será o ramo (TC). A certeza da independência entre TI e CIP é dada pela baixa de correlação entre ambos $(r=0,05)$.

Medidas de massa - Ainda na Figura 3, a TM é o resultado final da ação conjunta da TC $(r=0,71)$ e da TME ( $r=0,72)$, ou seja, quanto mais longo (TC) e espesso (TME) for um ramo, maior será a sua massa (TM). A TC e a TME não são totalmente independentes $(\mathrm{r}=0,45)$ pois com o alongamento do ramo sempre haverá um correspondente crescimento em diâmetro do seu respectivo caule, em magnitude variável. Esta característica ocorre pois para cada novo par de folhas, ou novo internódio, um novo anel de feixes vasculares forma-se ao longo do ramo. Por isso, a TME está mais ligada à $\mathrm{TI}(r=0,41)$ que ao $\mathrm{CIP}(\mathrm{r}=0,23)$. 
As variáveis que correspondem às relações entre as medidas de comprimento e massa, são discutidas com base na Tabela 4. A relação TC/TME não é afetada por TI $(r=0,01)$, pois, de acordo com o sistema de causas e efeitos da Figura 3, um aumento na TI resulta em aumentos de magnitude similar tanto na TC como na TME $(r=0,70$ e $r=0,41$, respectivamente). Sobre a relação $T C / T M$, a $\operatorname{TM}(r=-0,62)$ exerce maior influência do que a $\mathrm{TC}(=-0,15)$. $\mathrm{O}$ peso da $\mathrm{TM}$ sobre a relação $\mathrm{TC} / \mathrm{TM}$ é confirmado pelo coeficiente de correlação entre a relação TC/TM e a TME $(r=-0,57)$. A TC, para ser considerada causa importante sobre TC/TM, deveria ter apresentado, ao menos, coeficiente de correlação positivo, no entanto resultou em $r=-0,15$. Se a relação TC/TM fosse integrada no tempo, ao longo do periodo após a poda, obter-se-ia uma aproximação da relação $\mathrm{C} / \mathrm{M}$, existindo por isso alta correlação entre ambos $(r=0,95)$.

Uma vez estabelecidas as relações de causa e efeito entre as variáveis vegetativas do ramo do cafeeiro, definiram-se as faixas conceitualmente desejáveis dos valores de cada uma, as quais estão discutidas abaixo e resumidas na Tabela 5.

Conforme já fora justificado, partindo do nível de causa mais primário, os valores desejáveis da TI devem enquadrar-se em uma faixa máxima, e os de CIP, em uma faixa intermediária. Os valores desejáveis da $\mathrm{TC}$, que está sob influência de TI (valores desejáveis máximos) e CIP (valores desejáveis intermediários), deverão estar dentro de faixas intermediárias. A TME, estando fisiologicamente relacionada à $\mathrm{TI}$, que tem valores desejáveis na faixa máxima, deverá ter consequentemente seus valores ideais também numa faixa máxima. $\mathrm{O}$ mesmo irá ocorrer para a $\mathrm{TM}$, que sob a principal influência de TME deverá ter valores ideais na faixa máxima. Os valores de TC/TME, TC/TM e C/M ideais deverão estar numa faixa intermediária, já que estão sob efeito de TC e TM, com faixa ideal intermediária e máxima, respectivamente. 


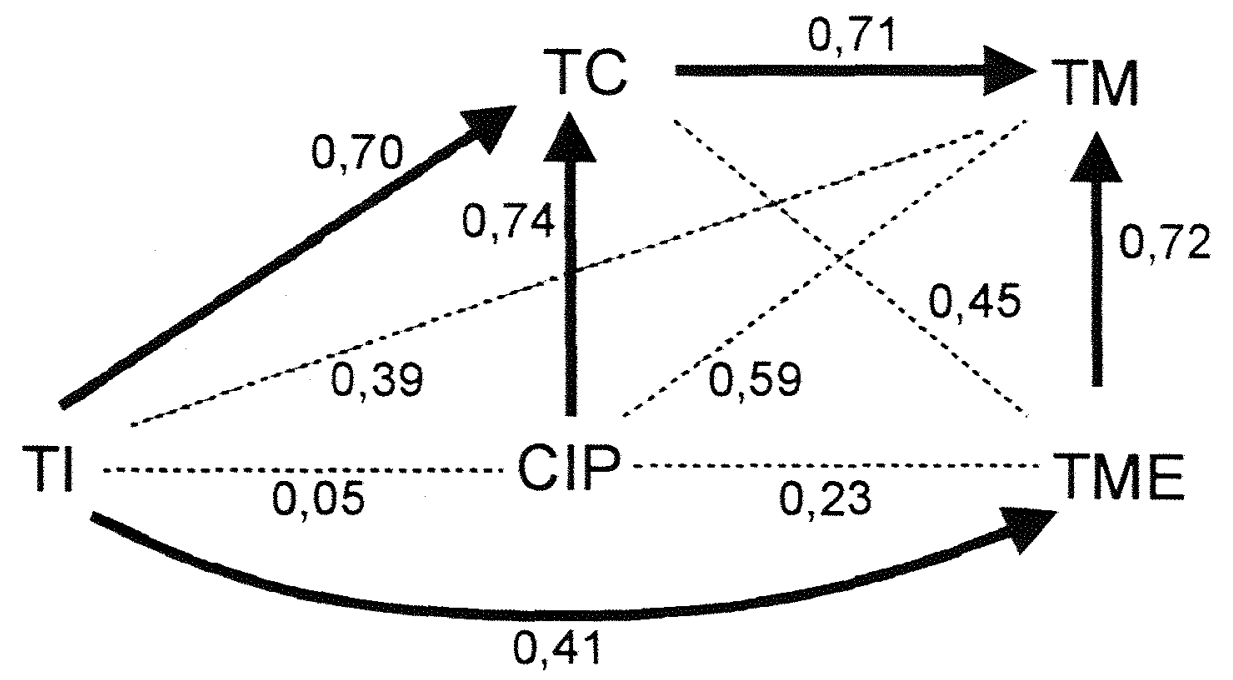

Figura 3. Relações de causa e efeito entre variáveis vegetativas do ramo do cafeeiro. Valores correspondem ao coeficiente de correlação (r). Linhas com flecha indicam relação causa $\rightarrow$ efeito direta.

TI - Taxa média diária de lançamento de internódios do ramo (intemódios $10^{-3} \mathrm{ramo}^{-1} \mathrm{dia}^{-1}$ ) TM - Taxa média diária de aumento da massa da matéria seca do ramo (mg $\mathrm{ramo}^{-1}$ dia $^{-1}$ )

TC - Taxa média diária de aumento do comprimento do ramo (mm ramo ${ }^{-1}$ dia $\left.^{-1}\right)$

CIP - Comprimento médio dos ínternódios gerados no periodo $\left(\mathrm{mm}\right.$ internodio $\left.{ }^{-1}\right)$

TME - Taxa média diária de aumento da massa específica do ramo $\left(\mu \mathrm{g} \mathrm{cm}^{-1} \mathrm{dia}^{-1}\right)$ 
Tabela 4. Coeficientes de correlação entre variáveis vegetativas do ramo do cafeeiro. Dados referentes ao período entre Fevereiro/97 e Julho/97, para todos os cultivares. $(\mathrm{n}=117)$

\begin{tabular}{|c|c|c|c|c|c|c|c|}
\hline VARIÁVEIS & TI & $\mathbf{T M}$ & TC & CIP & TME & TC/TME & TC/TM \\
\hline TM & 0,39 & & & & & & \\
\hline TC & 0,70 & 0,71 & & & & & \\
\hline CIP & 0,05 & 0,59 & 0,74 & & & & \\
\hline TME & 0,41 & 0,72 & 0,45 & 0,23 & & & \\
\hline TC/TME & 0,01 & $-0,20$ & 0,19 & 0,28 & $-0,68$ & & \\
\hline TC/TM & 0,06 & $-0,62$ & $-0,15$ & $-0,25$ & $-0,57$ & 0,52 & \\
\hline $\mathrm{C} / \mathrm{M}$ & $-0,15$ & $-0,70$ & $-0,28$ & $-0,24$ & $-0,66$ & 0,51 & 0,95 \\
\hline
\end{tabular}

*) Variaveis vegetativas do ramo do cafeciro:

ПI - Taxa média diária de lançamento de intemódios do ramo (internodios $10^{-3} \mathrm{ramo}^{-1} \mathrm{dia}^{-1}$ )

TM - Taxa média diária de aumento da massa da matéria seca do ramo (mg ramo ${ }^{-1} \mathrm{dia}^{-1}$ )

TC - Taxa média diária de aumento do comprimento do ramo (mm $\left.\mathrm{ramo}^{-1} \mathrm{dia}^{-1}\right)$

CIP - Comprimento médio dos internódios gerados no periodo ( $\mathrm{mm}$ internódio ${ }^{-1}$ )

TME - Taxa média diária de aumento da massa especifica do ramo $\left(\mu \mathrm{g} \mathrm{cm}^{-1} \mathrm{dia}^{-1}\right)$

TC/TME - Razão entre a taxa média diária de aumento do comprimento e a taxa média diária de aumento da massa especifica do ramo $\left(\mathrm{cm}^{2} \mathrm{ramo}^{-1} \mu^{-1}\right)$

TC/TM - Razão entre taxa média diária de aumento do comprimento e taxa média diária de aumento da massa do ramo $\left(\mathrm{mm} \mathrm{g}^{-1}\right)$

$\mathrm{C} / \mathrm{M}$ - Comprimento especifico do ramo $\left(\mathrm{mm} \mathrm{g}^{-1}\right)$ 
Tabela 5. Faixas conceituais de valores das variáveis vegetativas, maximizadoras do potencial de produção de grãos no ramo do cafeeiro.

\begin{tabular}{cc}
\hline VARIÁVEIS $^{*}$ & ConCEITo \\
\hline TI & Faixa de valores máximos \\
CIP & Faixa de valores intermediários \\
TC & Faixa de valores intermediários \\
TME & Faixa de valores máximos \\
TM & Faixa de valores máximos \\
TC/TM & Faixa de valores intermediários \\
TC/TME & Faixa de valores intermediários \\
C/M & Faixa de valores intermediários \\
\hline
\end{tabular}

*) Variáveis vegetativas do ramo do cafeeiro:

TI - Taxa média diária de lançamento de internódios do ramo (internódios $10^{-3} \mathrm{ramo}^{-1} \mathrm{dia}^{-1}$ )

TM - Taxa média diária de aumento da massa da matéria seca do ramo (mg ramo $^{-1}$ dia $^{-1}$ )

TC - Taxa média diária de aumento do comprimento do ramo (mm $\left.\mathrm{ramo}^{-1} \mathrm{dia}^{-1}\right)$

CIP - Comprimento médio dos internódios gerados no periodo ( $\mathrm{mm}$ intemódio $\left.{ }^{-1}\right)$

TME - Taxa média diária de aumento da massa especifica do ramo $\left(\mu \mathrm{g}^{-1} \mathrm{dia}^{-1}\right)$

TC/TME - Razão entre a taxa média diária de aumento do comprimento e a taxa média diária de aumento da massa especifica do ramo $\left(\mathrm{cm}^{2} \mathrm{ramo}^{-1} \mathrm{Hg}^{-1}\right)$

TC/TM - Razão entre taxa média diária de aumento do comprimento e taxa média diária de aumento da massa do ramo $\left(\mathrm{mm} \mathrm{g}^{-1}\right)$

C/M - Comprimento específico do ramo (mm $\left.\mathrm{g}^{-\mathrm{l}}\right)$ 
De acordo com as relações de causa e efeito, e com as faixas de valores desejáveis estabelecidas, a variável vegetativa que melhor reúne e expressa características determinantes do potencial produtivo do ramo, é o comprimento específico do ramo $\left(\mathrm{C} / \mathrm{M}, \mathrm{mm} \mathrm{g}^{-1}\right)$, conforme justifica-se a seguir.

De acordo com a Figura 3, um aumento na TI resulta num aumento tanto na TC $(=0,70)$ como na TME $(\mp 0,41)$. O aumento na TME por sua vez, provoca variação direta na TM $(r=0,72)$. Portanto, variações nos valores da TI provocam variações positivas tanto na TC como na TM, logo, pouco afetam os valores das relações TC/TM e $\mathrm{C} / \mathrm{M}$.

Entretanto, a variável básica que tem o maior poder de desbalancear as relações TC/TM e C/M é o CIP. Este afeta substancialmente a TC $(r=0,74)$ e pouco a TME $(r=0,23)$. A influência maior do CIP do que da TI sobre as relações TC/TM e C/M, é comprovada pelos coeficientes de correlação: para TI vs. TC/TM e TI vs. C/M, r é igual a 0,06 e $-0,15$, respectivamente; mas para CIP vs. TC/TM e CIP vs. C/M, r é igual a 0,25 e $-0,24$, respectivamente.

Estas correlações indicam que ramos com as relações $\mathrm{C} / \mathrm{M}$ ou TC/TM dentro da faixa de valores desejável (faixa de valores intermediária), possivelmente apresentarão TI, CIP e TME dentro de valores desejáveis. Em outras palavras, estes ramos deverão apresentar internódios numerosos, espessos e de comprimento intermediário, possibilitando melhor eficiência fotossintética e otimização da partição dos fotossintetatos, logo, inflorescências e frutos em maior número e vigor, portanto, produtividade potencial do ramo maximizada.

Com a necessidade de escolher-se apenas uma variável vegetativa, a relação $\mathrm{C} / \mathrm{M}$ apresentou uma importante vantagem de ordem prática sobre a relação TC/TM: sua determinação é pontual no tempo, ao passo que para obter TC/TM são necessárias determinações iniciais e finais de um periodo. 


\subsection{Avaliacão dos métodos de cálculo do DRIS}

Os valores de $\mathrm{R}^{2}$ resultantes das equações ajustadas entre os valores de IBN e da relação $\mathrm{C} / \mathrm{M}$, do sistema de pré-validação, estão apresentados na Tabela 6 , para o cultivar Catuai Amarelo, e Tabela 7, para o cultivar Mundo Novo.

Em virtude dos baixos valores de $\mathrm{R}^{2}$ para o cultivar Mundo Novo, realizou-se a análise de variância dos dados apenas para o cultivar Catuaí Amarelo. O quadro resumido da análise de variância está apresentado na Tabela 8. 


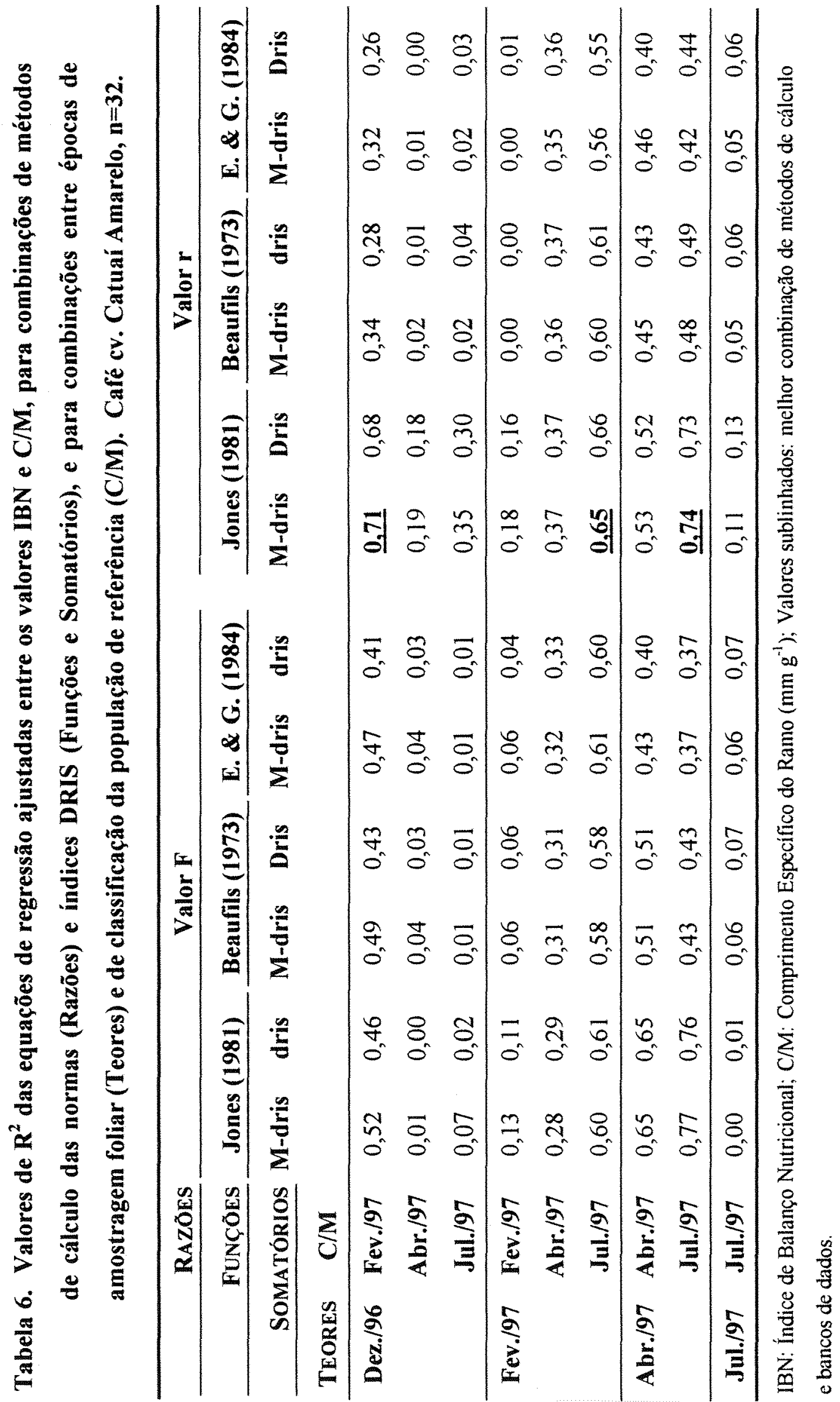




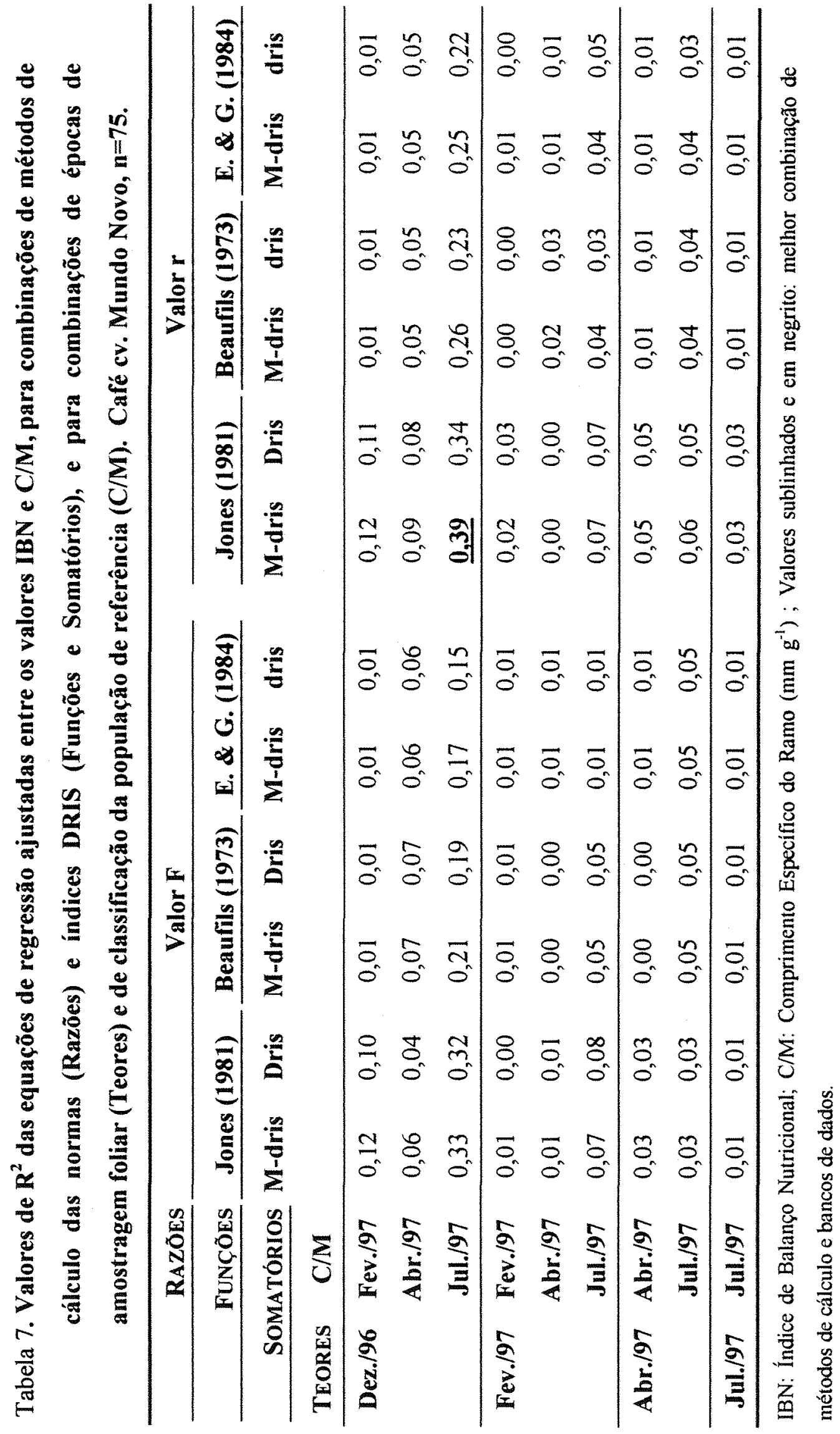


Tabela 8. Análise de variância para os métodos de cálculo das normas e índices DRIS. Base de dados do café cultivar Catuaí Amarelo.

\begin{tabular}{lc}
\hline MÉTodos de CÁlCULo dAS NORMAS E ÍNDICES DRIS & $\begin{array}{c}\text { NíLL DE SIGNIFICÂNCIA } \\
(\%)\end{array}$ \\
\hline Razões & 16,33 \\
Funções & 0,01 \\
Somatórios & 51,10 \\
Razões * Funções & 0,15 \\
Razões * Somatórios & 95,43 \\
Funções * Somatórios & 97,03 \\
Razões * Funções * Somatórios & 100,00 \\
\hline
\end{tabular}

Constata-se pela Tabela 8 , considerando-se o nível máximo de significância igual a $5 \%$, que não houve efeito individual dos métodos para a escolha da ordem da razão do par de nutrientes (Razões). Nem tampouco houve efeito individual dos métodos de somatório das funções das razões (Somatórios). Efeito individual houve apenas para os métodos de cálculo das funções das razões (Funções). O método de Jones (1981) foi superior aos métodos de Beaufils (1973) e Elwali \& Gascho (1984), que foram iguais entre si.

Houve porém, interação entre os métodos de escolha da ordem das razões e os métodos de cálculo das funções das razões. Os testes de média desta interação são apresentados na Tabela 9. Normas DRIS determinadas através do critério do Valor $r$, aplicadas ao cálculo das funções pelo método de Jones (1981), proporcionaram os resultados de IBN que melhor corresponderam com o comprimento especifico dos ramos $(\mathrm{C} / \mathrm{M})$. 
Tabela 9. Comparação das médias de $\mathbf{R}^{2}$, do sistema de pré-validação, gerados pelos métodos do Valor r e Valor F para a escolha da ordem das razões de pares de nutrientes, dentro de cada método de cálculo das funções.

ESCOLHA DA ORDEM DA RAZĀO DOS NUTRIENTES PARA AS NORMAS

\begin{tabular}{ccc} 
& \multicolumn{2}{c}{ AS NORMAS } \\
\cline { 2 - 3 } CÁlculo dAS FUnÇÕES & Valor $\mathbf{r}$ & Valor F (Letzsch, 1985) \\
DAS RAZÕES & A 0,422 & B 0,329 \\
Jones (1981) & B 0,257 & B 0,274 \\
Beaufils (1973) & B 0,240 & B 0,258 \\
\hline
\end{tabular}

OBS) Médias na linha acompanhadas de letras distintas diferem entre si pelo teste de Tukey ao nível de $1 \%$.

Em concordância com o que foi relatado por Bataglia \& Santos (1990), os métodos de Beaufils (1973) e Elwali \& Gascho (1984) apresentaram resultados semelhantes entre si. O que não foi relatado por estes autores é que o método de Jones (1981) foi superior aos demais. Os mesmos autores também constataram que o método de Jones (1981) mostrou-se muito dependente da ordem da razão de cada par de nutrientes. Isto pôde ser melhor comprovado aqui, pelo fato de que apenas para o cálculo das funções através do método de Jones (1981) é que houve diferença entre o método do Valor $\mathrm{r}$ e o Valor $\mathrm{F}$, que interferem na ordem da razão dos nutrientes.

Dos resultados extrai-se que o método de Jones (1981) deve ser utilizado para o cálculo das funções das razões dos nutrientes, e que se a este método forem aplicadas normas DRIS obtidas pelo critério do Valor $r$, a acurácia dos índices pode ser significativamente melhorada. 
Como não houve efeito do método de somatório das funções das razões dos nutrientes (DRIS ou M-DRIS), a decisão por adotar um ou outro passa a ser a quantidade e utilidade das informações geradas em cada um. Neste aspecto, o método MDRIS apresenta vantagem por gerar, além dos indices dos nutrientes, o índice de matéria seca $\left(\mathrm{I}_{\mathrm{MS}}\right)$.

\subsection{Definição das normas DRIS}

Para fazer a opção por uma única norma para cada época de amostragem foliar, avaliaram-se os valores de $\mathrm{R}^{2}$ da Tabela 6 e Tabela 7. Consideraram-se apenas os valores da coluna resultante da combinação dos métodos do Valor $\mathrm{r}$, Jones (1981) e M-DRIS. Para cada época de amostragem foliar foram aceitas como aplicáveis as normas que

resultaram no maior $R^{2}$, desde que este valor estivesse acima do limite inferior de 0,35 , arbitrariamente estabelecido. Estes valores estão destacados nestas duas tabelas (sublinhados e em negrito), e estão resumidos na Tabela 10. Poderão ser prontamente utilizadas as normas DRIS definidas em Dezembro, Fevereiro e Abril, para o cultivar Catuaí Amarelo, e as definidas em Dezembro, para o cultivar Mundo Novo.

Os gráficos correspondentes aos valores $R^{2}$ da Tabela 10 estão apresentados a seguir (Figura 4, Figura 5, Figura 6 e Figura 7). As normas definidas para cada uma destas situações estão apresentadas na Tabela 11, Tabela 12, Tabela 13 e Tabela 14. Os teores foliares dos nutrientes das populações de referência e não referência estão na Tabela 15, Tabela 16, Tabela 17 e Tabela 18. E os índices M-DRIS, inclusive o IBN, usado para gerar os gráficos, estão na Tabela 19, Tabela 20, Tabela 21 e Tabela 22. 
Tabela 10. Cultivares e épocas de amostragem cujos valores $R^{2}$ das equações de regressão entre IBN e C/M foram maiores que 0,35 .

\begin{tabular}{cccc}
\hline CULTIVAR & $\begin{array}{c}\text { ÉPOCA DE } \\
\text { AMOSTRAGEM } \\
\text { FOLIAR }\end{array}$ & $\begin{array}{c}\text { ÉPOCA DE AVALIAÇÃo DOS } \\
\text { VALORES C/M PARA A } \\
\text { CLASSIFICAÇÃo DA } \\
\text { POPULAÇÃo DE REFERÊNCIA }\end{array}$ & $\begin{array}{c}\text { VALOR R }{ }^{2} \text { DA } \\
\text { EQUAÇÃo DE } \\
\text { REGRESSÃo ENTRE } \\
\text { IBN E C/M }\end{array}$ \\
\hline Catuaí A. & Dezembro & Fevereiro & 0,71 \\
Catuaí A. & Fevereiro & Julho & 0,65 \\
Catuaí A. & Abril & Julho & 0,74 \\
Mundo N. & Dezembro & Julho & 0,39 \\
\hline
\end{tabular}

") $\mathrm{IBN}=$ Índice de Balanço Nutricional: $\mathrm{C} / \mathrm{M}=$ comprimento especifico do ramo ( $\left.\mathrm{mm} \mathrm{g}^{-1} \mathrm{MS}\right)$.

Os gráficos de pré-validação das normas DRIS foram elaborados através da correspondência entre valores do IBN e do comprimento especifico do ramo $(\mathrm{C} / \mathrm{M}, \mathrm{mm}$ $\mathrm{g}^{-1} \mathrm{MS}$ ). Os valores do IBN foram calculados para todas as amostras da população, incluindo as populações de referência e não referência (Tabela 19, Tabela 20, Tabela 21 e Tabela 22). Os gráficos foram divididos em três classes de valores do comprimento específico do ramo: uma faixa intermediária, correspondente à população de referência, e duas faixas extremas, correspondentes à população não referência. $O$ fato das melhores populações de referência terem sido aquelas de uma faixa intermediária de valores de comprimento específico do ramo, vem a confirmar o que foi previsto na Tabela 5 , onde estabeleceu-se que os valores desejáveis desta variável estariam dentro de uma faixa intermediária. 


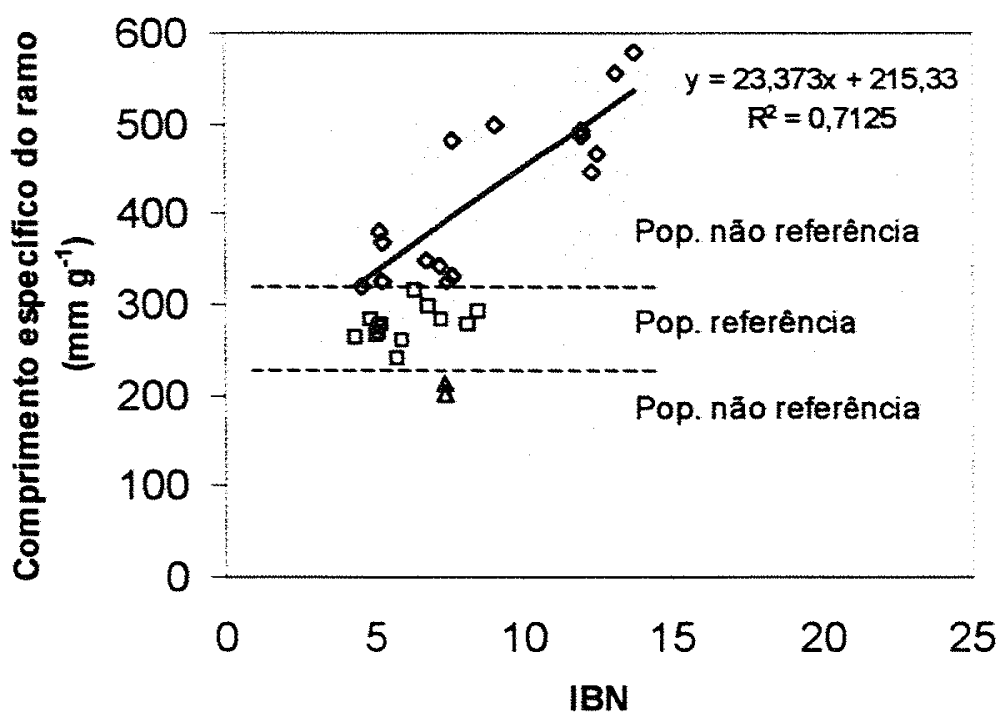

Figura 4. Pré-validação das normas DRIS para o café cv. Catuaí Amarelo, mês de Dezembro/96. A equação de regressão corresponde às observações da população não referência acima da população referência.

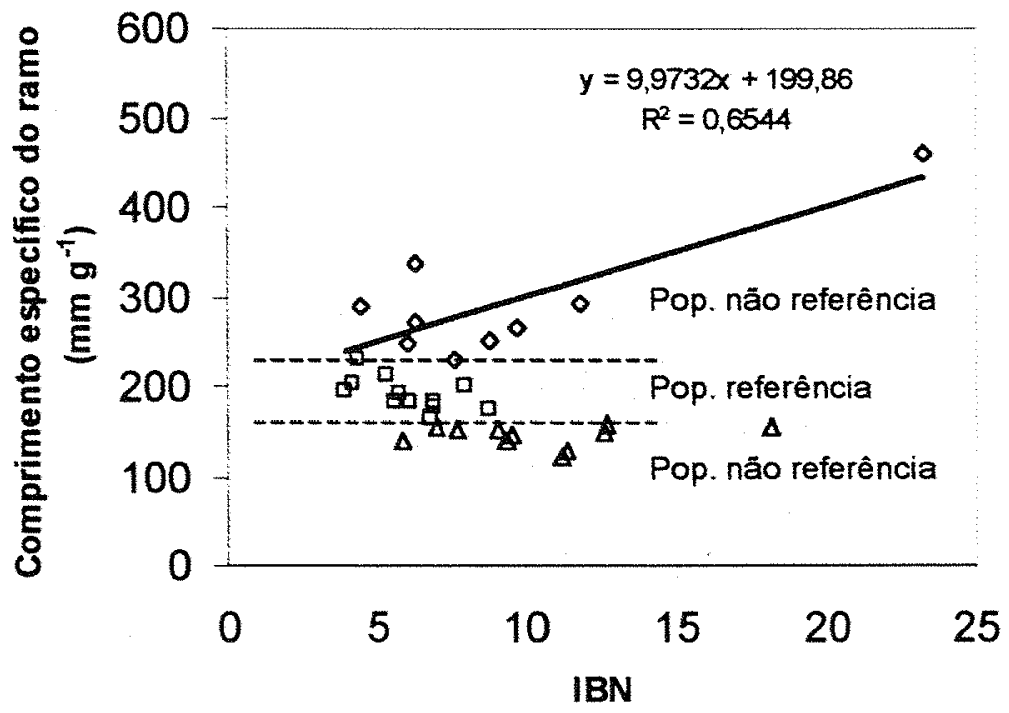

Figura 5. Pré-validação das normas DRIS para o café cv. Catuaí Amarelo, mês de Fevereiro/97. A equação de regressão corresponde às observações da população não referência acima da população referência. 


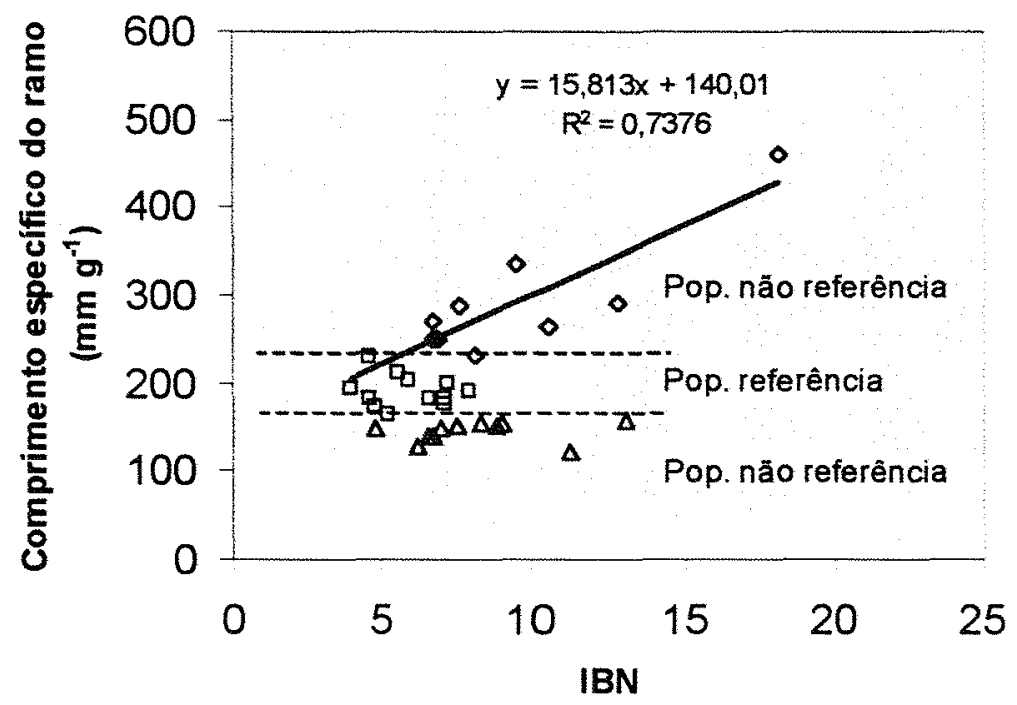

Figura 6. Pré-validação das normas DRIS para o café cv. Catuaí Amarelo, mês de Abril/97. A equação de regressão corresponde às observações da população não referência acima da população referência.

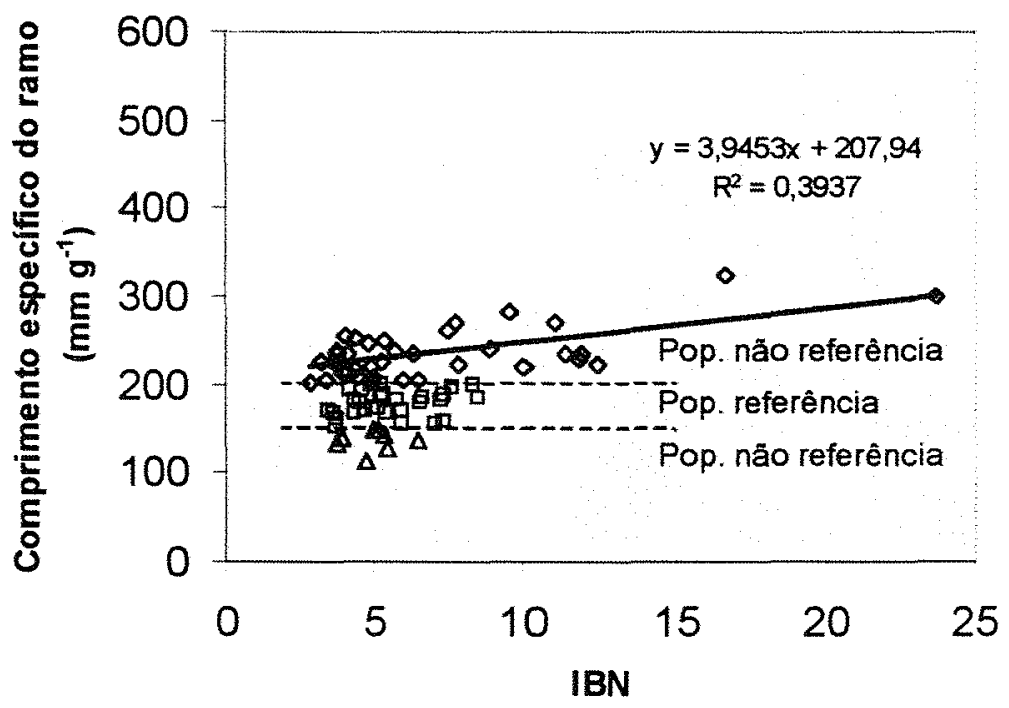

Figura 7. Pré-validação das normas DRIS para o café cv. Mundo Novo, mês de Dezembro/96. A equação de regressão corresponde às observações da população não referência acima da população referência. 
De acordo com a Tabela 6 e Tabela 7, as normas DRIS de Julho não foram prévalidadas para qualquer dos dois cultivares. Isto confirma o efeito maior das causas não nutricionais sobre o desenvolvimento vegetativo, nesta época do ano. Estas causas compreendem particularmente fatores climáticos. Nesta época ocorrem temperaturas mais baixas, fotoperiodo mais curto e menor precipitação pluviométrica. Além disso, há um outro fator importante: os teores foliares e a resposta vegetativa (comprimento específico do ramo) foram avaliados no mesmo dia. A resposta da planta ao estado nutricional não é instantânea, por isso, os teores foliares de Julho deveriam ter sido classificados com uma avaliação dos ramos de uma época posterior.

Nota-se pela Tabela 6 e Tabela 7, que salvo poucas exceções, existe a tendência de que quanto mais curto o espaço de tempo entre a coleta da amostra foliar e a avaliação da resposta da planta, menor a correspondência entre estas variáveis. De fato, em nenhuma das épocas de amostragem foliar a melhor população de referência foi determinada pelos valores $\mathrm{C} / \mathrm{M}$ da mesma época.

Para o cultivar Mundo Novo foram pré-validadas um menor número de normas (Dezembro) que para o cultivar Catuaí Amarelo (Dezembro, Fevereiro e Abril). Para este fato levantam-se duas possibilidades. A primeira delas é que o cultivar Mundo Novo possa ser mais tolerante que o cultivar Catuaí Amarelo à variações da fertilidade do solo. E a segunda, é o fato de que os talhões do cultivar Mundo Novo estariam localizados, em sua maioria, nas propriedades com nível tecnológico mais elevado, diminuindo as chances de apresentarem desordens nutricionais.

Pelos gráficos de pré-validação (Figura 4, Figura 5, Figura 6 e Figura 7) nota-se que os ramos de alto comprimento específico começam a ocorrer com maior freqüência a partir de valores IBN maiores que 8. Este limite inferior pode ser arbitrariamente estabelecido pela avaliação visual dos gráficos. Em todos estes gráficos existem, no entanto, observações de ramos com alto comprimento específico, mas que apresentam IBN menor que 8. A este comportamento podem ser atribuídas causas não nutricionais, 
tais como o sombreamento, provocado por quebra-ventos inadequados, e desfolhas excessivas, provocadas por descuidos no manejo fitossanitário.

Às observações de ramos com baixo comprimento específico do ramo e valor IBN menor que 8 , também podem ser atribuídas causas não nutricionais, como falhas na execução da poda. Neste caso, ramos suporte muito longos, por exemplo, podem competir com grande intensidade por açúcares solúveis do sistema de fontes e drenos, desfavorecendo o alongamento dos internódios dos ramos novos.

A qualidade, mais que a quantidade de observações, parece ser a característica mais importante de uma base de dados que contém a população de referência. No presente estudo, a população de talhões de café que deu origem à normas DRIS é reduzida, 12 para o cv. Catuaí Amarelo, e 32 para o cv. Mundo Novo. Da mesma forma, Walworth et al. (1988) demonstraram que normas DRIS desenvolvidas a partir de 10 observações de milho, cultivado a campo, com produtividade acima de $18 \mathrm{Mg} \mathrm{ha}^{-1}$, foram melhores que normas provenientes de bases de dados maiores.

A separação das populações de talhões pelo critério do cultivar contribuiu para a determinação de normas DRIS mais precisas. Para ilustrar, na Figura 8 e Figura 9 são aplicadas normas DRIS de um cultivar a teores foliares de outro. Na Figura 8 observa-se que normas DRIS do cr. Catuai Amarelo, de Dezembro, aplicadas a teores foliares de talhões do cv. Mundo Novo, da população não referência também de Dezembro, superestimaram os valores de IBN, se comparado ao seu gráfico original da Figura 7. O valor $\mathrm{R}^{2}$ da equação de regressão baixou de 0,39 para 0,31 . Com a inversão dos cultivares, na Figura 9, normas DRIS do cv. Mundo Novo, de Dezembro, aplicadas a teores foliares do cv. Catuaí Amarelo, por sua vez, subestimaram os valores de IBN, se comparado à situação original da Figura 4 . Neste caso, o valor de $\mathrm{R}^{2}$ da equação ajustada baixou de 0,71 para 0,46 . Ao que os resultados indicam, normas gerais envolvendo estes dois cultivares ao mesmo tempo, acarretariam em prejuizo à acurácia do diagnóstico. 


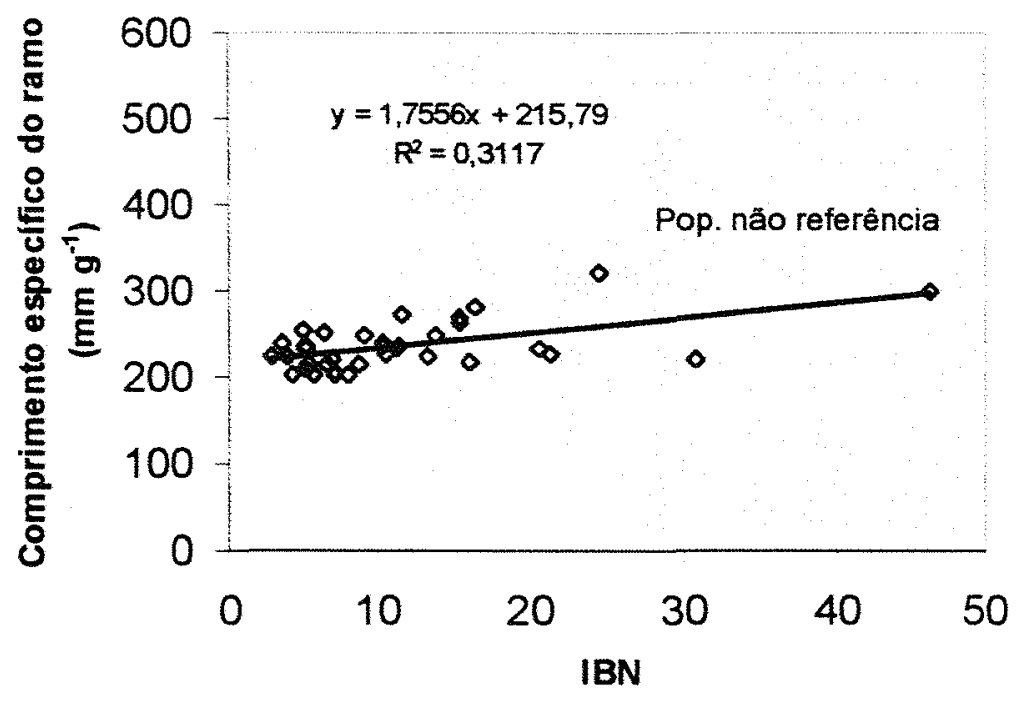

Figura 8. Pré-validação das normas DRIS do cv. Catuaí Amarelo, de Dezembro, aplicadas a teores foliares de talhões não referência do cv. Mundo Novo, também de Dezembro.

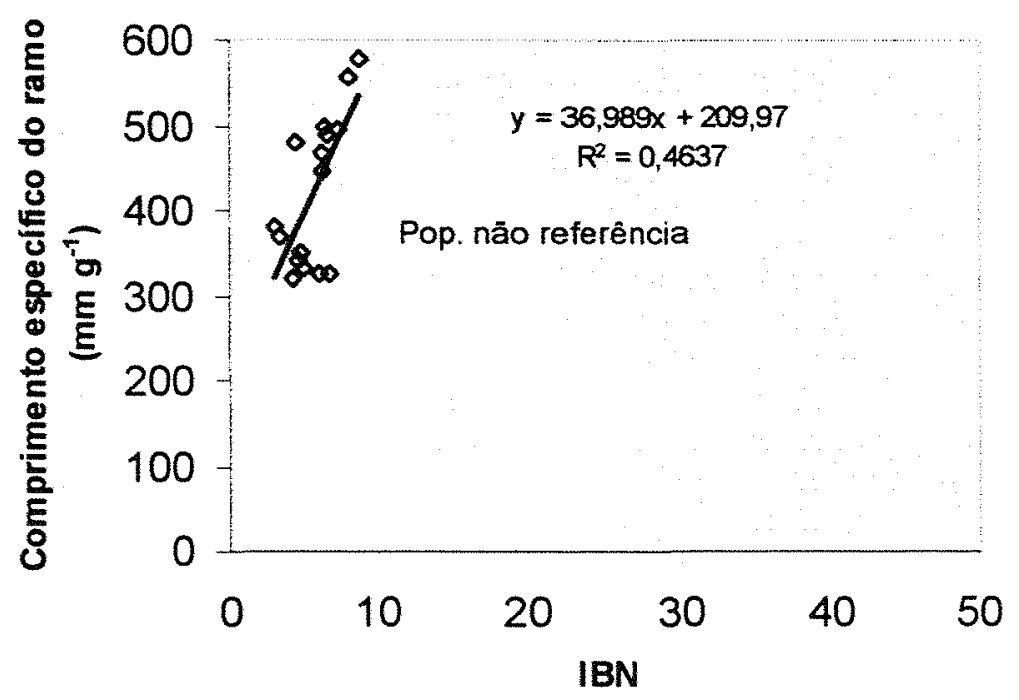

Figura 9. Pré-validação das normas DRIS do cv. Mundo Novo, de Dezembro, aplicadas a teores foliares de talhões não referência do cv. Catuaí Amarelo, também de Dezembro. 
Para o cultivar Catuai Amarelo, observou-se dois períodos nutricionais distintos durante $o$ ano vegetativo. O primeiro vai desde a poda até aproximadamente Dezembro, e o segundo começa a partir de Fevereiro, até o inverno. As normas DRIS definidas para Dezembro, aplicadas a teores foliares de Fevereiro, resultaram em valores IBN que não tiveram correspondência com o comprimento específico do ramo $\left(R^{2}=0,10\right)$. Já para 0 segundo período nutricional, normas DRIS de Abril aplicaram-se bem a teores foliares de Fevereiro $\left(\mathrm{R}^{2}=0,67\right.$, Figura 11$)$, e vice-versa $\left(\mathrm{R}^{2}=0,88\right.$, Figura 10). Para verificar a similaridade do diagnóstico, estes resultados devem ser comparados aos da Figura 5 e Figura 6, correspondente à pré-validação original dos meses de Fevereiro e Abril, respectivamente.

A distinção dos dois periodos nutricionais também pode ser constatada se forem observados os teores foliares do mês de Dezembro (Tabela 15), onde os teores de K, por exemplo, aproximam-se do dobro em relação aos meses de Fevereiro (Tabela 16) e Abril (Tabela 17).

Sugere-se, portanto, que o diagnóstico nas fases iniciais do pós poda, até aproximadamente o mês de Dezembro, deva ser feito com normas para o mês de Dezembro. E a diagnose em períodos posteriores, até Abril, aproximadamente, pode ser feita com as normas apenas de Fevereiro.

Para o cultivar Mundo Novo, seguindo o comportamento observado no cultivar Catuaí Amarelo, as normas DRIS de Dezembro deverão ser aplicadas a amostragens feitas próximo a esta época. Normas DRIS para épocas posteriores terão ainda de ser definidas.

As normas DRIS aqui definidas, possivelmente poderão ser utilizadas em outras situações, como em cafeeiros jovens, antes da sua primeira grande safra, sem que tenham sido submetidos a podas. A esta situação, considera-se que as normas de Fevereiro e Abril possam ser validadas. Outra situação à qual as normas possivelmente poderiam ser aplicadas, são a cafeeiros submetidos a podas drásticas do tronco, onde é eliminada a copa quase por completo, poda chamada de recepa. A esta situação, por envolver a 


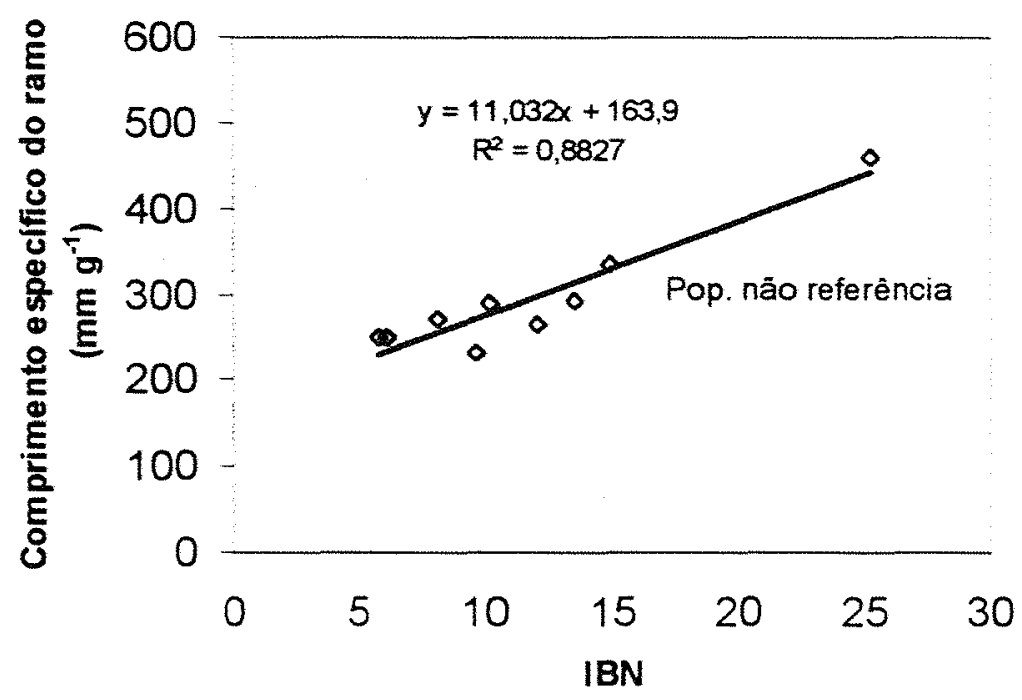

Figura 10. Pré-validação das normas DRIS de Fevereiro, aplicadas a teores foliares de Abril, para o cultivar Catuaí Amarelo.

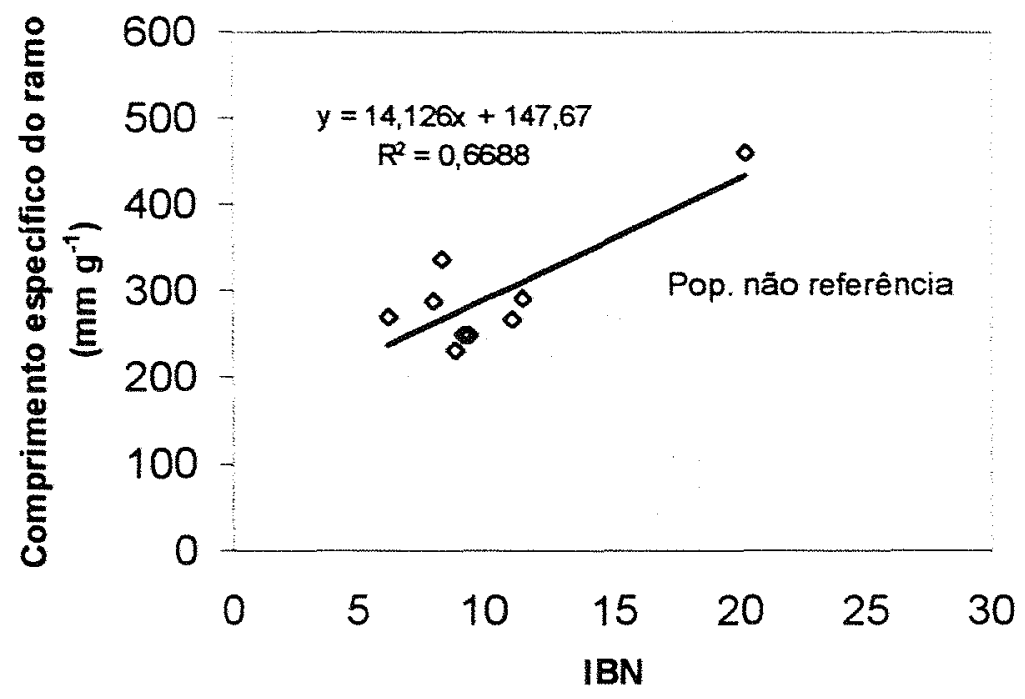

Figura 11. Pré-validação das normas DRIS de Abril, aplicadas a teores foliares de Fevereiro, para o cultivar Catuaí Amarelo. 
reciclagem dos nutrientes, possivelmente todas as normas poderão ser utilizadas, de acordo com a época do ano e o tempo decorrido após a poda. Estas normas DRIS, contudo, devem ser cuidadosamente submetidas à validação, antes de seu uso em situações diferentes àquelas do presente trabalho.

As normas apresentadas na Tabela 11, Tabela 12, Tabela 13 e Tabela 14, são consideradas prontamente utilizáveis, mas para isso deverão ser obedecidos os seguintes critérios de amostragem e cálculo dos índices DRIS. Os teores foliares dos nutrientes submetidos a estas normas deverão ser de amostras coletadas no ano vegetativo, de ramos de cafeeiros submetidos à poda tipo esqueletamento. Devem ser seguidos os respectivos cultivares e épocas aproximadas para as quais as normas foram estabelecidas. Devem ser coletados o $2^{\circ}$ e o $3^{\circ}$ pares de folhas totalmente expandidas, contadas a partir do ápice do ramo, à meia altura da copa, de aproximadamente 25 plantas por talhão. Os teores de $\mathrm{N}, \mathrm{P}, \mathrm{K}, \mathrm{Ca}, \mathrm{Mg}$ e S devem estar em $\mathrm{g} \mathrm{kg}^{-1}$, e os teores de $\mathrm{B}, \mathrm{Cu}, \mathrm{Fe}, \mathrm{Mn}$ e $\mathrm{Zn}$, $\mathrm{em} \mathrm{mg} \mathrm{kg}^{-1}$. As funções das razões dos nutrientes deverão ser calculadas pelo método de Jones (1981). O somatório das funções poderá ser calculado tanto pelo método DRIS como pelo M-DRIS.

Nas mesmas tabelas onde constam as normas DRIS (Tabela 11, Tabela 12, Tabela 13 e Tabela 14), são apresentados os valores do coeficiente de correlação ( $r$ ) entre a razão de cada par de nutrientes $(\mathrm{A} / \mathrm{B}$ ou $\mathrm{B} / \mathrm{A})$ e o comprimento específico do ramo $(\mathrm{C} / \mathrm{M}$, $\mathrm{mm}^{-1} \mathrm{~g}$ ). Estes valores $\mathrm{r}$ foram determinados tendo por base a população de talhões de referência e não referência, e são úteis para verificar a magnitude de influência de cada par de nutrientes sobre a variável produtiva, princípio do método do Valor $\mathrm{r}$ proposto neste estudo.

A título de observação para estudos futuros, os pares de nutrientes que apresentaram valores $\mathrm{r}$ absolutos maiores que 0,50 , foram: $1 / \mathrm{Ca}, 1 / \mathrm{B}, \mathrm{B}, \mathrm{P} / \mathrm{Ca}, \mathrm{Mg}$, $\mathrm{K} / \mathrm{Ca}, \mathrm{K} / \mathrm{B}, \mathrm{B} / \mathrm{K}, \mathrm{Mg} / \mathrm{Ca}, \mathrm{Mg} / \mathrm{B}, \mathrm{Zn} / \mathrm{Mn}, \mathrm{Mg} / \mathrm{N}, \mathrm{Ca} / \mathrm{Mn}, \mathrm{Mg} / \mathrm{Fe}, \mathrm{Mg} / \mathrm{Zn}, \mathrm{B} / \mathrm{N}, \mathrm{Mg} / \mathrm{K}$, $\mathrm{Mg} / \mathrm{Mn}, \mathrm{B} / \mathrm{Mn}$. Nota-se, na maioria destes pares de nutrientes, o envolvimento de cátions metálicos. 
Tabela 11. Normas DRIS para café cv. Catuaí Amarelo podado, mês de Dezembro. (População referência n=13; População não referência $n=18$ )

\begin{tabular}{|c|c|c|c|c|c|c|c|}
\hline Razão & $r^{-\infty}$ & Média & $\begin{array}{l}\text { Desvio } \\
\text { Padrāo }\end{array}$ & Razão & $r^{* *}$ & Média & $\begin{array}{l}\text { Desvio } \\
\text { Padrão }\end{array}$ \\
\hline $\mathrm{N}$ & $-0,45$ & 32,2108 & 1,4026 & $\mathrm{~K} / \mathrm{B}$ & 0,53 & 1,0893 & 0,3339 \\
\hline $1 / \mathrm{P}$ & 0,06 & 0,4000 & 0,0335 & $\mathrm{~K} / \mathrm{Cu}$ & $-0,19$ & 3,6541 & 1,9765 \\
\hline $\mathrm{K}$ & 0,33 & 48,8462 & 9,6188 & $\mathrm{~K} / \mathrm{Fe}$ & 0,40 & 0,4992 & 0,1575 \\
\hline $1 / \mathrm{Ca}$ & 0,59 & 0,0835 & 0,0110 & $\mathrm{~K} / \mathrm{Mn}$ & 0,46 & 0,4194 & 0,1912 \\
\hline $\mathrm{Mg}$ & 0,21 & 4,8462 & 0,4012 & $\mathrm{Zn} / \mathrm{K}$ & 0,17 & 0,2012 & 0,1021 \\
\hline $\mathrm{S}$ & $-0,28$ & 1,6231 & 0,2606 & $\mathrm{Mg} / \mathrm{Ca}$ & 0,63 & 0,4046 & 0,0644 \\
\hline $1 / \mathrm{B}$ & 0,51 & 0,0223 & 0,0047 & $\mathrm{~S} / \mathrm{Ca}$ & 0,18 & 0,1345 & 0,0229 \\
\hline $1 / \mathrm{Cu}$ & $-0,37$ & 0,0747 & 0,0367 & $\mathrm{Ca} / \mathrm{B}$ & 0,11 & 0,2713 & 0,0664 \\
\hline $1 / \mathrm{Fe}$ & 0,27 & 0,0102 & 0,0024 & $\mathrm{Ca} / \mathrm{Cu}$ & $-0,46$ & 0,8988 & 0,4286 \\
\hline $1 / \mathrm{Mn}$ & 0,39 & 0,0085 & 0,0031 & $\mathrm{Fe} / \mathrm{Ca}$ & 0,26 & 8,5124 & 1,8177 \\
\hline Z & 0,32 & 9,4615 & 4,8772 & $\mathrm{Mn} / \mathrm{Ca}$ & $-0,23$ & 11,2871 & 4,9695 \\
\hline $\mathrm{P} / \mathrm{N}$ & 0,36 & 0,0782 & 0,0064 & $\mathrm{Zn} / \mathrm{Ca}$ & 0,45 & 0,7833 & 0,3917 \\
\hline $\mathrm{K} N \mathrm{~N}$ & 0,47 & 1,5158 & 0,2952 & $\mathrm{~S} / \mathrm{Mg}$ & $-0,33$ & 0,3373 & 0,0618 \\
\hline $\mathrm{N} / \mathrm{Ca}$ & 0,36 & 2,6813 & 0,3155 & $\mathrm{Mg} / \mathrm{B}$ & 0,58 & 0,1072 & 0,0219 \\
\hline $\mathrm{N} / \mathrm{Mg}$ & $-0,49$ & 6,6840 & 0,5184 & $\mathrm{Mg} / \mathrm{Cu}$ & $-0,33$ & 0,3541 & 0,1645 \\
\hline $\mathrm{S} / \mathrm{N}$ & $-0,05$ & 0,0504 & 0,0078 & $\mathrm{Mg} / \mathrm{Fe}$ & 0,31 & 0,0495 & 0,0122 \\
\hline N/B & 0,35 & 0,7149 & 0,1412 & $\mathrm{Mg} / \mathrm{Mn}$ & 0,43 & 0,0408 & 0,0137 \\
\hline $\mathrm{N} / \mathrm{Cu}$ & $-0,41$ & 2,4133 & 1,2059 & $\mathrm{Zn} / \mathrm{Mg}$ & 0,33 & 1,9124 & 0,8403 \\
\hline $\mathrm{Fe} / \mathrm{N}$ & 0,07 & 3,1876 & 0,6642 & $\mathrm{~S} / \mathrm{B}$ & 0,26 & 0,0359 & 0,0087 \\
\hline $\mathrm{N} / \mathrm{Mn}$ & 0,31 & 0,2738 & 0,0962 & $\mathrm{~S} / \mathrm{Cu}$ & $-0,40$ & 0,1194 & 0,0612 \\
\hline $\mathrm{Zn} / \mathrm{N}$ & 0,41 & 0,2933 & 0,1491 & $\mathrm{Fe} / \mathrm{S}$ & 0,07 & 64,8015 & 16,5403 \\
\hline $\mathrm{K} / \mathrm{P}$ & 0,36 & 19,4068 & 3,5578 & $\mathrm{~S} / \mathrm{Mn}$ & 0,35 & 0,0136 & 0,0045 \\
\hline $\mathrm{P} / \mathrm{Ca}$ & 0,54 & 0,2090 & 0,0246 & $\mathrm{Zn} / \mathrm{S}$ & 0,42 & 5,8819 & 2,8934 \\
\hline $\mathrm{Mg} / \mathrm{P}$ & 0,17 & 1,9397 & 0,2418 & $\mathrm{~B} / \mathrm{Cu}$ & $-0,47$ & 3,4309 & 1,8218 \\
\hline $\mathrm{S} / \mathrm{P}$ & $-0,27$ & 0,6475 & 0,1061 & $\mathrm{Fe} / \mathrm{B}$ & 0,32 & 2,2417 & 0,4988 \\
\hline $\mathrm{P} / \mathrm{B}$ & 0,47 & 0,0560 & 0,0120 & $\mathrm{~B} / \mathrm{Mn}$ & 0,20 & 0,4046 & 0,1683 \\
\hline $\mathrm{P} / \mathrm{Cu}$ & $-0,36$ & 0,1854 & 0,0899 & $\mathrm{Zn} / \mathrm{B}$ & 0,49 & 0,1975 & 0,0687 \\
\hline $\mathrm{P} / \mathrm{Fe}$ & 0,26 & 0,0255 & 0,0053 & $\mathrm{Fe} / \mathrm{Cu}$ & $-0,40$ & 7,2937 & 3,5697 \\
\hline $\mathrm{P} / \mathrm{Mn}$ & 0,38 & 0,0216 & 0,0082 & $\mathrm{Cu} / \mathrm{Mn}$ & 0,46 & 0,1576 & 0,1081 \\
\hline $\mathrm{Zn} / \mathrm{P}$ & 0,32 & 3,7375 & 1,7740 & $\mathrm{Zn} / \mathrm{Cu}$ & 0,09 & 0,6084 & 0,2526 \\
\hline $\mathrm{K} / \mathrm{Ca}$ & 0,58 & 4,0528 & 0,9011 & $\mathrm{Fe} / \mathrm{Mn}$ & 0,30 & 0,8926 & 0,4129 \\
\hline $\mathrm{K} / \mathrm{Mg}$ & 0,23 & 10,1073 & 2,0496 & $\mathrm{Zn} / \mathrm{Fe}$ & 0,43 & 0,0923 & 0,0378 \\
\hline $\mathrm{S} / \mathrm{K}$ & $-0,44$ & 0,0355 & 0,0122 & $\mathrm{Zn} / \mathrm{Mn}$ & 0,53 & 0,0822 & 0,0574 \\
\hline
\end{tabular}

${ }^{*}$ Unidades dos nutrientes: $\mathrm{N}, \mathrm{P}, \mathrm{K}, \mathrm{Ca}, \mathrm{Mg}$ e S $\left(\mathrm{g} \mathrm{kg}^{-1}\right)$; B, Cu, Fe, Mn e Zn (mg kg $\left.{ }^{-1}\right)$.

$\left.{ }^{*}\right)_{\mathrm{r}}=$ coeficiente de correlação entre a razão do par de nutrientes e o comprimento específico do ramo. 
Tabela 12. Normas DRIS para café cv. Catuaí Amarelo podado, mês de Fevereiro. (População referência $n=12$; População não referência $n=20$ )

\begin{tabular}{|c|c|c|c|c|c|c|c|}
\hline Razão* & $r^{* *}$ & Média & $\begin{array}{l}\text { Desvio } \\
\text { Padrão }\end{array}$ & Razão* & $\mathbf{r}^{* *}$ & Média & $\begin{array}{l}\text { Desvio } \\
\text { Padrão }\end{array}$ \\
\hline $\mathrm{N}$ & 0,09 & 31,8967 & 2,0882 & $\mathrm{~K} / \mathrm{B}$ & 0,25 & 0,5845 & 0,1169 \\
\hline $\mathrm{P}$ & 0,16 & 1,9833 & 0,2034 & $\mathrm{Cu} / \mathrm{K}$ & $-0,13$ & 0,7406 & 0,1722 \\
\hline $\mathrm{K}$ & 0,13 & 24,9417 & 2,3845 & $\mathrm{Fe} / \mathrm{K}$ & $-0,26$ & 2,4964 & 0,3774 \\
\hline $\mathrm{Ca}$ & 0,29 & 7,2583 & 1,2114 & $\mathrm{~K} / \mathrm{Mn}$ & 0,39 & 0,1645 & 0,0777 \\
\hline $\mathrm{Mg}$ & 0,60 & 2,8167 & 0,2734 & $\mathrm{~K} / \mathrm{Zn}$ & 0,38 & 2,4717 & 0,5929 \\
\hline $1 / \mathrm{S}$ & $-0,24$ & 0,7995 & 0,2746 & $\mathrm{Mg} / \mathrm{Ca}$ & 0,23 & 0,3972 & 0,0690 \\
\hline $\mathrm{B}$ & $-0,22$ & 44,2783 & 9,3700 & $\mathrm{Ca} / \mathrm{S}$ & $-0,18$ & 5,8990 & 2,3658 \\
\hline $\mathrm{Cu}$ & $-0,10$ & 18,2500 & 3,4671 & $\mathrm{~B} / \mathrm{Ca}$ & $-0,41$ & 6,1787 & 1,1976 \\
\hline $1 / \mathrm{Fe}$ & 0,26 & 0,0165 & 0,0024 & $\mathrm{Ca} / \mathrm{Cu}$ & 0,19 & 0,4136 & 0,1020 \\
\hline $1 / \mathrm{Mn}$ & 0,46 & 0,0067 & 0,0031 & $\mathrm{Ca} / \mathrm{Fe}$ & 0,42 & 0,1186 & 0,0209 \\
\hline $1 / \mathrm{Zn}$ & 0,37 & 0,1003 & 0,0251 & $\mathrm{Ca} / \mathrm{Mn}$ & 0,54 & 0,0478 & 0,0253 \\
\hline $\mathrm{P} / \mathrm{N}$ & 0,14 & 0,0621 & 0,0043 & $\mathrm{Ca} / \mathrm{Zn}$ & 0,50 & 0,7084 & 0,1741 \\
\hline $\mathrm{K} / \mathrm{N}$ & 0,06 & 0,7828 & 0,0634 & $\mathrm{Mg} / \mathrm{S}$ & $-0,09$ & 2,2654 & 0,8557 \\
\hline $\mathrm{Ca} / \mathrm{N}$ & 0,29 & 0,2277 & 0,0355 & $\mathrm{Mg} / \mathrm{B}$ & 0,66 & 0,0654 & 0,0095 \\
\hline $\mathrm{Mg} / \mathrm{N}$ & 0,56 & 0,0883 & 0,0060 & $\mathrm{Mg} / \mathrm{Cu}$ & 0,33 & 0,1597 & 0,0309 \\
\hline $\mathrm{N} / \mathrm{S}$ & $-0,23$ & 25,5035 & 9,1014 & $\mathrm{Mg} / \mathrm{Fe}$ & 0,62 & 0,0462 & 0,0060 \\
\hline N/B & 0,23 & 0,7445 & 0,1236 & $\mathrm{Mg} / \mathrm{Mn}$ & 0,65 & 0,0185 & 0,0084 \\
\hline $\mathrm{Cu} / \mathrm{N}$ & $-0,13$ & 0,5751 & 0,1207 & $\mathrm{Mg} / \mathrm{Zn}$ & 0,61 & 0,2788 & 0,0679 \\
\hline $\mathrm{Fe} / \mathrm{N}$ & $-0,29$ & 1,9417 & 0,2513 & $\mathrm{~B} / \mathrm{S}$ & $-0,31$ & 35,4518 & 15,8234 \\
\hline $\mathrm{N} / \mathrm{Mn}$ & 0,47 & 0,2099 & 0,0959 & $\mathrm{Cu} / \mathrm{S}$ & $-0,28$ & 14,4640 & 5,6587 \\
\hline $\mathrm{N} / \mathrm{Zn}$ & 0,39 & 3,1725 & 0,7660 & $\mathrm{Fe} / \mathrm{S}$ & $-0,33$ & 48,6823 & 16,8617 \\
\hline $\mathrm{P} / \mathrm{K}$ & 0,09 & 0,0799 & 0,0093 & $\mathrm{~S} / \mathrm{Mn}$ & 0,42 & 0,0098 & 0,0068 \\
\hline $\mathrm{Ca} / \mathrm{P}$ & 0,22 & 3,6720 & 0,5520 & $\mathrm{~S} / \mathrm{Zn}$ & 0,31 & 0,1512 & 0,0837 \\
\hline $\mathrm{Mg} / \mathrm{P}$ & 0,45 & 1,4283 & 0,1356 & $\mathrm{~B} / \mathrm{Cu}$ & $-0,09$ & 2,4925 & 0,5685 \\
\hline $\mathrm{P} / \mathrm{S}$ & $-0,19$ & 1,5765 & 0,5536 & $\mathrm{~B} / \mathrm{Fe}$ & 0,17 & 0,7156 & 0,1027 \\
\hline $\mathrm{P} / \mathrm{B}$ & 0,27 & 0,0460 & 0,0071 & $\mathrm{~B} / \mathrm{Mn}$ & 0,43 & 0,2811 & 0,1293 \\
\hline $\mathrm{Cu} / \mathrm{P}$ & $-0,15$ & 9,2951 & 2,0566 & $\mathrm{~B} / \mathrm{Zn}$ & 0,27 & 4,2883 & 1,0402 \\
\hline $\mathrm{P} / \mathrm{Fe}$ & 0,32 & 0,0324 & 0,0041 & $\mathrm{Fe} / \mathrm{Cu}$ & $-0,21$ & 3,4729 & 0,5916 \\
\hline $\mathrm{P} / \mathrm{Mn}$ & 0,45 & 0,0130 & 0,0061 & $\mathrm{Cu} / \mathrm{Mn}$ & 0,32 & 0,1247 & 0,0764 \\
\hline $\mathrm{P} / \mathrm{Zn}$ & 0,42 & 0,1967 & 0,0482 & $\mathrm{Cu} / \mathrm{Zn}$ & 0,31 & 1,7968 & 0,5074 \\
\hline $\mathrm{Ca} / \mathrm{K}$ & 0,29 & 0,2917 & 0,0461 & $\mathrm{Fe} / \mathrm{Mn}$ & 0,26 & 0,4131 & 0,2131 \\
\hline $\mathrm{Mg} / \mathrm{K}$ & 0,48 & 0,1138 & 0,0145 & $\mathrm{Zn} / \mathrm{Fe}$ & $-0,20$ & 0,1835 & 0,0874 \\
\hline $\mathrm{K} / \mathrm{S}$ & $-0,19$ & 20,1602 & 7,5502 & $\mathrm{Zn} / \mathrm{Mn}$ & $-0,13$ & 0,0690 & 0,0357 \\
\hline
\end{tabular}

") Unidades dos nutrientes: N. P, K, Ca, Mg e S ( $\left.\mathrm{g} \mathrm{kg}^{-1}\right)$; B, Cu, Fe, Mn e $\mathrm{Zn}\left(\mathrm{mg} \mathrm{kg}^{-1}\right)$.

${ }^{* *} \mathrm{r}=$ coeficiente de correlação entre a razão do par de nutrientes e o comprimento especifíco do ramo. 
Tabela 13. Normas DRIS para café cv. Catuaí Amarelo podado, mês de Abril. (População referência $n=12$; População não referência $n=20$ )

\begin{tabular}{|c|c|c|c|c|c|c|c|}
\hline Razão* & $r^{* *}$ & Média & $\begin{array}{l}\text { Desvio } \\
\text { Padrão }\end{array}$ & Razão* & $\mathbf{R}^{* *}$ & Média & $\begin{array}{l}\text { Desvio } \\
\text { Padrão }\end{array}$ \\
\hline $1 / \mathrm{N}$ & $-0,15$ & 0,0321 & 0,0016 & $\mathrm{~B} / \mathrm{K}$ & 0,55 & 1,8253 & 0,3426 \\
\hline $1 / \mathrm{P}$ & $-0,25$ & 0,5556 & 0,0375 & $\mathrm{Cu} / \mathrm{K}$ & $-0,14$ & 0,8559 & 0,1245 \\
\hline $1 / \mathrm{K}$ & 0,25 & 0,0459 & 0,0029 & $\mathrm{~K} / \mathrm{Fe}$ & $-0,25$ & 0,2966 & 0,0467 \\
\hline $\mathrm{Ca}$ & 0,31 & 9,0583 & 1,6681 & $\mathrm{~K} / \mathrm{Mn}$ & 0,33 & 0,1248 & 0,0832 \\
\hline $\mathrm{Mg}$ & 0,58 & 3,0667 & 0,4069 & $\mathrm{Zn} / \mathrm{K}$ & $-0,07$ & 0,4990 & 0,1686 \\
\hline $\mathrm{S}$ & $-0,08$ & 1,3000 & 0,5802 & $\mathrm{Mg} / \mathrm{Ca}$ & 0,22 & 0,3467 & 0,0628 \\
\hline $\mathrm{B}$ & 0,51 & 39,5958 & 5,9764 & $\mathrm{~S} / \mathrm{Ca}$ & $-0,19$ & 0,1508 & 0,0780 \\
\hline $\mathrm{Cu}$ & $-0,29$ & 18,6667 & 2,5604 & $\mathrm{~B} / \mathrm{Ca}$ & 0,18 & 4,5492 & 1,1519 \\
\hline $\mathrm{Fe}$ & 0,16 & 75,3333 & 10,9798 & $\mathrm{Cu} / \mathrm{Ca}$ & $-0,42$ & 2,1154 & 0,4206 \\
\hline $1 / \mathrm{Mn}$ & 0,45 & 0,0056 & 0,0034 & $\mathrm{Ca} / \mathrm{Fe}$ & 0,20 & 0,1230 & 0,0303 \\
\hline $1 / \mathrm{Zn}$ & 0,13 & 0,1012 & 0,0301 & $\mathrm{Ca} / \mathrm{Mn}$ & 0,51 & 0,0525 & 0,0383 \\
\hline N/P & $-0,21$ & 17,3332 & 1,3604 & $\mathrm{Ca} / \mathrm{Zn}$ & 0,31 & 0,8883 & 0,2181 \\
\hline $\mathrm{N} / \mathrm{K}$ & 0,29 & 1,4328 & 0,1225 & $\mathrm{~S} / \mathrm{Mg}$ & $-0,27$ & 0,4310 & 0,2051 \\
\hline $\mathrm{Ca} / \mathrm{N}$ & 0,31 & 0,2902 & 0,0509 & $\mathrm{Mg} / \mathrm{B}$ & 0,04 & 0,0790 & 0,0148 \\
\hline $\mathrm{Mg} / \mathrm{N}$ & 0,53 & 0,0984 & 0,0134 & $\mathrm{Mg} / \mathrm{Cu}$ & 0,46 & 0,1675 & 0,0323 \\
\hline $\mathrm{S} / \mathrm{N}$ & $-0,11$ & 0,0424 & 0,0213 & $\mathrm{Mg} / \mathrm{Fe}$ & 0,38 & 0,0413 & 0,0065 \\
\hline $\mathrm{B} / \mathrm{N}$ & 0,50 & 1,2675 & 0,1642 & $\mathrm{Mg} / \mathrm{Mn}$ & 0,65 & 0,0172 & 0,0113 \\
\hline $\mathrm{Cu} / \mathrm{N}$ & $-0,35$ & 0,5988 & 0,0799 & $\mathrm{Mg} / \mathrm{Zn}$ & 0,44 & 0,3126 & 0,1123 \\
\hline $\mathrm{Fe} / \mathrm{N}$ & 0,13 & 2,4142 & 0,3353 & S/B & $-0,24$ & 0,0336 & 0,0165 \\
\hline $\mathrm{N} / \mathrm{Mn}$ & 0,45 & 0,1735 & 0,1094 & $\mathrm{Cu} / \mathrm{S}$ & $-0,15$ & 17,1079 & 7,4038 \\
\hline $\mathrm{N} / \mathrm{Zn}$ & 0,15 & 3,1531 & 0,9241 & $\mathrm{~S} / \mathrm{Fe}$ & $-0,13$ & 0,0174 & 0,0078 \\
\hline $\mathrm{P} / \mathrm{K}$ & 0,38 & 0,0829 & 0,0071 & $\mathrm{~S} / \mathrm{Mn}$ & 0,33 & 0,0068 & 0,0044 \\
\hline $\mathrm{P} / \mathrm{Ca}$ & $-0,09$ & 0,2052 & 0,0336 & $\mathrm{Zn} / \mathrm{S}$ & $-0,10$ & 9,9019 & 5,1611 \\
\hline $\mathrm{Mg} / \mathrm{P}$ & 0,35 & 1,6993 & 0,2223 & $\mathrm{~B} / \mathrm{Cu}$ & 0,48 & 2,1689 & 0,4802 \\
\hline $\mathrm{S} / \mathrm{P}$ & $-0,19$ & 0,7125 & 0,2955 & $\mathrm{~B} / \mathrm{Fe}$ & 0,38 & 0,5308 & 0,0750 \\
\hline $\mathrm{P} / \mathrm{B}$ & $-0,23$ & 0,0466 & 0,0074 & $\mathrm{~B} / \mathrm{Mn}$ & 0,60 & 0,2175 & 0,1334 \\
\hline $\mathrm{Cu} / \mathrm{P}$ & $-0,40$ & 10,3779 & 1,6898 & $\mathrm{~B} / \mathrm{Zn}$ & 0,35 & 4,0358 & 1,3867 \\
\hline $\mathrm{Fe} / \mathrm{P}$ & $-0,06$ & 41,5613 & 4,3413 & $\mathrm{Cu} / \mathrm{Fe}$ & $-0,31$ & 0,2532 & 0,0510 \\
\hline $\mathrm{P} / \mathrm{Mn}$ & 0,47 & 0,0101 & 0,0062 & $\mathrm{Cu} / \mathrm{Mn}$ & 0,28 & 0,1011 & 0,0613 \\
\hline $\mathrm{Zn} / \mathrm{P}$ & $-0,18$ & 6,0385 & 2,0055 & $\mathrm{Cu} / \mathrm{Zn}$ & $-0,05$ & 1,8673 & 0,5252 \\
\hline $\mathrm{Ca} / \mathrm{K}$ & 0,43 & 0,4144 & 0,0720 & $\mathrm{Fe} / \mathrm{Mn}$ & 0,42 & 0,4175 & 0,2650 \\
\hline $\mathrm{Mg} / \mathrm{K}$ & 0,59 & 0,1412 & 0,0240 & $\mathrm{Zn} / \mathrm{Fe}$ & $-0,19$ & 0,1477 & 0,0548 \\
\hline $\mathrm{K} / \mathrm{S}$ & $-0,06$ & 20,1484 & 9,7491 & $\mathrm{Zn} / \mathrm{Mn}$ & 0,23 & 0,0653 & 0,0532 \\
\hline
\end{tabular}


Tabela 14. Normas DRIS para café cv. Mundo Novo podado, mês de Dezembro.

\begin{tabular}{|c|c|c|c|c|c|c|c|}
\hline $\operatorname{Razão}^{*}$ & $r^{* *}$ & Média & $\begin{array}{l}\text { Desvio } \\
\text { Padrão }\end{array}$ & Razão* & $r^{* *}$ & Média & $\begin{array}{l}\text { Desvio } \\
\text { Padrão }\end{array}$ \\
\hline $\mathrm{N}$ & 0,06 & 30,9841 & 2,7954 & $\mathrm{~K} / \mathrm{B}$ & 0,14 & 1,4066 & 0,7169 \\
\hline $\mathrm{P}$ & 0,47 & 2,4692 & 0,2239 & $\mathrm{~K} / \mathrm{Cu}$ & 0,02 & 3,3761 & 3,1627 \\
\hline K & 0,12 & 49,9846 & 10,4437 & $\mathrm{~K} / \mathrm{Fe}$ & 0,04 & 0,5294 & 0,1531 \\
\hline $1 / \mathrm{Ca}$ & 0,44 & 0,0886 & 0,0172 & $\mathrm{Mn} / \mathrm{K}$ & $-0,17$ & 3,1154 & 1,7408 \\
\hline $\mathrm{Mg}$ & 0,15 & 4,9103 & 0,5642 & $\mathrm{Zn} / \mathrm{K}$ & 0,10 & 0,2107 & 0,1582 \\
\hline $\mathrm{S}$ & 0,28 & 1,3615 & 0,2639 & $\mathrm{Mg} / \mathrm{Ca}$ & 0,49 & 0,4335 & 0,0869 \\
\hline B & $-0,13$ & 39,4872 & 9,8452 & $\mathrm{~S} / \mathrm{Ca}$ & 0,48 & 0,1214 & 0,0353 \\
\hline $\mathrm{Cu}$ & $-0,03$ & 28,7692 & 38,4437 & $\mathrm{~B} / \mathrm{Ca}$ & 0,21 & 3,5044 & 1,0610 \\
\hline $\mathrm{Fe}$ & 0,09 & 98,1282 & 21,4817 & $\mathrm{Ca} / \mathrm{Cu}$ & $-0,08$ & 0,7960 & 0,6954 \\
\hline $\mathrm{Mn}$ & $-0,16$ & 143,051 & 73,0721 & $\mathrm{Fe} / \mathrm{Ca}$ & 0,42 & 8,5966 & 2,0162 \\
\hline $1 / \mathrm{Zn}$ & $-0,16$ & 0,1236 & 0,0440 & $\mathrm{Ca} / \mathrm{Mn}$ & $-0,07$ & 0,1183 & 0,0920 \\
\hline $\mathrm{P} / \mathrm{N}$ & 0,52 & 0,0802 & 0,0095 & $\mathrm{Ca} / \mathrm{Zn}$ & $-0,26$ & 1,4504 & 0,6164 \\
\hline $\mathrm{K} / \mathrm{N}$ & 0,08 & 1,6268 & 0,3914 & $\mathrm{~S} / \mathrm{Mg}$ & 0,20 & 0,2791 & 0,0568 \\
\hline $\mathrm{N} / \mathrm{Ca}$ & 0,42 & 2,7402 & 0,5221 & $\mathrm{~B} / \mathrm{Mg}$ & $-0,22$ & 8,0807 & 1,9939 \\
\hline $\mathrm{Mg} / \mathrm{N}$ & 0,12 & 0,1589 & 0,0161 & $\mathrm{Mg} / \mathrm{Cu}$ & 0,04 & 0,3338 & 0,3684 \\
\hline $\mathrm{S} / \mathrm{N}$ & 0,26 & 0,0441 & 0,0087 & $\mathrm{Fe} / \mathrm{Mg}$ & 0,00 & 20,1061 & 4,4592 \\
\hline N/B & 0,16 & 0,8506 & 0,3065 & $\mathrm{Mg} / \mathrm{Mn}$ & 0,20 & 0,0468 & 0,0297 \\
\hline $\mathrm{Cu} / \mathrm{N}$ & $-0,03$ & 0,9256 & 1,2098 & $\mathrm{Zn} / \mathrm{Mg}$ & 0,10 & 1,9548 & 0,9941 \\
\hline $\mathrm{Fe} / \mathrm{N}$ & 0,08 & 3,1832 & 0,7068 & S/B & 0,29 & 0,0373 & 0,0157 \\
\hline $\mathrm{Mn} / \mathrm{N}$ & $-0,16$ & 4,5667 & 2,2156 & $\mathrm{Cu} / \mathrm{S}$ & $-0,08$ & 22,5462 & 30,3749 \\
\hline $\mathrm{N} / \mathrm{Zn}$ & $-0,17$ & 3,8156 & 1,4363 & $\mathrm{~S} / \mathrm{Fe}$ & 0,17 & 0,0145 & 0,0043 \\
\hline $\mathrm{P} / \mathrm{K}$ & 0,30 & 0,0523 & 0,0174 & $\mathrm{~S} / \mathrm{Mn}$ & 0,29 & 0,0129 & 0,0089 \\
\hline $\mathrm{Ca} / \mathrm{P}$ & $-0,50$ & 4,7195 & 0,7755 & $\mathrm{Zn} / \mathrm{S}$ & 0,06 & 7,1520 & 3,8339 \\
\hline $\mathrm{P} / \mathrm{Mg}$ & 0,41 & 0,5079 & 0,0653 & $\mathrm{Cu} / \mathrm{B}$ & 0,02 & 0,7902 & 1,1255 \\
\hline $\mathrm{P} / \mathrm{S}$ & 0,24 & 1,8942 & 0,4986 & $\mathrm{~B} / \mathrm{Fe}$ & $-0,24$ & 0,4132 & 0,1114 \\
\hline $\mathrm{P} / \mathrm{B}$ & 0,41 & 0,0687 & 0,0297 & $\mathrm{Mn} / \mathrm{B}$ & $-0,09$ & 3,7675 & 2,0495 \\
\hline $\mathrm{P} / \mathrm{Cu}$ & 0,12 & 0,1656 & 0,1513 & $\mathrm{Zn} / \mathrm{B}$ & 0,15 & 0,2678 & 0,2213 \\
\hline $\mathrm{P} / \mathrm{Fe}$ & 0,39 & 0,0262 & 0,0058 & $\mathrm{Fe} / \mathrm{Cu}$ & 0,07 & 6,4338 & 6,2987 \\
\hline $\mathrm{P} / \mathrm{Mn}$ & 0,35 & 0,0245 & 0,0182 & $\mathrm{Cu} / \mathrm{Mn}$ & 0,13 & 0,2391 & 0,3345 \\
\hline $\mathrm{P} / \mathrm{Zn}$ & 0,13 & 0,3022 & 0,1062 & $\mathrm{Cu} / \mathrm{Zn}$ & $-0,08$ & 3,7422 & 6,2764 \\
\hline $\mathrm{K} / \mathrm{Ca}$ & 0,45 & 4,3683 & 1,0871 & $\mathrm{Mn} / \mathrm{Fe}$ & $-0,20$ & 1,5044 & 0,8149 \\
\hline $\mathrm{Mg} / \mathrm{K}$ & 0,04 & 0,1040 & 0,0323 & $\mathrm{Zn} / \mathrm{Fe}$ & 0,11 & 0,1007 & 0,0541 \\
\hline $\mathrm{S} / \mathrm{K}$ & 0,10 & 0,0292 & 0,0118 & $\mathrm{Zn} / \mathrm{Mn}$ & 0,26 & 0,0873 & 0,0588 \\
\hline
\end{tabular}

") Unidades dos nutrientes: N, P, K, Ca, Mg e S ( $\left.\mathrm{g} \mathrm{kg}^{-1}\right)$; B, Cu, Fe, Mn e Zn (mg kg ${ }^{-1}$ ).

${ }^{* *} \mathrm{r}$ = coeficiente de correlação entre a razão do par de nutrientes e o comprimento específico do ramo. 
Tabela 15. Teores foliares dos talhões de café cv. Catuaí Amarelo, mês de Dezembro/96, classificados pelos valores C/M de Fevereiro/97.

\begin{tabular}{|c|c|c|c|c|c|c|c|c|c|c|c|c|}
\hline \multirow[t]{2}{*}{ TalHão } & \multirow{2}{*}{$\begin{array}{c}\mathrm{C} / \mathrm{M} \\
\left(\mathrm{mm} \mathrm{g}^{-1}\right)\end{array}$} & $\mathbf{N}$ & $\mathbf{P}$ & $\mathbf{K}$ & $\mathbf{C a}$ & $\mathbf{M g}$ & $\mathbf{S}$ & $\mathbf{B}$ & $\mathrm{Cu}$ & $\mathrm{Fe}$ & $\mathbf{M n}$ & $\mathbf{Z n}$ \\
\hline & & \multicolumn{6}{|c|}{$\left(\mathrm{g} \mathrm{kg}^{-1}\right)$} & \multicolumn{5}{|c|}{$\left(\mathrm{mg} \mathrm{kg}^{-1}\right)$} \\
\hline 33 & 580 & 30 & 3,2 & 47 & 10,1 & 5,7 & 1,7 & 50 & 22 & 153 & 40 & 10 \\
\hline 101 & 556 & 29 & 2,4 & 61 & 8,3 & 4,1 & 1,5 & 30 & 18 & 57 & 102 & 22 \\
\hline 112 & 500 & 34 & 2,3 & 37 & 10,4 & 5,9 & 1,1 & 44 & 28 & 157 & 163 & 7 \\
\hline 15 & 494 & 19 & 2,3 & 55 & 8,8 & 4,6 & 1,0 & 35 & 24 & 63 & 86 & 9 \\
\hline 105 & 488 & 30 & 2,7 & 63 & 9,4 & 4,3 & 1,4 & 30 & 19 & 70 & 82 & 20 \\
\hline 70 & 481 & 32 & 2,2 & 57 & 12,5 & 5,4 & 1,4 & 28 & 17 & 95 & 199 & 6 \\
\hline 2 & 468 & 30 & 3,0 & 66 & 9,2 & 5,1 & 1,7 & 28 & 16 & 86 & 52 & 8 \\
\hline 100 & 446 & 31 & 2,0 & 49 & 8,9 & 5,0 & 1,5 & 30 & 22 & 76 & 112 & 27 \\
\hline 109 & 381 & 32 & 2,7 & 54 & 12,3 & 4,9 & 1,6 & 31 & 23 & 103 & 160 & 7 \\
\hline 111 & 368 & 28 & 2,4 & 46 & 10,1 & 5,3 & 1,4 & 43 & 26 & 104 & 101 & 6 \\
\hline 110 & 349 & 32 & 2,4 & 43 & 13,3 & 7,1 & 1,4 & 50 & 24 & 95 & 116 & 7 \\
\hline 7 & 343 & 30 & 2,9 & 58 & 9,9 & 5,4 & 1,7 & 37 & 18 & 79 & 97 & 8 \\
\hline 85 & 331 & 32 & 2,8 & 55 & 14,8 & 4,8 & 1,2 & 40 & 15 & 115 & 61 & 6 \\
\hline 75 & 327 & 31 & 2,6 & 29 & 12,5 & 4,8 & 1,1 & 48 & 52 & 134 & 216 & 8 \\
\hline 39 & 326 & 34 & 2,6 & 46 & 13,0 & 5,0 & 1,9 & 63 & 16 & 101 & 352 & 6 \\
\hline 50 & 320 & 32 & 2,6 & 61 & 12,5 & 4,8 & 1,5 & 42 & 8 & 89 & 124 & 6 \\
\hline 10 & 314 & 34 & 2,5 & 55 & 14,6 & 5,0 & 1,8 & 36 & 14 & 61 & 178 & 9 \\
\hline 52 & 296 & 33 & 2,6 & 52 & 13,3 & 5,7 & 1,5 & 66 & 22 & 121 & 109 & 21 \\
\hline 53 & 291 & 32 & 2,8 & 47 & 11,7 & 5,1 & 2,0 & 57 & 36 & 142 & 91 & 20 \\
\hline 71 & 283 & 30 & 2,4 & 57 & 9,7 & 5,2 & 1,3 & 32 & 19 & 94 & 234 & 7 \\
\hline 49 & 282 & 32 & 2,5 & 52 & 11,1 & 4,3 & 1,7 & 50 & 8 & 90 & 102 & 6 \\
\hline 91 & 277 & 33 & 2,5 & 60 & 12,5 & 4,9 & 1,3 & 51 & 11 & 93 & 82 & 6 \\
\hline 13 & 276 & 33 & 2,0 & 35 & 99 & 5,1 & 1,7 & 60 & 9 & 77 & 157 & 9 \\
\hline 45 & 275 & 34 & 2,6 & 57 & 11,3 & 4,8 & 1,4 & 42 & 8 & 116 & 135 & 7 \\
\hline 46 & 268 & 33 & 2,7 & 54 & 15,4 & 4,6 & 2,1 & 42 & 11 & 104 & 124 & 6 \\
\hline 73 & 265 & 32 & 2,4 & 37 & 13,6 & 4,9 & 1,7 & 47 & 40 & 127 & 157 & 8 \\
\hline 77 & 263 & 32 & 2,7 & 51 & 11,7 & 4,9 & 1,7 & 51 & 69 & 104 & 198 & 10 \\
\hline 87 & 260 & 31 & 2,5 & 54 & 12,6 & 4,3 & 1,2 & 41 & 11 & 113 & 63 & 8 \\
\hline 47 & 241 & 30 & 2,5 & 26 & 11,1 & 4,2 & 1,7 & 35 & 10 & 89 & 104 & 6 \\
\hline 48 & 213 & 33 & 2,6 & 30 & 12,6 & 4,6 & 1,2 & 45 & 9 & 103 & 78 & 6 \\
\hline 37 & 202 & 36 & 2,8 & 47 & 11,6 & 4,4 & 2,2 & 50 & 18 & 103 & 493 & 11 \\
\hline
\end{tabular}

Valores hachurados: população de referência. $\mathrm{C} / \mathrm{M}$ : comprimento específico do ramo ( $\left.\mathrm{mm} \mathrm{g}^{-1} \mathrm{MS}\right)$ 
Tabela 16. Teores foliares dos talhões de café cv. Catuaí Amarelo, mês de Fevereiro/97, classificados pelos valores C/M de Julho/97.

\begin{tabular}{|c|c|c|c|c|c|c|c|c|c|c|c|c|}
\hline \multirow[t]{2}{*}{ TALHÃO } & \multirow{2}{*}{$\begin{array}{c}\mathrm{C} / \mathrm{M} \\
\left(\mathbf{m m} \mathbf{g}^{-1}\right)\end{array}$} & $\mathbf{N}$ & $\mathbf{P}$ & $\mathbf{K}$ & $\mathbf{C a}$ & $\mathbf{M g}$ & $\mathbf{S}$ & $\mathbf{B}$ & $\mathrm{Cu}$ & $\mathbf{F e}$ & Mn & $\mathbf{Z n}$ \\
\hline & & \multicolumn{6}{|c|}{$\left(\mathrm{g} \mathrm{kg}^{-1}\right)$} & \multicolumn{5}{|c|}{$\left(\mathrm{mg} \mathrm{kg}^{-1}\right)$} \\
\hline 33 & 460 & 27 & 1,7 & 18 & 9,3 & 4,3 & 1,7 & 54 & 12 & 48 & 46 & 6 \\
\hline 7 & 336 & 32 & 1,8 & 27 & 6,7 & 3,5 & 1,3 & 43 & 15 & 63 & 120 & 7 \\
\hline 4 & 292 & 32 & 2,5 & 35 & 8,5 & 2,7 & 1,3 & 39 & 17 & 70 & 50 & 9 \\
\hline 10 & 288 & 33 & 2,0 & 26 & 6,1 & 3,1 & 1,1 & 46 & 17 & 57 & 215 & 9 \\
\hline 109 & 271 & 34 & 2,2 & 27 & 9,1 & 2,9 & 2,1 & 48 & 22 & 88 & 297 & 10 \\
\hline 2 & 266 & 31 & 2,3 & 28 & 7,7 & 3,3 & 1,4 & 40 & 12 & 62 & 72 & 8 \\
\hline 105 & 250 & 34 & 2,5 & 27 & 7,6 & 2,5 & 0,8 & 40 & 15 & 71 & 112 & 14 \\
\hline 101 & 249 & 32 & 2,1 & 27 & 6,4 & 2,4 & 1,7 & 39 & 13 & 61 & 157 & 12 \\
\hline 110 & 230 & 37 & 2,3 & 22 & 6,3 & 3,2 & 2,5 & 41 & 17 & 70 & 119 & 10 \\
\hline 100 & 229 & 31 & 2,0 & 27 & 7,9 & 2,8 & 1,4 & 39 & 18 & 73 & 113 & 11 \\
\hline 77 & 211 & 32 & 1,8 & 26 & 6,4 & 2,6 & 0,9 & 34 & 14 & 48 & 142 & 10 \\
\hline 75 & 203 & 32 & 2,1 & 27 & 7,3 & 2,8 & 0,9 & 43 & 15 & 63 & 162 & 9 \\
\hline 111 & 199 & 34 & 2,1 & 21 & 5,1 & 3,0 & 3,2 & 43 & 23 & 68 & 124 & 9 \\
\hline 15 & 194 & 35 & 2,1 & 29 & 7,0 & 2,9 & 1,5 & 40 & 17 & 59 & 139 & 9 \\
\hline 91 & 190 & 32 & 2,1 & 23 & 8,3 & 3,2 & 1,0 & 58 & 19 & 68 & 119 & 11 \\
\hline 70 & 182 & 28 & 1,6 & 23 & 5,3 & 2,5 & 0,9 & 34 & 22 & 50 & 176 & 8 \\
\hline 85 & 182 & 30 & 19 & 25 & 8,0 & 2,5 & 1,4 & 37 & 24 & 63 & 74 & 12 \\
\hline 49 & 182 & 29 & 1,6 & 22 & 7,1 & 2,7 & 1,8 & 44 & 14 & 61 & 125 & 8 \\
\hline 71 & 176 & 32 & 2,1 & 23 & 8,3 & 2,9 & 1,3 & 38 & 14 & 50 & 294 & 8 \\
\hline 39 & 174 & 36 & 2,2 & 28 & 9,5 & 3,4 & 0,9 & 65 & 21 & 71 & 571 & 33 \\
\hline 37 & 164 & 32 & 2,2 & 25 & 6,9 & 2,5 & 2,4 & 55 & 18 & 68 & 555 & 10 \\
\hline 13 & 159 & 31 & 1,8 & 26 & 8,2 & 3,7 & 1,8 & 60 & 10 & 81 & 224 & 9 \\
\hline 45 & 155 & 30 & 1,9 & 24 & 6,6 & 2,6 & 0,9 & 55 & 29 & 75 & 152 & 170 \\
\hline 48 & 155 & 28 & 1,6 & 20 & 6,1 & 2,2 & 1,8 & 41 & 10 & 55 & 101 & 8 \\
\hline 46 & 152 & 28 & 1,8 & 22 & 6,4 & 2,4 & 0,6 & 53 & 14 & 72 & 133 & 8 \\
\hline 50 & 152 & 30 & 1,9 & 23 & 5,2 & 3,0 & 1,0 & 47 & 20 & 65 & 157 & 61 \\
\hline 53 & 149 & 28 & 1,8 & 20 & 6,7 & 2,8 & 1,1 & 54 & 14 & 134 & 118 & 9 \\
\hline 73 & 147 & 33 & 2,0 & 25 & 7,7 & 2,6 & 1,6 & 46 & 15 & 45 & 91 & 28 \\
\hline 112 & 141 & 34 & 2,1 & 24 & 7,9 & 3,0 & 1,2 & 67 & 18 & 125 & 168 & 9 \\
\hline 87 & 140 & 30 & 2,0 & 25 & 7,6 & 2,5 & 1,3 & 50 & 19 & 69 & 81 & 10 \\
\hline 52 & 128 & 26 & 1,8 & 24 & 6,1 & 2,5 & 2,3 & 49 & 8 & 63 & 79 & 8 \\
\hline 47 & 122 & 32 & 1,9 & 23 & 7,6 & 2,5 & 0,4 & 44 & 14 & 69 & 149 & 8 \\
\hline
\end{tabular}

Valores hachurados: população de referência. C/M: comprimento especifico do ramo ( $\left.\mathrm{mm} \mathrm{g}^{-1} \mathrm{MS}\right)$ 
Tabela 17. Teores foliares dos talhões de café cv. Catuaí Amarelo, mês de Abril/97, classificados pelos valores C/M de Julho/97.

\begin{tabular}{|c|c|c|c|c|c|c|c|c|c|c|c|c|}
\hline \multirow[t]{2}{*}{ TALHĀO } & \multirow{2}{*}{$\begin{array}{c}\mathrm{C} / \mathbf{M} \\
\left(\mathbf{m m} \mathbf{g}^{-1}\right)\end{array}$} & $\mathbf{N}$ & $\mathbf{P}$ & $\mathbf{K}$ & $\mathrm{Ca}$ & Mg & $\mathbf{S}$ & B & $\mathrm{Cu}$ & $\mathbf{F e}$ & $\mathbf{M n}$ & Zn \\
\hline & & \multicolumn{6}{|c|}{$\left(\mathrm{g} \mathrm{kg}^{-1}\right)$} & \multicolumn{5}{|c|}{$\left(\mathrm{mg} \mathrm{kg}^{-1}\right)$} \\
\hline 33 & 460 & 29 & 1,7 & 16 & 12,1 & 5,7 & 1,5 & 52 & 15 & 63 & 65 & 8 \\
\hline 7 & 336 & 31 & 1,8 & 20 & 9,2 & 4,0 & 1,7 & 53 & 15 & 103 & 118 & 13 \\
\hline 4 & 292 & 28 & 1,9 & 27 & 8,3 & 3,0 & 1,9 & 50 & 15 & 93 & 72 & 29 \\
\hline 10 & 288 & 33 & 2,0 & 29 & 12,2 & 3,3 & 1,5 & 56 & 13 & 81 & 192 & 10 \\
\hline 109 & 271 & 32 & 1,8 & 22 & 9,6 & 2,7 & 1,9 & 25 & 18 & 63 & 420 & 9 \\
\hline 2 & 266 & 32 & 1,7 & 22 & 6,9 & 3,6 & 1,8 & 46 & 13 & 95 & 78 & 11 \\
\hline 105 & 250 & 31 & 2,1 & 28 & 9,0 & 2,8 & 1,5 & 50 & 20 & 86 & 109 & 10 \\
\hline 101 & 249 & 32 & 2,0 & 27 & 7,8 & 2,5 & 1,0 & 46 & 16 & 94 & 146 & 10 \\
\hline 110 & 230 & 32 & 1,8 & 21 & 9,3 & 3,5 & 2,6 & 41 & 12 & 59 & 160 & 8 \\
\hline 100 & 229 & 33 & 1,9 & 23 & 7,9 & 3,2 & 1,2 & 52 & 19 & 86 & 114 & 10 \\
\hline 77 & 211 & 32 & 1,9 & 24 & 12,4 & 2,8 & 1,3 & 32 & 19 & 65 & 199 & 14 \\
\hline 75 & 203 & 32 & 1,9 & 21 & 8,2 & 2,6 & 1,2 & 48 & 17 & 97 & 245 & 13 \\
\hline 111 & 199 & 30 & 2,1 & 21 & 9,1 & 3,6 & 2,3 & 36 & 19 & 94 & 333 & 8 \\
\hline 15 & 194 & 29 & 1,6 & 22 & 8,0 & 2,7 & 1,1 & 38 & 17 & 60 & 139 & 7 \\
\hline 91 & 190 & 31 & 1,8 & 21 & 12,3 & 3,8 & 1,0 & 35 & 20 & 72 & 101 & 20 \\
\hline 70 & 182 & 30 & 1,8 & 21 & 7,0 & 3,3 & 1,3 & 38 & 18 & 68 & 298 & 7 \\
\hline 85 & 182 & 32 & 1,8 & 25 & 10,3 & 3,0 & 0,5 & 34 & 17 & 77 & 77 & 10 \\
\hline 49 & 182 & 28 & 1,8 & 22 & 7,7 & 2,7 & 2,7 & 38 & 16 & 69 & 148 & 14 \\
\hline 71 & 176 & 33 & 1,7 & 19 & 8,7 & 3,6 & 1,1 & 46 & 15 & 76 & 449 & 7 \\
\hline 39 & 174 & 32 & 1,7 & 21 & 8,9 & 2,9 & 0,9 & 43 & 23 & 68 & 598 & 10 \\
\hline 37 & 164 & 32 & 1,7 & 22 & 8,2 & 2,6 & 1,0 & 34 & 24 & 72 & 558 & 11 \\
\hline 13 & 159 & 31 & 1,8 & 28 & 9,5 & 3,9 & 2,2 & 40 & 9 & 80 & 306 & 45 \\
\hline 45 & 155 & 30 & 1,7 & 27 & 9,0 & 3,7 & 1,9 & 29 & 19 & 62 & 148 & 15 \\
\hline 48 & 155 & 26 & 1,7 & 21 & 7,0 & 2,6 & 2,4 & 35 & 16 & 55 & 108 & 16 \\
\hline 46 & 152 & 29 & 1,8 & 28 & 6,9 & 3,7 & 2,1 & 32 & 17 & 66 & 169 & 13 \\
\hline 50 & 152 & 26 & 1,6 & 21 & 6,1 & 2,5 & 2,2 & 36 & 14 & 57 & 169 & 11 \\
\hline 53 & 149 & 30 & 1,5 & 22 & 10,0 & 2,8 & 1,7 & 49 & 21 & 77 & 126 & 16 \\
\hline 73 & 147 & 33 & 2,0 & 24 & 9,2 & 2,9 & 1,4 & 39 & 24 & 76 & 150 & 16 \\
\hline 112 & 141 & 30 & 1,9 & 19 & 8,7 & 3,3 & 2,2 & 42 & 14 & 88 & 147 & 8 \\
\hline 87 & 140 & 31 & 1,8 & 22 & 10,2 & 3,1 & 2,4 & 31 & 19 & 102 & 127 & 10 \\
\hline 52 & 128 & 32 & 1,9 & 23 & 10,4 & 2,8 & 1,1 & 47 & 21 & 91 & 105 & 8 \\
\hline 47 & 122 & 28 & 0,9 & 21 & 8,0 & 2,5 & 1,7 & 36 & 16 & 61 & 189 & 14 \\
\hline
\end{tabular}

Valores hachurados: população de referência. C/M: comprimento específico do ramo ( $\left.\mathrm{mm} \mathrm{g}^{-1} \mathrm{MS}\right)$ 
Tabela 18. Teores foliares dos talhões de café cv. Mundo Novo, mês de Dezembro/96, classificados pelos valores C/M de Julho/97.

\begin{tabular}{|c|c|c|c|c|c|c|c|c|c|c|c|c|}
\hline \multirow[t]{2}{*}{ TALHÃo } & \multirow{2}{*}{$\begin{array}{c}\mathrm{C} / \mathrm{M} \\
\left(\mathrm{mm} \mathrm{g}^{-1}\right)\end{array}$} & $\mathbf{N}$ & $\mathbf{P}$ & $\mathbf{K}$ & $\mathrm{Ca}$ & $\mathbf{M g}$ & $\mathbf{S}$ & $\mathbf{B}$ & $\mathrm{Cu}$ & $\mathbf{F e}$ & $\mathbf{M n}$ & $\mathbf{Z n}$ \\
\hline & & \multicolumn{6}{|c|}{$\left(\mathrm{g} \mathrm{kg}^{-1}\right)$} & \multicolumn{5}{|c|}{$\left(\mathrm{mg} \mathrm{kg}^{-1}\right)$} \\
\hline 5 & 322,5 & 37 & 6,5 & 60 & 8,9 & 5,4 & 2,4 & 24 & 34 & 83 & 100 & 16 \\
\hline 31 & 298,8 & 40 & 8,0 & 61 & 4,2 & 5,0 & 1,7 & 25 & 26 & 123 & 45 & 15 \\
\hline 3 & 282,7 & 34 & 4,5 & 61 & 7,7 & 5,2 & 1,6 & 34 & 25 & 82 & 66 & 13 \\
\hline 23 & 271,3 & 31 & 2,5 & 38 & 10,3 & 6,1 & 2,0 & 53 & 4 & 120 & 126 & 7 \\
\hline 59 & 270,9 & 30 & 3,3 & 64 & 7,9 & 5,9 & 1,9 & 56 & 29 & 154 & 65 & 13 \\
\hline 27 & 262,3 & 29 & 2,4 & 57 & 9,8 & 5,1 & 1,0 & 42 & 3 & 124 & 196 & 8 \\
\hline 16 & 254,4 & 28 & 2,2 & 52 & 11,3 & 5,0 & 1,4 & 39 & 14 & 94 & 84 & 5 \\
\hline 115 & 251,1 & 31 & 2,3 & 55 & 11,3 & 4,9 & 1,3 & 51 & 27 & 128 & 233 & 8 \\
\hline 93 & 248,2 & 30 & 2,7 & 60 & 13,8 & 4,7 & 1,2 & 21 & 16 & 90 & 46 & 7 \\
\hline 43 & 247,3 & 32 & 2,5 & 60 & 12,7 & 4,7 & 1,3 & 22 & 12 & 80 & 156 & 7 \\
\hline 113 & 239,2 & 26 & 2,4 & 47 & 9,3 & 6,6 & 1,8 & 49 & 26 & 137 & 238 & 6 \\
\hline 29 & 239,0 & 32 & 2,5 & 57 & 11,0 & 4,9 & 1,6 & 56 & 14 & 102 & 80 & 9 \\
\hline 21 & 236,2 & 27 & 2,6 & 57 & 8,8 & 5,9 & 1,3 & 38 & 28 & 79 & 71 & 9 \\
\hline 14 & 235,5 & 28 & 2,5 & 49 & 11,5 & 4,7 & 1,7 & 43 & 17 & 121 & 86 & 6 \\
\hline 6 & 234,9 & 28 & 2,5 & 20 & 9,9 & 6,4 & 2,1 & 61 & 20 & 152 & 128 & 10 \\
\hline 17 & 234,6 & 25 & 2,2 & 60 & 11,1 & 3,9 & 1,0 & 40 & 18 & 65 & 40 & 9 \\
\hline 114 & 234,4 & 32 & 2,3 & 46 & 10,9 & 4,7 & 1,2 & 41 & 17 & 117 & 285 & 9 \\
\hline 102 & 233,8 & 30 & 2,9 & 19 & 6,6 & 5,0 & 1,3 & 24 & 40 & 80 & 84 & 23 \\
\hline 32 & 227,9 & 35 & 5,8 & 55 & 6,9 & 5,4 & 1,7 & 33 & 26 & 105 & 56 & 12 \\
\hline 99 & 226,6 & 28 & 2,0 & 58 & 8,8 & 4,1 & 1,1 & 26 & 19 & 89 & 148 & 15 \\
\hline 28 & 225,7 & 32 & 2,6 & 47 & 13,3 & 5,1 & 1,7 & 54 & 17 & 108 & 102 & 9 \\
\hline 30 & 225,4 & 31 & 2,5 & 47 & 10,6 & 5,5 & 1,6 & 46 & 18 & 120 & 106 & 7 \\
\hline 103 & 223,0 & 29 & 2,7 & 38 & 8,0 & 3,3 & 1,1 & 32 & 23 & 74 & 101 & 21 \\
\hline 97 & 222,2 & 28 & 2,1 & 57 & 9,2 & 4,4 & 1,5 & 32 & 17 & 86 & 125 & 75 \\
\hline 42 & 220,2 & 31 & 2,4 & 49 & 14,8 & 5,8 & 1,5 & 43 & 18 & 106 & 56 & 6 \\
\hline 104 & 219,4 & 30 & 2,7 & 28 & 6,3 & 4,4 & 1,7 & 33 & 24 & 67 & 108 & 23 \\
\hline 11 & 216,2 & 33 & 2,4 & 57 & 11,6 & 5,3 & 1,2 & 38 & 17 & 73 & 251 & 10 \\
\hline 90 & 215,1 & 32 & 2,5 & 57 & 11,8 & 5,6 & 1,4 & 56 & 11 & 105 & 82 & 6 \\
\hline 89 & 213,9 & 30 & 2,3 & 57 & 13,2 & 4,9 & 1,2 & 27 & 14 & 105 & 66 & 7 \\
\hline 22 & 208,6 & 32 & 2,6 & 51 & 11,3 & 6,1 & 1,6 & 57 & 17 & 116 & 157 & 7 \\
\hline 26 & 207,1 & 29 & 2,6 & 52 & 13,6 & 6,0 & 1,0 & 51 & 14 & 113 & 87 & 8 \\
\hline 106 & 204,1 & 35 & 2,6 & 47 & 9,7 & 4,9 & 1,7 & 38 & 12 & 120 & 486 & 8 \\
\hline 25 & 203,6 & 28 & 2,5 & 43 & 7,7 & 4,7 & 1,6 & 52 & 18 & 120 & 98 & 6 \\
\hline 80 & 203,5 & 29 & 2,6 & 49 & 12,0 & 5,5 & 1,3 & 40 & 16 & 121 & 162 & 7 \\
\hline 44 & 203,2 & 32 & 2,6 & 51 & 14,8 & 5,4 & 1,3 & 49 & 18 & 109 & 113 & 8 \\
\hline 35 & 201,9 & 34 & 2,6 & 55 & 10,8 & 4,6 & 1,6 & 47 & 28 & 110 & 277 & 6 \\
\hline 20 & 198,5 & 32 & 2,5 & 34 & 10,8 & 4,8 & 1,7 & 41 & 23 & 80 & 150 & 15 \\
\hline 40 & 198,2 & 33 & 2,6 & 60 & 13,4 & 5,3 & 1,5 & 26 & 14. & 65 & 132 & 8 \\
\hline 98 & 197,7 & 27 & 2,2 & 16 & 7,4 & 3,9 & 1,2 & 28 & 17 & 62 & 112 & 13 \\
\hline 19 & 195,7 & 26 & 2,7 & 60 & 10,2 & 3,6 & 1,4 & 41 & 26 & 99 & 31 & 7 \\
\hline
\end{tabular}


Teores foliares dos talhões de café cv. Mundo Novo, mês de Dezembro/96, classificados pelos valores $\mathbf{C} / \mathbf{M}$ de Julho/97.

\begin{tabular}{|c|c|c|c|c|c|c|c|c|c|c|c|c|}
\hline \multirow[t]{2}{*}{ TALHĀo } & \multirow{2}{*}{$\begin{array}{c}\mathrm{C} / \mathrm{M} \\
\left(\mathrm{mm}^{-1}\right)\end{array}$} & $\mathbf{N}$ & $\mathbf{P}$ & $\mathbf{K}$ & $\mathrm{Ca}$ & $\mathbf{M g}$ & $\mathbf{S}$ & B & $\mathrm{Cu}$ & $\mathrm{Fe}$ & Mn & $\mathbf{Z n}$ \\
\hline & & \multicolumn{6}{|c|}{$\left(\mathrm{g} \mathrm{kg}^{-1}\right)$} & \multicolumn{5}{|c|}{$\left(\mathrm{mg} \mathrm{kg}^{-1}\right)$} \\
\hline 38 & 194,4 & 34 & 2,8 & 49 & 10,2 & 5,1 & 1,5 & 44 & 20 & 118 & 257 & 15 \\
\hline 68 & 191,8 & 31 & 25 & 58 & 10,4 & 5,0 & 1,4 & 32 & 141 & 95 & 143 & 7 \\
\hline 55 & 188,4 & 34 & 2,7 & 51 & 13,1 & 5,4 & 1,1 & 44 & 39 & 124 & 92 & 23 \\
\hline 67 & 186,7 & 32 & 2,4 & 58 & 8,2 & 5,3 & 1,4 & 35 & 191 & 70 & 110 & 6 \\
\hline 66 & 186,6 & 30 & 2,0 & 51 & 8,7 & 4,8 & 1,5 & 28 & 15 & 78 & 177 & 6 \\
\hline 54 & 185,3 & 32 & 2,6 & 63 & 9,4 & 4,9 & 1,4 & 52 & 24 & 135 & 156 & 12 \\
\hline 24 & 184,9 & 32 & 2,6 & 52 & 10,8 & 6,5 & 1,7 & 53 & 3 & 110 & 62 & 10 \\
\hline 118 & 184,5 & 32 & 2,4 & 40 & 11,7 & 5,3 & 0,6 & 40 & 57 & 120 & 177 & 6 \\
\hline 117 & 181,4 & 32 & 2,5 & 38 & 11,9 & 5,3 & 2,0 & 47 & 33 & 132 & 206 & 7 \\
\hline 72 & 180,8 & 30 & 2,2 & 54 & 11,5 & 4,5 & 1,0 & 29 & 15 & 113 & 175 & 6 \\
\hline 88 & 180,4 & 24 & 2,5 & 61 & 17,2 & 4,5 & 1,0 & 23 & 11 & 102 & 68 & 6 \\
\hline 96 & 178,9 & 27 & 19 & 32 & 8,1 & 4,1 & 1,4 & 29 & 22 & 69 & 148 & 17 \\
\hline 92 & 176,8 & 29 & 2,4 & 61 & 13,2 & 43 & 1,4 & 32 & 8 & 94 & 60 & 7 \\
\hline 69 & 172,3 & 32 & 2,7 & 52 & 11,7 & 5,3 & 1,1 & 32 & 17 & 84 & 312 & 6 \\
\hline 41 & 171,0 & 32 & 2,7 & 55 & 14,5 & 5.2 & 1,3 & 34 & 13 & 69 & 72 & 6 \\
\hline 86 & 170,6 & 28 & 2,5 & 55 & 139 & 4,7 & 1,2 & 31 & 13 & 101 & 66 & 8 \\
\hline 58 & 169,6 & 31 & 2,7 & 55 & 14,0 & 5,3 & 1,4 & 16 & 28 & 100 & 118 & 21 \\
\hline 78 & 169,5 & 31 & 2,3 & 46 & 11,3 & 5,5 & 1,1 & 48 & 60 & 93 & 239 & 7 \\
\hline 74 & 167,4 & 31 & 2,4 & 55 & 11,1 & 5,1 & 1,3 & 43 & 56 & 116 & 198 & 8 \\
\hline 9 & 166,8 & 32 & 2,4 & 61 & 10,0 & 5,3 & 1,6 & 40 & 14 & 77 & 235 & 12 \\
\hline 56 & 165,0 & 30 & 2,7 & 55 & 12,9 & 4,8 & 1,3 & 48 & 33 & 119 & 133 & 19 \\
\hline 76 & 159,4 & 31 & 2,2 & 41 & 12,7 & 4,7 & 1,3 & 45 & 36 & 128 & 113 & 8 \\
\hline 95 & 1579 & 39 & 2,5 & 52 & 14,7 & 4,6 & 1,0 & 43 & 8 & 108 & 36 & 6 \\
\hline 94 & 154,5 & 28 & 2,6 & 57 & 12,5 & 4,4 & 13 & 15 & 12 & 90 & 48 & 6 \\
\hline 51 & 154,2 & 32 & 2,0 & 35 & 10,2 & 4,2 & 1,0 & 45 & 7 & 60 & 86 & 5 \\
\hline 81 & 151,6 & 30 & 2,5 & 57 & 10,7 & 5,5 & 1,4 & 46 & 15 & 110 & 65 & 8 \\
\hline 12 & 149,9 & 33 & 2,2 & 43 & 12,6 & 5,2 & 1,5 & 47 & 11 & 76 & 192 & 8 \\
\hline 18 & 148,4 & 26 & 2,1 & 51 & 12,3 & 4,3 & 1,0 & 52 & 14 & 81 & 77 & 5 \\
\hline 84 & 141,8 & 31 & 2,7 & 58 & 13,2 & 4,2 & 1,2 & 37 & 7 & 92 & 48 & 8 \\
\hline 8 & 140,9 & 35 & 2,7 & 55 & 13,3 & 5,6 & 1,6 & 46 & 15 & 88 & 205 & 12 \\
\hline 36 & 136,1 & 33 & 2,7 & 29 & 12,1 & 4,8 & 1,8 & 53 & 12 & 117 & 223 & 11 \\
\hline 57 & 135,1 & 32 & 2,5 & 51 & 9,5 & 4,6 & 1,5 & 46 & 20 & 93 & 147 & 13 \\
\hline 116 & 127,8 & 32 & 2,5 & 44 & 11,7 & 5,4 & 1,8 & 50 & 33 & 124 & 276 & 7 \\
\hline 79 & 113,7 & 29 & 2,6 & 51 & 11,6 & 5,6 & 1,6 & 52 & 11 & 125 & 157 & 11 \\
\hline
\end{tabular}

Valores hachurados: população de referència. C/M: comprimento especifico do ramo ( $\left.\mathrm{mm} \mathrm{g}^{-1} \mathrm{MS}\right)$ 
Tabela 19. Indices M-DRIS dos talhões de café cv. Catuaí Amarelo, mês de Dezembro/96, classificados pelos valores C/M de Fevereiro/97.

\begin{tabular}{|c|c|c|c|c|c|c|c|c|c|c|c|c|c|c|}
\hline \multirow[t]{2}{*}{ ГALHÃO } & $\mathbf{C} / \mathbf{M}$ & $\mathbf{N}$ & $\mathbf{P}$ & $\mathbf{K}$ & $\mathbf{C a}$ & Mg & $\mathbf{S}$ & B & $\mathrm{Cu}$ & Fe & Mn & $\mathrm{Zn}$ & MS & IBN \\
\hline & $\left(\mathrm{mm} \mathrm{g}^{-1}\right)$ & \multicolumn{13}{|c|}{ (Índices DRIS) } \\
\hline 33 & 580 & -7 & 22 & 1 & -15 & 15 & 6 & 6 & 11 & 23 & -54 & 3 & 0 & 14 \\
\hline 101 & 556 & 0 & 6 & 19 & -20 & -6 & 2 & -20 & & -26 & -2 & 44 & 9 & 13 \\
\hline 11 & 500 & 4 & -5 & -9 & -9 & 15 & -18 & -2 & 12 & 22 & & -5 & -1 & \\
\hline 1 & 494 & -32 & 12 & 17 & -7 & 11 & -11 & -2 & 13 & -12 & -3 & & 18 & 12 \\
\hline 105 & 488 & 0 & 13 & 18 & -13 & -4 & -3 & -21 & 6 & -15 & -10 & 35 & 5 & 12 \\
\hline 7 & $4 \varepsilon$ & 4 & -7 & 9 & 6 & 12 & -4 & -23 & & & 13 & -7 & & 8 \\
\hline 2 & 468 & 0 & 23 & 22 & -15 & 12 & 11 & -23 & 6 & -2 & -29 & 1 & 5 & 12 \\
\hline 100 & 446 & 2 & -14 & 3 & -17 & 7 & -1 & -24 & 7 & -13 & -1 & 54 & 5 & 12 \\
\hline & 381 & -1 & 6 & 5 & 2 & 2 & 0 & -19 & 10 & 3 & 8 & -5 & 0 & 5 \\
\hline & 368 & -7 & 2 & 1 & -7 & 11 & -3 & 1 & 13 & 5 & -2 & -7 & 4 & \\
\hline 1 & 349 & -4 & -5 & -5 & 5 & 27 & -7 & 4 & 10 & -3 & 0 & -6 & -4 & \\
\hline 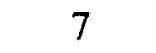 & 343 & -4 & 15 & 11 & -11 & 11 & 5 & -8 & & -9 & -4 & -2 & 1 & \\
\hline 8 & 331 & 2 & 11 & 8 & 13 & 3 & -11 & -3 & 4 & 10 & -20 & -7 & 1 & $\delta$ \\
\hline & 327 & -2 & 3 & -16 & 2 & 0 & -18 & 2 & 17 & 13 & 12 & -3 & 0 & 8 \\
\hline 3 & & 0 & -2 & -4 & -1 & -2 & 4 & 11 & 3 & -2 & 20 & -9 & -6 & 5 \\
\hline & & 2 & 5 & 14 & 6 & 2 & -1 & 0 & -13 & -2 & 3 & -6 & 1 & 5 \\
\hline & & 6 & 0 & 7 & 12 & 3 & 5 & -11 & 1 & -21 & 10 & 1 & -2 & 6 \\
\hline & & -5 & -5 & -2 & 0 & 5 & -10 & 10 & 6 & 2 & -6 & 24 & -8 & \\
\hline 5 & & -9 & 2 & -6 & -9 & -3 & 7 & 4 & 14 & 10 & -13 & 21 & -7 & \\
\hline 71 & 283 & -3 & 1 & 10 & -11 & 10 & -7 & -14 & 7 & 1 & 16 & -4 & 4 & 7 \\
\hline 49 & 282 & 4 & 4 & 7 & 0 & -4 & 7 & 9 & -12 & -1 & -1 & -6 & 4 & 5 \\
\hline 91 & 277 & 5 & 2 & 12 & 5 & 4 & -7 & 8 & -3 & -1 & -9 & -7 & 1 & 5 \\
\hline 13 & 276 & 7 & -12 & -9 & -7 & 9 & 7 & 15 & -9 & -7 & 9 & 3 & 5 & 3 \\
\hline 45 & 275 & 8 & 4 & 9 & -2 & 1 & -5 & -1 & -14 & 9 & 5 & -3 & 0 & 5 \\
\hline 46 & 268 & 0 & 3 & 4 & 13 & -5 & 14 & -4 & -5 & 1 & 2 & -8 & -3 & 5 \\
\hline 73 & $2 t$ & -2 & -5 & -11 & 6 & -1 & 1 & 0 & 15 & 8 & $\mathbf{0}$ & -4 & -2 & 5 \\
\hline 7 & & -5 & 2 & -1 & -5 & -3 & -1 & 2 & 19 & -1 & 9 & -1 & -4 & 4 \\
\hline 8 & 2 & 2 & 6 & 9 & 8 & -2 & -9 & 0 & -3 & 11 & -17 & 0 & 6 & 6 \\
\hline 47 & & 5 & 9 & -16 & 4 & -1 & 11 & -5 & -3 & 2 & 2 & -4 & 8 & \\
\hline 48 & 213 & 9 & 10 & -12 & 9 & 4 & -8 & 6 & -7 & 7 & -7 & -5 & 5 & \\
\hline 37 & 202 & 4 & 3 & -4 & -12 & -13 & 12 & 0 & 4 & -2 & 25 & 2 & -7 & \\
\hline
\end{tabular}

Valores hachurados: população de referência. C/M: comprimento especifico do ramo $\left(\mathrm{mm} \mathrm{g}^{-1}\right)$. MS: índice de massa da matéria seca. IBN: índice de balanço nutricional. 
Tabela 20. Índices M-DRIS dos talhões de café cv. Catuaí Amarelo, mês de Fevereiro/97, classificados pelos valores $\mathrm{C} / \mathrm{M}$ de Julho/97.

\begin{tabular}{|c|c|c|c|c|c|c|c|c|c|c|c|c|c|c|}
\hline \multirow[t]{2}{*}{ TALHÃO } & \multirow{2}{*}{$\begin{array}{c}\mathrm{C} / \mathrm{M} \\
\left(\mathrm{mm} \mathrm{g}^{-1}\right)\end{array}$} & $\mathbf{N}$ & $\mathbf{P}$ & $\mathbf{K}$ & $\mathrm{Ca}$ & $\mathrm{Mg}$ & $\mathbf{S}$ & B & $\mathrm{Cu}$ & $\mathrm{Fe}$ & Mn & $\mathrm{Zn}$ & MS & IBN \\
\hline & & \multicolumn{13}{|c|}{ (Índices M-DRIS) } \\
\hline 33 & 460 & -9 & -6 & -20 & 31 & 67 & 13 & 25 & -17 & -13 & -47 & -23 & 8 & 23 \\
\hline 7 & 336 & 0 & -6 & 9 & -2 & 25 & 3 & 2 & -7 & 4 & -4 & -15 & 1 & 6 \\
\hline 4 & 292 & -3 & 22 & 31 & 11 & -3 & 2 & -5 & -1 & 10 & -47 & -3 & -3 & 12 \\
\hline 10 & 288 & 5 & 1 & 4 & -9 & 9 & -3 & 5 & -1 & -4 & 8 & -4 & 0 & 4 \\
\hline 109 & 271 & -4 & -1 & -3 & 6 & -7 & 9 & -2 & 3 & 15 & 10 & -5 & -10 & 6 \\
\hline 2 & 266 & -3 & 16 & 11 & 8 & 19 & 5 & -2 & -17 & 4 & -22 & -8 & 1 & 10 \\
\hline 105 & 250 & 5 & 20 & 5 & 3 & -10 & -15 & -5 & -8 & 12 & -7 & 13 & -2 & 9 \\
\hline 101 & 249 & 2 & 8 & 8 & -4 & -10 & 8 & -4 & -12 & 4 & 2 & 8 & 1 & 6 \\
\hline 110 & 230 & 11 & 10 & -11 & -9 & 8 & 16 & -5 & -4 & 7 & -7 & -1 & -4 & 8 \\
\hline 100 & 229 & -5 & 1 & 6 & 5 & -1 & 3 & -7 & 0 & 12 & -7 & 4 & -1 & 4 \\
\hline 77 & 211 & 11 & 1 & 11 & 0 & 2 & -6 & -7 & -5 & -8 & 2 & 4 & 6 & 5 \\
\hline 75 & 203 & 3 & 7 & 8 & 3 & 1 & -10 & 2 & -7 & 4 & 3 & -3 & 1 & 4 \\
\hline 111 & 199 & 5 & 5 & -12 & -18 & 5 & 20 & 1 & 12 & 6 & -6 & -6 & -2 & 8 \\
\hline 15 & 194 & 7 & 4 & 12 & -2 & 2 & 5 & -4 & -2 & -2 & -1 & -4 & -2 & 4 \\
\hline 91 & 190 & -3 & 2 & -9 & 7 & 8 & -8 & 15 & 1 & 5 & -6 & 2 & $\mathbf{- 3}$ & 6 \\
\hline 70 & 182 & $\mathbf{1}$ & -6 & 5 & -8 & 2 & -6 & -4 & 18 & -4 & 7 & -4 & 10 & 6 \\
\hline 85 & 182 & -2 & 0 & 2 & 9 & -6 & 4 & -6 & 17 & 5 & -22 & 9 & 2 & 7 \\
\hline 49 & 182 & 1 & -11 & -2 & 5 & 4 & 11 & 7 & -8 & 6 & -2 & -6 & 6 & 6 \\
\hline 71 & 176 & 3 & 9 & -3 & 12 & 6 & 2 & -5 & -9 & -11 & 12 & -8 & 2 & 7 \\
\hline 39 & 174 & -4 & -5 & -3 & 6 & 2 & -17 & 11 & -1 & -3 & 15 & 26 & -14 & 9 \\
\hline 37 & 164 & -4 & 5 & -2 & -6 & -13 & 12 & 10 & -3 & 3 & 16 & -3 & -4 & 7 \\
\hline 13 & 159 & -10 & -13 & 0 & 7 & 25 & 8 & 18 & -36 & 18 & 7 & -7 & -5 & 13 \\
\hline 45 & 155 & -9 & -8 & -8 & -9 & -10 & -13 & 8 & 20 & -12 & -29 & 86 & -5 & 18 \\
\hline 48 & 155 & 5 & -3 & -3 & 2 & -5 & 13 & 9 & -19 & 6 & -5 & -2 & 12 & 7 \\
\hline 46 & 152 & -2 & 2 & 0 & 0 & -4 & -24 & 20 & -7 & 20 & 0 & -5 & 9 & 8 \\
\hline 50 & 152 & -5 & -4 & -6 & -18 & 5 & -7 & 4 & 4 & -2 & -6 & 47 & -1 & 9 \\
\hline 53 & 149 & -14 & -5 & -20 & -2 & 3 & -5 & 14 & -17 & 62 & -6 & -2 & 3 & 13 \\
\hline 73 & 147 & 4 & 3 & 2 & 5 & -5 & 7 & 5 & -7 & -22 & -18 & 35 & 1 & 10 \\
\hline 112 & 141 & -5 & -2 & -13 & 0 & -2 & -5 & 19 & -8 & 43 & 0 & -8 & -7 & 9 \\
\hline 87 & 140 & -4 & 3 & 3 & 5 & -8 & 2 & 10 & 4 & 10 & -18 & 2 & 1 & 6 \\
\hline 52 & 128 & -8 & 3 & 6 & 0 & 3 & 18 & 19 & -35 & 15 & -16 & -4 & 9 & 11 \\
\hline 47 & 122 & 11 & 6 & 3 & 12 & -1 & -50 & 9 & -5 & 19 & 3 & -6 & 9 & 11 \\
\hline
\end{tabular}

Valores hachurados: população de referência. C/M: comprimento especifico do ramo ( $\left.\mathrm{mm} \mathrm{g}^{-1}\right)$. MS: índice de massa da matéria seca. IBN: índice de balanço nutricional. 
Tabela 21. Índices M-DRIS dos talhões de café cv. Catuaí Amarelo, mês de Abril/97, classificados pelos valores C/M de Julho/97.

\begin{tabular}{|c|c|c|c|c|c|c|c|c|c|c|c|c|c|c|}
\hline \multirow[t]{2}{*}{ TALHÃo } & \multirow{2}{*}{$\begin{array}{c}\mathrm{C} / \mathrm{M} \\
\left(\begin{array}{c}\mathrm{mm} \\
\mathrm{l}\end{array}\right)\end{array}$} & $\mathbf{N}$ & P & $\mathbf{K}$ & $\mathrm{Ca}$ & $\mathbf{M g}$ & $\mathbf{S}$ & B & $\mathrm{Cu}$ & $\mathrm{Fe}$ & Mn & $\mathrm{Zn}$ & MS & IBN \\
\hline & & \multicolumn{13}{|c|}{ (Índices DRIS) } \\
\hline 33 & 460 & -5 & -3 & -30 & 21 & 60 & 8 & 23 & -12 & -13 & -31 & -9 & 3 & 18 \\
\hline 7 & 336 & -4 & -5 & -11 & -1 & 16 & 7 & 16 & -15 & 18 & -11 & 6 & -4 & 10 \\
\hline 4 & 292 & -13 & -1 & 12 & -6 & -2 & 12 & 14 & -13 & 11 & -32 & 33 & -3 & 13 \\
\hline 10 & 288 & -2 & 1 & 16 & 12 & 0 & 3 & 18 & -24 & -1 & 0 & -4 & -10 & 8 \\
\hline 109 & 271 & 7 & 4 & 4 & 6 & -5 & 12 & -21 & 0 & -7 & 11 & -3 & 2 & 7 \\
\hline 2 & 266 & 5 & -5 & 4 & -12 & 14 & 12 & 12 & -18 & 18 & -23 & 4 & 0 & 11 \\
\hline 105 & 250 & -5 & 9 & 14 & -2 & -8 & 5 & 12 & 2 & 6 & -12 & -2 & -7 & 7 \\
\hline 101 & 249 & 0 & 8 & 15 & -6 & -11 & -3 & 9 & -8 & 14 & -3 & 0 & -3 & 7 \\
\hline 110 & 230 & 6 & 2 & 2 & 4 & 12 & 22 & 5 & -21 & -14 & -2 & -7 & 1 & 8 \\
\hline 100 & 229 & 4 & 2 & 2 & -7 & 1 & 0 & 16 & 0 & 8 & -10 & -1 & -4 & 5 \\
\hline 77 & 211 & 2 & 4 & 5 & 16 & -6 & 1 & -10 & 0 & -9 & 2 & 9 & -3 & 6 \\
\hline 75 & 203 & 2 & 3 & -6 & -5 & -10 & -1 & 10 & -6 & 15 & 5 & 7 & -3 & 6 \\
\hline 111 & 199 & 9 & 9 & -5 & -1 & 7 & 14 & -9 & -1 & 11 & 8 & -9 & -5 & 7 \\
\hline 15 & 194 & 3 & -2 & 10 & 1 & -1 & 1 & 5 & 2 & -6 & -2 & -9 & 8 & 4 \\
\hline 91 & 190 & -2 & -3 & -5 & 15 & 13 & -5 & -7 & 3 & -4 & -14 & 22 & -3 & 8 \\
\hline 70 & 182 & 1 & 4 & 2 & -9 & 9 & 3 & 1 & 2 & -3 & 8 & -10 & 3 & 5 \\
\hline 85 & 182 & 6 & 4 & 15 & 11 & 2 & -16 & -3 & 0 & 7 & -19 & 3 & 2 & 7 \\
\hline 49 & 182 & -7 & 2 & 5 & -7 & -6 & 25 & -1 & -6 & -3 & -4 & 10 & 2 & 7 \\
\hline 71 & 176 & 8 & -4 & -10 & 1 & 13 & -1 & 11 & -11 & 2 & 11 & -12 & 2 & 7 \\
\hline 39 & 174 & 2 & -4 & -4 & 0 & -3 & -6 & 5 & 14 & -5 & 13 & -1 & 0 & 5 \\
\hline 37 & 164 & 3 & -4 & 2 & -4 & -8 & -4 & -6 & 17 & 0 & 13 & 3 & 0 & 5 \\
\hline 13 & 159 & -5 & -14 & 8 & -2 & 16 & 10 & -1 & -39 & -6 & 5 & 44 & -6 & 13 \\
\hline 45 & 155 & -5 & -5 & 17 & 0 & 14 & 13 & -17 & 1 & -12 & -4 & 12 & -1 & 8 \\
\hline 48 & 155 & -10 & 3 & 7 & -8 & -4 & 25 & 0 & -2 & -15 & -10 & 17 & 8 & 9 \\
\hline 46 & 152 & -7 & 0 & 20 & -14 & 15 & 16 & -11 & -5 & -8 & -1 & 8 & -1 & 9 \\
\hline 50 & 152 & -6 & 1 & 7 & -13 & -4 & 21 & 3 & -8 & -9 & 1 & 7 & 11 & 8 \\
\hline 53 & 149 & -4 & -19 & 1 & 5 & -6 & 8 & 12 & 6 & 2 & -8 & 14 & -1 & 7 \\
\hline 73 & 147 & 1 & 5 & 2 & -2 & -6 & 2 & -3 & 12 & -2 & -4 & 12 & -6 & 5 \\
\hline 112 & 141 & -2 & 6 & -9 & 0 & 6 & 16 & 6 & -14 & 11 & -4 & -7 & 1 & 7 \\
\hline 87 & 140 & -2 & -3 & 1 & 6 & -1 & 19 & -15 & 0 & 20 & -8 & -1 & -3 & 7 \\
\hline 52 & 128 & 2 & 2 & 2 & 8 & -6 & -1 & 10 & 7 & 12 & -12 & -9 & -4 & 6 \\
\hline 47 & 122 & 9 & -61 & 10 & 1 & -2 & 13 & 2 & 0 & -1 & 3 & 15 & 18 & 11 \\
\hline
\end{tabular}

Valores hachurados: população de referência. C/M: comprimento específico do ramo (mm $\left.\mathrm{g}^{-1}\right)$. MS: índice de massa da matéria seca. IBN: índice de balanço nutricional. 
Tabela 22. Indices M-DRIS dos talhões de café cv. Mundo Novo, mês de Dezembro/96, classificados pelos valores C/M de Julho/97.

\begin{tabular}{|c|c|c|c|c|c|c|c|c|c|c|c|c|c|c|}
\hline \multirow[t]{2}{*}{ TALHÃo } & $\mathrm{C} / \mathrm{M}$ & $\mathbf{N}$ & $\mathbf{P}$ & $\mathbf{K}$ & $\mathbf{C a}$ & $\mathbf{M g}$ & $\mathbf{S}$ & B & $\mathrm{Cu}$ & Fe & Mn & Zn & MS & IBN \\
\hline & $\left(\mathbf{m m ~ g} \mathbf{g}^{-1}\right)$ & \multicolumn{13}{|c|}{ (Índices DRIS) } \\
\hline 5 & 322,5 & -3 & 68 & 2 & -18 & -10 & 23 & -20 & 3 & -16 & -6 & 10 & -21 & 17 \\
\hline 31 & 298,8 & 10 & 97 & 9 & -68 & -10 & 10 & -15 & 2 & 9 & -23 & 11 & -20 & 24 \\
\hline 3 & 282,7 & 1 & 38 & 8 & -21 & -1 & 7 & -1 & 2 & -9 & -10 & 8 & -8 & 10 \\
\hline 23 & 271,3 & -3 & 1 & -7 & -5 & 13 & 15 & 10 & -18 & 11 & 2 & -4 & -4 & 8 \\
\hline 59 & 270,9 & -10 & 10 & 7 & -27 & 5 & 12 & 11 & 2 & 17 & -12 & 7 & -10 & 11 \\
\hline 27 & 262,3 & -3 & 3 & 10 & -3 & 7 & -8 & 5 & -26 & 16 & 9 & 0 & 0 & 7 \\
\hline 16 & 254,4 & -2 & -3 & 4 & 4 & 5 & 5 & 5 & -2 & 2 & -3 & -9 & 4 & 4 \\
\hline 115 & 251,1 & -2 & -6 & 2 & -2 & -2 & -2 & 9 & 2 & 10 & 10 & -2 & -3 & 4 \\
\hline 93 & 248,2 & 2 & 9 & 9 & 12 & 2 & 1 & -11 & -1 & 1 & -13 & -2 & 2 & 5 \\
\hline 43 & 247,3 & 6 & 3 & 9 & 7 & 0 & 2 & -12 & -4 & -5 & 7 & -3 & 1 & 5 \\
\hline 113 & 239,2 & -17 & -3 & -3 & -13 & 17 & 10 & 7 & 1 & 13 & 11 & -7 & -4 & 9 \\
\hline 29 & 239,0 & 0 & -1 & 4 & -3 & -2 & 7 & 14 & -3 & 1 & -5 & 1 & -3 & 4 \\
\hline 21 & 236,2 & -7 & 5 & 7 & -10 & 14 & 2 & 5 & 3 & -5 & -7 & 3 & 1 & 6 \\
\hline 14 & 235,5 & -6 & 1 & 0 & 1 & -2 & 11 & 6 & -1 & 10 & -3 & -6 & 0 & 4 \\
\hline 6 & 234,9 & -13 & 0 & -33 & -11 & 17 & 20 & 13 & 0 & 17 & 2 & 3 & -6 & 11 \\
\hline 17 & 234,6 & -3 & 2 & 12 & 6 & -3 & -3 & 9 & 1 & -10 & -14 & 6 & 7 & 6 \\
\hline 114 & 234,4 & 1 & -4 & -3 & -2 & -2 & -3 & 3 & -1 & 8 & 15 & 1 & -1 & 4 \\
\hline 102 & 233,8 & 6 & 17 & -31 & -19 & 9 & 4 & -9 & 6 & -3 & -5 & 30 & 5 & 12 \\
\hline 32 & 227,9 & 0 & 59 & 2 & -29 & -2 & 8 & -4 & 2 & 0 & -15 & 6 & -14 & 12 \\
\hline 99 & 226,6 & 1 & -6 & 9 & -7 & -4 & -3 & -6 & 0 & 1 & 5 & 14 & 6 & 5 \\
\hline 28 & 225,7 & 0 & -1 & -3 & 4 & -2 & 8 & 11 & -1 & 2 & -2 & 0 & -5 & 3 \\
\hline 30 & 225,4 & -2 & -1 & -1 & -4 & 5 & 6 & 7 & -1 & 9 & -1 & -4 & -2 & 4 \\
\hline 103 & 223,0 & 4 & 13 & -4 & -9 & -18 & -3 & 2 & 2 & -6 & -1 & 25 & 7 & 8 \\
\hline 97 & 222,2 & -4 & -7 & 0 & -8 & -16 & -3 & -9 & -1 & -15 & -6 & 77 & 2 & 12 \\
\hline 42 & 220,2 & 0 & -3 & -1 & 12 & 9 & 5 & 5 & 0 & 4 & -11 & -7 & -2 & 5 \\
\hline 104 & 219,4 & 4 & 10 & -16 & -23 & -2 & 16 & 2 & 2 & -12 & -1 & 26 & 5 & 10 \\
\hline 11 & 216,2 & 3 & -2 & 4 & 1 & 4 & -3 & 2 & -1 & -12 & 14 & 3 & -2 & 4 \\
\hline 90 & 215,1 & 1 & 0 & 4 & 1 & 6 & 2 & 13 & -5 & 3 & -4 & -7 & -3 & 4 \\
\hline 89 & 213,9 & 1 & -2 & 6 & 9 & 3 & -1 & -5 & -2 & 6 & -6 & -2 & 3 & 4 \\
\hline 22 & 208,6 & -2 & -1 & -1 & -4 & 8 & 4 & 12 & -2 & 5 & 4 & -5 & -6 & 4 \\
\hline 26 & 207,1 & -5 & 1 & 1 & 7 & 11 & -9 & 10 & -3 & 6 & -4 & -1 & -2 & 5 \\
\hline 106 & 204,1 & 2 & 0 & -6 & -9 & -3 & 8 & -2 & -4 & 6 & 29 & -2 & -7 & 6 \\
\hline 25 & 203,6 & -3 & 3 & -2 & -18 & -1 & 10 & 13 & 0 & 12 & -1 & -5 & 2 & 6 \\
\hline 80 & 203,5 & -5 & 1 & -1 & 2 & 6 & -1 & 3 & -2 & 9 & 6 & -4 & -2 & 3 \\
\hline 44 & 203,2 & 0 & -1 & -1 & 9 & 2 & -2 & 8 & -1 & 3 & 0 & -2 & -4 & 3 \\
\hline 35 & 201,9 & 4 & 1 & 1 & -4 & -7 & 5 & 6 & 2 & 3 & 14 & -8 & -5 & 5 \\
\hline 20 & 198,5 & 2 & 0 & -12 & -2 & -2 & 10 & 5 & 1 & -8 & 5 & 12 & -1 & 5 \\
\hline 40 & 198,2 & 4 & 3 & 8 & 8 & 5 & 6 & -8 & -2 & -14 & 4 & -1 & -1 & 5 \\
\hline 98 & 197,7 & 5 & 7 & -30 & -8 & 1 & 7 & 1 & 1 & -7 & 5 & 16 & 12 & 8 \\
\hline
\end{tabular}


Índices M-DRIS dos talhões de café cv. Mundo Novo, mês de Dezembro/97, classificados pelos valores $\mathrm{C} / \mathrm{M}$ de Julho/98.

\begin{tabular}{|c|c|c|c|c|c|c|c|c|c|c|c|c|c|c|}
\hline \multirow[t]{2}{*}{ TALHĀO } & \multirow{2}{*}{$\begin{array}{c}\mathrm{C} / \mathrm{M} \\
\left(\mathrm{mm} \mathrm{g}^{-1}\right)\end{array}$} & $\mathbf{N}$ & $\mathbf{P}$ & K & $\mathrm{Ca}$ & Mg & $\mathbf{S}$ & B & $\mathrm{Cu}$ & $\mathrm{Fe}$ & Mn & $\mathbf{Z n}$ & MS & IBN \\
\hline & & \multicolumn{13}{|c|}{ (Índices DRIS) } \\
\hline 19 & 195,7 & -6 & 13 & 9 & 0 & -12 & 9 & 8 & 4 & 5 & -22 & 0 & 4 & 8 \\
\hline 38 & 194,4 & 1 & 2 & -3 & -9 & $-\mathbf{3}$ & 1 & 4 & -1 & 5 & 12 & 9 & -7 & 5 \\
\hline 68 & 191,8 & -1 & 0 & 6 & 4 & 1 & 0 & -5 & 21 & 0 & 2 & -6 & -3 & 4 \\
\hline 55 & 188,4 & 1 & 0 & -3 & 2 & 0 & -11 & 4 & 4 & 6 & -6 & 21 & -6 & \\
\hline 67 & 186,7 & 2 & 1 & 8 & -13 & 7 & 1 & -1 & 30 & -10 & -4 & -10 & -1 & \\
\hline 66 & 186,6 & 5 & -6 & 4 & -7 & 4 & 9 & -4 & -1 & -4 & 9 & -5 & 5 & 5 \\
\hline 54 & 185,3 & -2 & -1 & 6 & -13 & -4 & 0 & 10 & 1 & 12 & 3 & 5 & -5 & 5 \\
\hline 24 & 184,9 & -1 & 4 & 5 & -2 & 19 & 8 & 11 & -26 & 8 & -10 & 3 & -6 & 9 \\
\hline 118 & 184,5 & 3 & 2 & -6 & 3 & 6 & -22 & 4 & 10 & 10 & 7 & -7 & 1 & 7 \\
\hline 117 & 181,4 & -3 & -3 & -11 & -1 & 0 & 14 & 5 & 3 & 10 & 9 & -5 & -5 & 6 \\
\hline 72 & 180,8 & 2 & -3 & 4 & 4 & -1 & -6 & -4 & -2 & 9 & 8 & -6 & 4 & 4 \\
\hline 88 & 180,4 & -10 & 5 & 10 & 21 & 1 & -5 & -8 & -5 & 7 & -5 & -6 & 5 & 7 \\
\hline 96 & 178,9 & 2 & -7 & -10 & -7 & -2 & 8 & -1 & 2 & -7 & 7 & 18 & 9 & 7 \\
\hline 92 & 176,8 & -1 & 2 & 10 & 10 & -3 & 5 & 0 & -8 & 3 & -8 & -2 & 3 & 5 \\
\hline 69 & 172,3 & 2 & 6 & 1 & 3 & 5 & -5 & -4 & -1 & -6 & 19 & -7 & -1 & 5 \\
\hline 41 & 171,0 & 4 & 7 & 6 & 12 & 5 & 1 & 1 & -3 & -10 & -6 & -7 & 0 & 5 \\
\hline 86 & 170,6 & -3 & 2 & 5 & 11 & 1 & -1 & -1 & -3 & 5 & -7 & 0 & 2 & 3 \\
\hline 58 & 169,6 & 0 & 3 & 4 & 7 & 2 & 2 & -27 & 3 & 0 & 1 & 21 & -3 & 6 \\
\hline 78 & 169,5 & 0 & -4 & -3 & 0 & 6 & -7 & 8 & 8 & -2 & 12 & -4 & -2 & 5 \\
\hline 74 & 167,4 & -2 & -4 & 2 & -3 & 1 & -2 & 4 & 7 & 6 & 8 & -2 & -3 & 4 \\
\hline 9 & 166,8 & 1 & -3 & 7 & -7 & 3 & 6 & 3 & -3 & -11 & 12 & 6 & -3 & 5 \\
\hline 56 & 165,0 & -5 & 0 & 1 & 1 & -6 & -4 & 7 & 3 & 5 & 0 & 15 & -5 & 4 \\
\hline 76 & 159,4 & 1 & -7 & -5 & 5 & -3 & 0 & 7 & 4 & 11 & 0 & -1 & 0 & 4 \\
\hline 95 & 157,9 & 16 & 3 & 3 & 15 & -1 & -6 & 7 & -8 & 6 & -17 & -6 & -1 & 7 \\
\hline 94 & 154,5 & 1 & 11 & 10 & 10 & 1 & 7 & -20 & -3 & 3 & -11 & -4 & 5 & 7 \\
\hline 51 & 154,2 & 13 & -2 & -3 & 4 & 1 & -2 & 14 & -6 & -10 & 0 & -7 & 9 & \\
\hline 81 & 151,6 & -2 & 0 & 5 & -3 & 7 & 3 & 8 & -2 & 6 & -8 & 0 & -1 & 4 \\
\hline 12 & 149,9 & 5 & -6 & -4 & 6 & 3 & 5 & 9 & -4 & -9 & 9 & -1 & -1 & 5 \\
\hline 18 & 148 & -2 & -3 & 5 & 9 & -1 & -4 & 15 & -1 & -2 & -3 & -8 & 7 & 5 \\
\hline 84 & 141 & 2 & 9 & 8 & 10 & -5 & 0 & 4 & -9 & 2 & -12 & 1 & 1 & 5 \\
\hline 8 & 140,9 & 1 & -1 & 1 & 3 & 2 & 4 & 5 & -3 & -7 & 8 & 5 & -7 & 4 \\
\hline 36 & 136,1 & 0 & 3 & -19 & 0 & -5 & 11 & 10 & -4 & 6 & 11 & 4 & -5 & 6 \\
\hline 57 & & 3 & 0 & 1 & -9 & -5 & 4 & 8 & 0 & -2 & 4 & 8 & -1 & 4 \\
\hline 116 & 127,8 & -2 & -3 & -7 & -2 & 1 & 9 & 7 & 3 & 6 & 14 & -5 & -6 & 5 \\
\hline 79 & 113,7 & -8 & -1 & -1 & -2 & 4 & 5 & 9 & -5 & 9 & 4 & 3 & -5 & 5 \\
\hline
\end{tabular}

Valores hachurados: população de referência. C/M: comprimento específico do ramo $\left(\mathrm{mm} \mathrm{g}^{-1}\right)$. MS: índice de massa da matéria seca. IBN: índice de balanço nutricional. 


\subsection{Considerações finais}

\section{Comprimento Específico do Ramo ( $\mathrm{mm} \mathrm{g}^{-1}$ )}

A variável resposta alternativa, encontrada para contornar as distorções embutidas na variável "produtividade de grãos de café" com base em área, de lavouras estruturalmente heterogêneas, foi o comprimento especifico do ramo $\left(\mathrm{C} / \mathrm{M}, \mathrm{mm} \mathrm{g}^{-1}\right.$ matéria seca). Seu desenvolvimento foi feito com base na união entre os conceitos fisiológicos e características agronômicas desejáveis do ramo do cafeeiro.

Além de refletir o potencial produtivo máximo do ramo para o ano seguinte, esta variável apresenta a importante característica de poder ser determinada no ano vegetativo, através de avaliações pontuais no tempo. Isto significa uma redução no intervalo de tempo que separam a determinações de causa (teores foliares dos nutrientes) e efeito (resposta vegetativa), que foi, neste estudo, de 2 a 6 meses. Esta redução no tempo imprime maior agilidade aos estudos de nutrição do café, refletindo também no abaixamento dos custos de execução da pesquisa.

A correspondência entre o comprimento específico do ramo e o Índice de Balanço Nutricional (IBN), permitiu que fossem definidas as populações de referência e as normas DRIS, e que fossem realizadas as pré-validações destas normas. Contudo, a confirmação da correspondência entre o comprimento específico do ramo e sua produção de grãos deverá concretizar a utilização desta variável no ajuste precoce de padrões nutricionais de cafeeiros podados.

\section{Métodos de cálculo do DRIS}

A realização da etapa deste estudo onde foram propostos e avaliados métodos de cálculo das normas e índices DRIS, teve resultados de fundamental importância para a ciência do solo. Seus resultados traduziram-se na melhoria da acurácia do método DRIS como um todo. Além de útil para atingir o objetivo final deste trabalho, o de estabelecer normas DRIS para cafeeiros podados, os beneficios desta melhoria poderão ser 
estendidos a quaisquer novos trabalhos de determinação de normas e índices DRIS, independentemente da espécie vegetal.

Os resultados positivos da etapa da avaliação dos métodos de cálculo do DRIS dão o indicativo de que este sistema ainda não está plenamente desenvolvido, e que pode ser melhorado ainda mais. Tem-se observado que há o empenho de cientistas em comparar o desempenho dos métodos de diagnose foliar, como o do método DRIS e o das Faixas de Suficiência. Estes estudos são indiscutivelmente necessários. No entanto, a postura de alguns destes trabalhos tem se voltado mais à tarefa de promover ou desmerecer um determinado método em relação ao outro, ao invés de procurar identificar a origem metodológica das fragilidades de cada um, a fim de melhorá-los.

Ao que os resultados do presente trabalho indicaram, todas as etapas do DRIS podem ser potencialmente melhoradas. São elas: a determinação das normas, o cálculo das funções das razões dos nutrientes, o somatório das funções das razões dos nutrientes, e a interpretação dos índices DRIS. De todas estas etapas, a última é atualmente a que mais carece de critérios melhor definidos.

\section{Normas DRIS estabelecidas}

As normas DRIS definidas para os cultivares Catuaí Amarelo e Mundo Novo são, mais que uma contribuição para a ciência do solo, uma contribuição direta para o exercício da cafeicultura moderna. Estas poderão ser seguramente aplicadas a cafezais da região de onde foram originadas, pois foram pré-validadas com dados amostrais dela mesmo obtidos.

A representatividade destas normas é reforçada pelo fato de terem sido determinadas a partir de uma ampla base de talhões comerciais. Foram utilizados talhões de diversas propriedades, sob diversos manejos, de uma região de transição geológica, onde são encontrados uma ampla variedade de classes de solo (LE, PE, PV, C, TR e LR). 
A aplicação destas normas DRIS a lavouras podadas, poderá ser feita em substituição às tabelas de faixas de suficiência. Os padrões atuais para as faixas de suficiência são genéricos quanto à abrangência territorial, diversidade de cultivares e aos estágios fenológicos. Estas tabelas, no entanto, não deixarão de ter grande utilidade para a diagnose foliar do cafeeiro. $\mathrm{Na}$ falta de padrões mais especificos para cada situação ou cultivar em particular, os padrões atuais das faixas de suficiência poderão auxiliar, junto com os do DRIS, no fornecimento de parâmetros de orientação.

As contribuições deste estudo ao método DRIS e ao banco de normas DRIS, se traduzem na melhoria dos instrumentos disponiveis aos cafeicultores para diagnosticar problemas nutricionais em cafezais submetidos à poda. Assim, procura-se atingir os objetivos básicos da cafeicultura atual, que são, aumentar a produtividade da lavoura e diminuir o custo de produção unitário. Estas duas metas têm por finalidade única garantir a permanência do cafeicultor na sua atividade, mesmo durante periodos de preços baixos do café e sob as inesperadas adversidades climáticas. 


\section{CONCLUSÕES}

De acordo com os objetivos estabelecidos e os resultados obtidos, chegou-se às seguintes conclusões:

O comprimento especifico do ramo ( $\mathrm{mm} \mathrm{g}^{-1}$ matéria seca), determinado no ano vegetativo após a poda, foi identificado como a variável vegetativa que melhor representa o potencial produtivo de grãos do ramo para o ano seguinte.

As normas DRIS definidas através do critério do Valor $r$, proposto no presente estudo, foram mais precisas que aquelas determinadas pelo critério do Valor $\mathrm{F}$, de Letzsch (1985), desde que seguidas pelo método de Jones (1981) para o cálculo das funções das razões dos nutrientes.

O método de Jones (1981), para o cálculo das funções das razões de nutrientes, resultou em índices DRIS e M-DRIS mais precisos que os gerados pelos métodos de Beaufils (1973) e Elwali \& Gascho (1984).

O uso dos métodos DRIS ou M-DRIS, para o somatório das funções das razões dos nutrientes, não influiu sobre a acurácia dos índices gerados.

Das normas DRIS estabelecidas e testadas para os meses de Dezembro, Fevereiro, Abril e Julho, foram consideradas prontamente aplicáveis as de Dezembro, Fevereiro e Abril, para o cultivar Catuaí Amarelo, e as de Dezembro, para o cultivar Mundo Novo. 


\section{REFERÊNCIAS BIBLIOGRÁFICAS}

ADOBE SYSTEMS INCORPORATED. Adobe Photoshop v3.0.5. (software). Mountain View, 1995.

ARBOLEDA, C.; ARCILA, J.; MARTINEZ, R. Sistema integrado de recomendación y diagnosis: una alternativa para la interpretación de resultados de analisis foliar en café. Agronomia Colombianda, v.5, p.17-30, 1988.

BALDOCK, J.O.; SCHULTE, E.E. Plant analysis with standardized scores combines DRIS and sufficiency range approaches for corn. Agronomy Journal, v.88, n.3, p.448-456, 1996.

BATAGLIA, O.C.; SANTOS, W.R. dos. Efeito do procedimento de cálculo e da população de referência nos índices do sistema integrado de diagnose $\mathrm{e}$ recomendação (DRIS). Revista Brasileira de Ciência do Solo, Campinas, v. 14, n.3, p.339-344, 1990.

BEAUFILS, E.R. Diagnosis and recommendation integrated system (DRIS). Pietermaritzburg: University of Natal, 1973. 132p. (Soil Science Bulletin, 1).

BEVERLY, R.B. A practical guide to the diagnosis and recommendation integrated system (DRIS). Athens: Micro-Macro, 1991. 87p.

BLANCHAR, R.W.; REHM, G.; CALDWEL, A.C. Sulfur in plant materials by digestion with nitric and percloric acid. Soil Science Society of America Proceedings, v.29, p.71-72, 1963. 
BOLIVAR, G.B.; ALVAREZ V., V.H.; RIBEIRO, A.C.; NOVAIS, R.F. de; OLIVEIRA, J.A. de. Movimentação de cálcio, magnésio, alumínio e enxofre pela adição de calcário e gesso no plantio do cafeeiro. In: CONGRESSO BRASILEIRO DE PESQUISAS CAFEEIRAS, 19., Três Pontas, 1993. Anais. Rio de Janeiro: MAARA,PROCAFÉ, 1993. p.91-95.

ELWALI, A.M.O. ; GASCHO, G.J. Soil testing, foliar analysis, and DRIS as guide for sugarcane fertilization. Agronomy Journal, v.76, p.466-470, 1984.

ELWALI, A.M.O. ; GASCHO, G.J. Supplemental fertilization of irrigated corn guided by foliar critical nutrient levels and diagnosis and recomendation integrated system norms. Agronomy Journal, v.80, p.243-249, 1988.

EMPRESA BRASILEIRA DE PESQUISA AGROPECUÁRIA. Centro Nacional de Pesquisa e Desenvolvimento de Instrumentação Agrícola. Programa SIARCS v3.1: sistema de análise de raizes e cobertura do solo (software). São Carlos, 1996.

GATHAARA, M.P.H. Pruning arabica coffee: some physiological aspects to consider. Kenya Coffee, v.61, n.717, p.2261-2262, July 1996.

HALLMARK, W.B. Increasing soybean yields through the use of the diagnosis and recommendation integrated system. In: FLUID FERTILIZER SYMPOSIUM, St. Louis, 1987. Proceedings. St. Louis, 1987. p.180-188.

JONES, C.A. Proposed modifications of the diagnosis and recommendation integrated system (DRIS) for interpreting plant analysis. Communications in Soil Science and Plant Analysis, v.12, n.8, p.785-794, 1981.

LEITE, R. de A. Avaliação do estado nutricional do cafeeiro conilon no estado do Espírito Santo utilizando diferentes métodos de interpretação de análise foliar. Viçosa, 1992. 87p. Tese (D.S.) - Universidade Federal de Viçosa.

LETZSCH, W.S. Computer program for selection of norms for use in the diagnosis and recommendation integrated system (DRIS). Communications in Soil Science and Plant Analysis, v.16, n.4, p.339-347,1985. 
LETZSCH, W.S.; SUMNER, M.E. Effect of population size and yield level in selection of diagnosis and recommendation integrated system (DRIS) norms. Communications in Soil Science and Plant Analysis, v. 15, n.9, p.997-1006, 1984.

MALAVOLTA, E. Nutrição mineral e adubação do cafeeiro. São Paulo: Agronômica Ceres, 1993. 210p.

MICROSOFT CORPORATION. Microsoft Excel para Windows 95 v7.0. (software). New York, 1995a.

MICROSOFT CORPORATION. Microsoft Word para Windows 95 v7.0. (software). New York, 1995b.

MIGUEL, A.E.; OLIVEIRA, J.A.; MATIELLO, J.B.; FIORAVANTE, N.; FREIRE, A.C.F. Efeitos dos diferentes tipos de podas na morte de raizes do cafeeiro. In: CONGRESSO BRASILEIRO DE PESQUISAS CAFEEIRAS, 11., Londrina, 1984. Resumos. Rio de Janeiro: IBC/GERCA, 1984. p.240-241.

MINERAIS DO PARANÁ S.A. Mapa geológico do estado do Paraná. Curitiba: DNPM/MINERAIS DO PARANÁ S.A., 1989. Folha única, Escala 1:650.000.

MOTA, F.S. Meteorologia agrícola. São Paulo: Nobel, 1981. 425p.

NICK, J.A.; YORINORI, G.T.; MOTTA, A.C.V.; SCOPEL, I; FERNANDES, J.S.C. Efeito de 11 anos de cultivo de café, em LE, sobre parâmetros químicos do solo e crescimento de raiz, no município de Tomazina - PR. In: CONGRESSO BRASILEIRO DE CIÊNCIA DO SOLO, 25., Viçosa, 1995. O solo nos grandes domínios morfoclimáticos do Brasil e o desenvolvimento sustentado; resumos expandidos. Viçosa: SBCS/UFV, 1995. p.633-635.

PAVAN, M.A.; CHAVES, J.C.D.; MIYAZAWA, M.; CARDOSO, R.M.L.; SILVA, E. da. Remoção de resíduos químicos e físicos da superficie das folhas para diagnóstico nutricional do cafeeiro. Revista Brasileira de Ciência do Solo, v.8, n.3, p.319-324, 1984. 
PLAY INCORPORATED. Snappy Software v1.0. (software). Rancho Cordova, 1995.

RENA, A.B.; MAESTRI, M. Ecofisiologia do Cafeeiro. In: CASTRO, P.R.C.; FERREIRA, S.O.; YAMADA, T. (Ed.). Ecofisiologia da produção agrícola. Piracicaba: POTAFOS, 1987. p. 119-147.

SANTOS, W.R. dos. Avaliação do equilibrio nutricional dos macronutrientes em citros com diferentes adubações. Piracicaba, 1997. 112p. Dissertação (Mestrado) Escola Superior de Agricultura "Luiz de Queiroz", Universidade de São Paulo.

SARRUGE, J.R.; HAAG, H.P. Análises químicas em plantas. Piracicaba: Escola Superior de Agricultura 'Luiz de Queiroz", Departamento de Química, 1974. 56p.

SOFTWARE PUBLISHING CORPORATION. Harvard F/X v1.10. (software). New York, 1994.

SUMNER, M.E. Aplication of Beaufils' diagnostic indices to corn data published in literature irrespective of age and conditions. Plant and Soil, v.46, p.359-363, $1977 \mathrm{a}$.

SUMNER, M.E. Use of the DRIS system in foliar diagnosis of crops at high yields levels. Communications in Soil Science and Plant Analysis, v.8, n.3, p.251-268, $1977 \mathrm{~b}$.

SUMNER, M.E. Interpretation of foliar analysis for diagnostic purposes. Agronomy Journal, v.71, p.343-348, 1979.

SUMNER, M.E. Diagnosis of sulfur requirements of corn and wheat using foliar analysis. Soil Science Society of America Journal, v.45, p.87-90, 1981.

T.A.L. TECHNOLOGIES INCORPORATED. Software Wedge for Windows v1.2. (software). Philadelphia: 1997.

TAIZ, L.; ZEIGER, E. Plant physiology. Redwood City: Benjamin/Cummins, 1991. 
WALWORTH, J.L.; LETZSCH, W.S.; SUMNER, M.E. Use of boundry lines in establishing diagnostic norms. Soil Science Society of America Journal, v.50, p.123-128, 1986.

WALWORTH, J.L.; WOODDARD, H.J.; SUMNER, M.E. Generation of corn tissue norms from a small, high-yield data base. Communications in Soil Science and Plant Analysis, v. 19, n.5, p.563-577, 1988. 